\title{
Systematic Exploration of the Structural Features of Yatakemycin Impacting DNA Alkylation and Biological Activity
}

\author{
Mark S. Tichenor, Karen S. MacMillan, John D. Trzupek, Thomas J. Rayl, Inkyu \\ Hwang, and Dale L. Boger*
}

Department of Chemistry and the Skaggs Institute for Chemical Biology, The Scripps

Research Institute, 10550 North Torrey Pines Road, La Jolla, California 92037

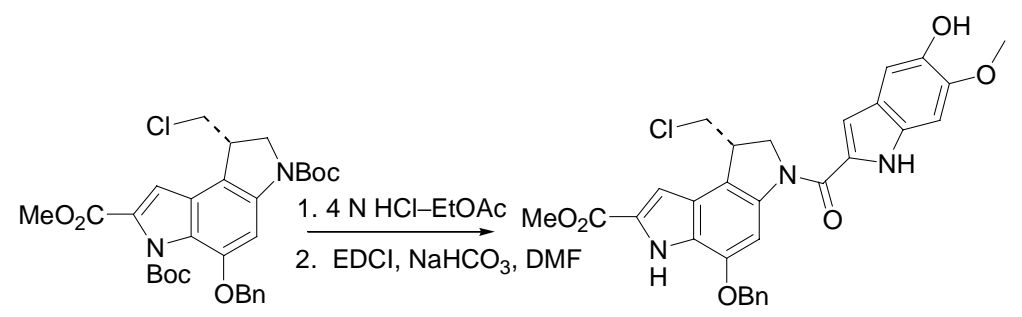

Methyl 3-[(5-Hydroxy-6-methoxyindol-2-yl)carbonyl]-1-(chloromethyl)-5benzyloxy-1,2-dihydro-3H-pyrrolo[3,2-e]indole-7-carboxylate (7a). Compound 6 (39.3 mg, $0.0688 \mathrm{mmol})$ was dissolved in $4 \mathrm{~N} \mathrm{HCl-EtOAc}(1 \mathrm{~mL})$ and the solution was stirred at $70{ }^{\circ} \mathrm{C}$ for $1 \mathrm{~h}$. The solvent was removed by a $\mathrm{N}_{2}$ stream, and the sample was dried under vacuum for $3 \mathrm{~h}$. The crude residue was dissolved in DMF (0.60 mL), treated with EDCI (65.9 mg, $0.344 \mathrm{mmol})$, 5-hydroxy-6-methoxyindole-2-carboxylic acid (5a, $21.0 \mathrm{mg}, 0.103 \mathrm{mmol})$ and $\mathrm{NaHCO}_{3}(12.0 \mathrm{mg}, 0.138 \mathrm{mmol})$, and the mixture was stirred for $14 \mathrm{~h}$ at $25{ }^{\circ} \mathrm{C}$. The solvent was removed by a $\mathrm{N}_{2}$ stream and the residue was purified by flash chromatography $\left(\mathrm{SiO}_{2}, 66 \%\right.$ EtOAc-hexanes) to afford $7 \mathbf{a}(28.9 \mathrm{mg}, 75 \%)$ as a white solid: ${ }^{1} \mathrm{H}$ NMR (DMSO- $\left.d_{6}, 400 \mathrm{MHz}\right) \delta 8.56$ (1H, br s), $8.08(1 \mathrm{H}, \mathrm{s}), 7.64$ (2H, d, $J$ $=8.3 \mathrm{~Hz}), 7.41(2 \mathrm{H}, \mathrm{t}, J=7.0 \mathrm{~Hz}), 7.34(2 \mathrm{H}, \mathrm{m}), 6.99(1 \mathrm{H}, \mathrm{s}), 6.93(1 \mathrm{H}, \mathrm{d}, J=1.8 \mathrm{~Hz})$, $6.92(1 \mathrm{H}, \mathrm{s}), 5.28(2 \mathrm{H}, \mathrm{s}), 4.73(1 \mathrm{H}, \mathrm{t}, J=11.6 \mathrm{~Hz}), 4.42(1 \mathrm{H}, \mathrm{dd}, J=7.0,3.8 \mathrm{~Hz}), 4.15$ $(1 \mathrm{H}, \mathrm{m}), 4.10(1 \mathrm{H}, \mathrm{m}), 4.02(1 \mathrm{H}, \mathrm{m}), 3.88(3 \mathrm{H}, \mathrm{s}), 3.81(3 \mathrm{H}, \mathrm{s}) ;{ }^{13} \mathrm{C}$ NMR (DMSO-d $d_{6}$ $100 \mathrm{MHz}) \delta 172.1,161.5,159.5,148.3,145.0,142.5,138.5,136.9,131.0,129.1,128.4$, 128.3 (2C), 127.7, 127.4 (2C), 126.3, 123.6, 120.8, 114.3, 105.1, 105.0, 98.3, 94.1, 69.4, 
55.5, 54.4, 51.8, 47.6, 42.0; IR (film) $v_{\max }$ 1682, $1505 \mathrm{~cm}^{-1}$; ESITOF-HRMS $\mathrm{m} / z$ $560.1573\left(\mathrm{M}+\mathrm{H}^{+}, \mathrm{C}_{30} \mathrm{H}_{26} \mathrm{ClN}_{3} \mathrm{O}_{6}\right.$ requires 560.1583).

7a: $[\alpha]^{23}-8(c 0.2, \mathrm{THF})$.

ent-7a: $[\alpha]^{23}{ }_{D}+7(c 0.2$, THF $)$.

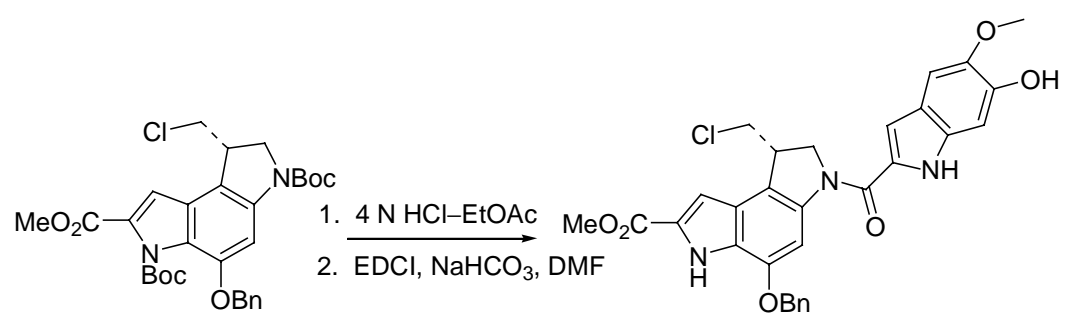

Methyl

3-[(6-Hydroxy-5-methoxyindol-2-yl)carbonyl]-1-(chloromethyl)-5benzyloxy-1,2-dihydro-3H-pyrrolo[3,2-e]indole-7-carboxylate (7b). Compound 6 (15.5 mg, $0.0272 \mathrm{mmol})$ was dissolved in $4 \mathrm{~N} \mathrm{HCl-EtOAc}(1 \mathrm{~mL})$ and the solution was stirred at $70{ }^{\circ} \mathrm{C}$ for $1 \mathrm{~h}$. The solvent was removed by a $\mathrm{N}_{2}$ stream, and the sample was dried under vacuum for $3 \mathrm{~h}$. The crude residue was dissolved in DMF $(0.15 \mathrm{~mL})$, treated with EDCI (20.8 mg, $0.109 \mathrm{mmol})$, 6-hydroxy-5-methoxyindole-2-carboxylic acid (5b, $6.7 \mathrm{mg}, 0.033 \mathrm{mmol})$, and $\mathrm{NaHCO}_{3}(2.3 \mathrm{mg}, 0.027 \mathrm{mmol})$ and the reaction mixture was stirred for $12 \mathrm{~h}$ at $25^{\circ} \mathrm{C}$. The solvent was removed by a $\mathrm{N}_{2}$ stream and the crude residue was purified by flash chromatography $\left(\mathrm{SiO}_{2}, 66 \%\right.$ EtOAc-hexanes) to afford $\mathbf{7 b}$ (13.9 mg, 78\%) as an off-white solid: ${ }^{1} \mathrm{H}$ NMR (DMSO- $\left.d_{6}, 400 \mathrm{MHz}\right) \delta 9.05(1 \mathrm{H}, \mathrm{s}), 8.07(1 \mathrm{H}$, s), $7.64(2 \mathrm{H}, \mathrm{d}, J=7.1 \mathrm{~Hz}), 7.41(2 \mathrm{H}, \mathrm{t}, J=7.3 \mathrm{~Hz}), 7.33-7.36(3 \mathrm{H}, \mathrm{m}), 7.09(1 \mathrm{H}, \mathrm{s})$, $6.97(1 \mathrm{H}, \mathrm{s}), 6.88(1 \mathrm{H}, \mathrm{s}), 5.28(2 \mathrm{H}, \mathrm{s}), 4.73(1 \mathrm{H}, \mathrm{t}, J=10.6 \mathrm{~Hz}), 4.42(1 \mathrm{H}, \mathrm{dd}, J=6.8$, $4.1 \mathrm{~Hz}), 4.11(2 \mathrm{H}, \mathrm{m}), 3.99(1 \mathrm{H}, \mathrm{dd}, J=7.8,3.3 \mathrm{~Hz}), 3.87(3 \mathrm{H}, \mathrm{s}), 3.79(3 \mathrm{H}, \mathrm{s}) ;{ }^{13} \mathrm{C} \mathrm{NMR}$ (DMSO- $\left.d_{6}, 100 \mathrm{MHz}\right) \delta 161.4,159.6,146.5,145.0,144.9,138.5,136.9,131.8,128.7$, $128.4,128.3$ (2C), 127.7, 127.4 (2C), 126.3, 123.6, 119.9, 114.1, 106.6, 105.6, 102.6, 98.3, 97.2, 69.4, 55.8, 54.5, 51.8, 47.5, 42.0; IR (film) $v_{\max } 3321,2950,1316,1211 \mathrm{~cm}^{-1}$; MALDIFT-HRMS (DHB) $m / z 559.1507\left(\mathrm{M}^{+}, \mathrm{C}_{30} \mathrm{H}_{26} \mathrm{ClN}_{3} \mathrm{O}_{6}\right.$ requires 559.1505).

7b: $[\alpha]^{23}-4.0(c 0.20$, acetone).

ent-7b: $[\alpha]_{\mathrm{D}}^{23}+3.4(c 0.35$, acetone $)$. 


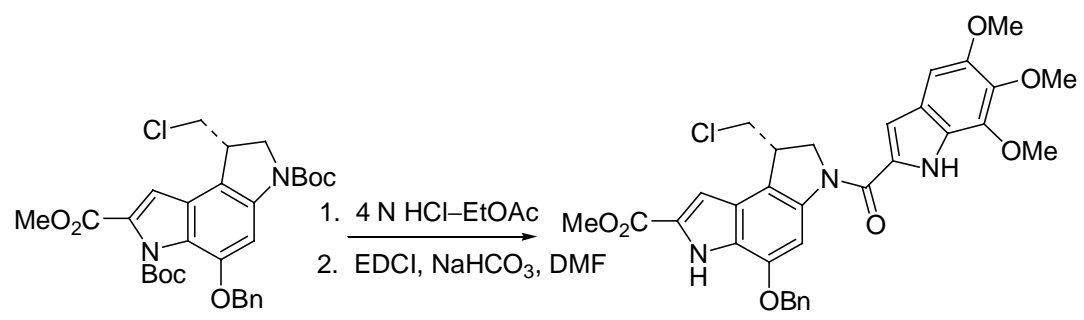

Methyl (S)-3-[(5,6,7-Trimethoxyindole-2-yl)carbonyl]-1-(chloromethyl)-5benzyloxy-1,2-dihydro-3H-pyrrolo[3,2-e]indole-7-carboxylate (7c). Compound 6 (31.6 mg, $0.0553 \mathrm{mmol})$ was dissolved in $4 \mathrm{~N} \mathrm{HCl}-$ EtOAc $(3 \mathrm{~mL})$ and stirred at $25^{\circ} \mathrm{C}$ for $4 \mathrm{~h}$. The solution was cooled to $25{ }^{\circ} \mathrm{C}$, the solvent was removed by a $\mathrm{N}_{2}$ stream, and the sample was dried under high vacuum for $3 \mathrm{~h}$. The crude residue was dissolved in DMF (1.0 mL), treated with EDCI (42.4 mg, $0.221 \mathrm{mmol})$, 5,6,7-trimethoxyindole-2carboxylic acid (5c, $20.8 \mathrm{mg}, 0.0830 \mathrm{mmol})$, and $\mathrm{NaHCO}_{3}(9.3 \mathrm{mg}, 0.11 \mathrm{mmol})$. The reaction mixture was stirred for $12 \mathrm{~h}$ at $25^{\circ} \mathrm{C}$, poured over saturated aqueous $\mathrm{NaCl}(5$ $\mathrm{mL}$ ), filtered, and washed with $\mathrm{H}_{2} \mathrm{O}$. The crude residue was purified by flash chromatography $\left(\mathrm{SiO}_{2}, 35 \%\right.$ EtOAc-hexanes) to afford 7c $(26.3 \mathrm{mg}, 79 \%)$ as an offwhite solid which was identical with authentic matieral: ${ }^{11}{ }^{1} \mathrm{H}$ NMR (acetone- $d_{6}, 500$ MHz) $\delta 11.12(1 \mathrm{H}, \mathrm{s}), 10.19(1 \mathrm{H}, \mathrm{s}), 8.17(1 \mathrm{H}, \mathrm{s}), 7.34-7.62(5 \mathrm{H}, \mathrm{m}), 7.31(1 \mathrm{H}, \mathrm{d}, J=2.2$ Hz), $7.10(1 \mathrm{H}, \mathrm{d}, J=2.2 \mathrm{~Hz}), 6.99(1 \mathrm{H}, \mathrm{s}), 5.29(2 \mathrm{H}, \mathrm{s}), 4.81(1 \mathrm{H}, \mathrm{dd}, J=9.5,10.4 \mathrm{~Hz})$, $4.62(1 \mathrm{H}, \mathrm{dd}, J=4.1,10.9 \mathrm{~Hz}), 4.23(1 \mathrm{H}, \mathrm{m}), 4.18(1 \mathrm{H}, \mathrm{dd}, J=3.6,11.0 \mathrm{~Hz}), 4.05(3 \mathrm{H}$, s), $3.95(1 \mathrm{H}, \mathrm{dd}, J=7.8,10.9 \mathrm{~Hz}), 3.88(3 \mathrm{H}, \mathrm{s}), 3.87(3 \mathrm{H}, \mathrm{s})$.

7c: $[\alpha]^{23}+4.5(c 0.4, \mathrm{THF})$.

ent-7c: $[\alpha]^{23}{ }_{\mathrm{D}}+5(c 0.4, \mathrm{THF})$.

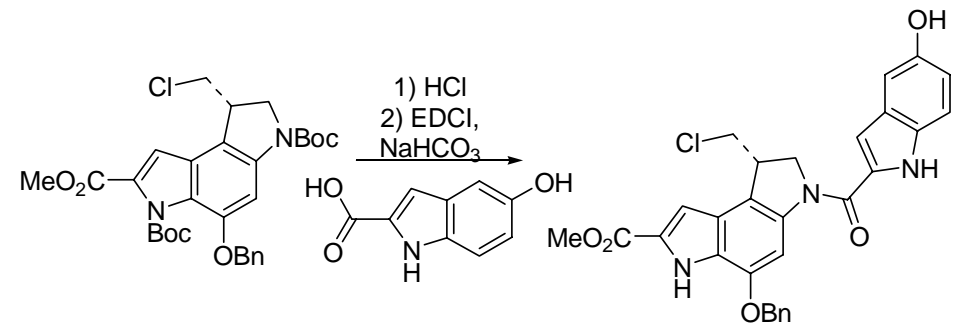


Methyl 3-[(5-Hydroxyindol-2-yl)carbonyl]-1-(chloromethyl)-5-benzyloxy-1,2dihydro-3H-pyrrolo[3,2-e]indole-7-carboxylate (7d). Compound $6(28.7 \mathrm{mg}, 0.052$ mmol) was dissolved in $4 \mathrm{~N} \mathrm{HCl-EtOAc}(1 \mathrm{~mL})$ and the solution was stirred at $70{ }^{\circ} \mathrm{C}$ for $1 \mathrm{~h}$. The solvent was removed by a $\mathrm{N}_{2}$ stream, and the sample was dried under vacuum for $3 \mathrm{~h}$. The crude residue was dissolved in DMF $(0.3 \mathrm{~mL})$ and treated with carboxylic acid 5d (13.0 mg, $0.0753 \mathrm{mmol})$, EDCI (40.0 mg, $0.201 \mathrm{mmol})$ and $\mathrm{NaHCO}_{3}(10 \mathrm{mg}$, $0.19 \mathrm{mmol}$ ) and the reaction mixture was stirred for $15 \mathrm{~h}$ at $25^{\circ} \mathrm{C}$. The reaction mixture was diluted with THF, applied to a silica gel plug, and eluted with THF. The THF was removed by a $\mathrm{N}_{2}$ stream and the residue was purified by flash chromatography $\left(\mathrm{SiO}_{2}\right.$, $50 \%$ EtOAc-hexanes) to provide $7 \mathbf{d}(18.9 \mathrm{mg}, 71 \%)$ as a tan solid: ${ }^{1} \mathrm{H}$ NMR (acetone- $d_{6}$, $400 \mathrm{MHz}) \delta 11.13(1 \mathrm{H}, \mathrm{br} \mathrm{s}), 10.59(1 \mathrm{H}, \mathrm{br} \mathrm{s}), 8.20(1 \mathrm{H}, \mathrm{br} \mathrm{s}), 7.88(1 \mathrm{H}, \mathrm{s}), 7.60(2 \mathrm{H}, \mathrm{d}, J$ $=7.4 \mathrm{~Hz}), 7.33-7.46(4 \mathrm{H}, \mathrm{m}), 7.32(1 \mathrm{H}, \mathrm{d}, J=1.6 \mathrm{~Hz}), 7.10(1 \mathrm{H}, \mathrm{d}, J=2.2 \mathrm{~Hz}), 7.03$ $(1 \mathrm{H}, \mathrm{s}), 6.90(1 \mathrm{H}, \mathrm{dd}, J=2.4,8.8 \mathrm{~Hz}), 5.29(2 \mathrm{H}, \mathrm{s}), 4.84(1 \mathrm{H}, \mathrm{t}, J=10.1 \mathrm{~Hz}), 4.65(1 \mathrm{H}$, $\mathrm{dd}, J=4.0,10.8 \mathrm{~Hz}), 4.21-4.28(1 \mathrm{H}, \mathrm{m}), 4.18(1 \mathrm{H}, \mathrm{dd}, J=3.5,11.0 \mathrm{~Hz}), 3.97(1 \mathrm{H}, \mathrm{dd}, J$ $=7.8,11.0 \mathrm{~Hz}$ ), $3.88(3 \mathrm{H}, \mathrm{s})$; IR (film) $v_{\max } 1708,1603,1522,1437,1303,1218,1174$ $\mathrm{cm}^{-1}$; ESITOF-HRMS $m / z 530.1479\left(\mathrm{M}+\mathrm{H}^{+}, \mathrm{C}_{29} \mathrm{H}_{24} \mathrm{ClN}_{3} \mathrm{O}_{5}\right.$ requires 530.1477).

7d: $[\alpha]^{23}{ }_{\mathrm{D}}+8(c 0.2, \mathrm{THF})$.

ent-7d: $[\alpha]^{23}{ }_{D}-7$ (c 0.2, THF).

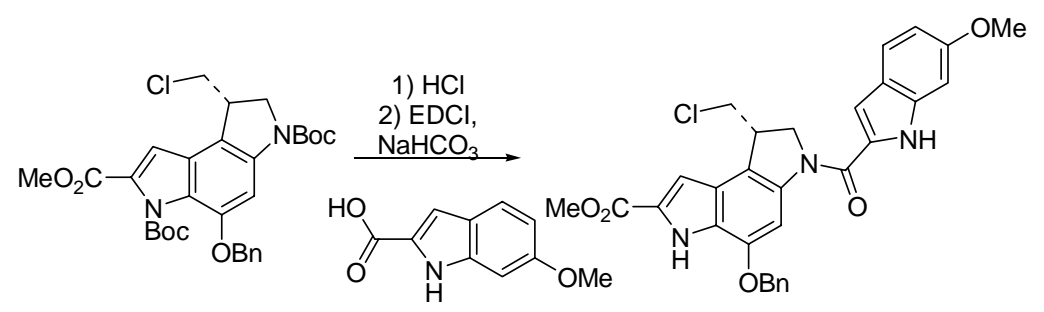

Methyl 3-[(6-Methoxyindol-2-yl)carbonyl]-1-(chloromethyl)-5-benzyloxy-1,2dihydro-3H-pyrrolo[3,2-e]indole-7-carboxylate (7e). Compound 6 (25.4 mg, 0.0445 mmol) in $4 \mathrm{~N} \mathrm{HCl-EtOAc}(1.5 \mathrm{~mL})$ and the solution was stirred for $1 \mathrm{~h}$ at $70{ }^{\circ} \mathrm{C}$. The solvent was removed under a stream of $\mathrm{N}_{2}$ and the sample was dried under vacuum for 3 h. The crude residue was dissolved in DMF $(0.3 \mathrm{~mL})$, treated with carboxylic acid $\mathbf{5 e}$ (12.8 mg, $0.0667 \mathrm{mmol}$ ), EDCI (34.1 mg, $0.178 \mathrm{mmol}$ ) and $\mathrm{NaHCO}_{3}(7.0 \mathrm{mg}, 0.083)$ and stirred for $15 \mathrm{~h}$ at $25^{\circ} \mathrm{C}$. The reaction mixture was diluted with THF, applied to a silica 
gel plug, and eluted with THF. The THF was removed by a $\mathrm{N}_{2}$ stream and the residue was purified by flash chromatography $\left(\mathrm{SiO}_{2}, 50 \%\right.$ EtOAc-hexanes) to provide $7 \mathrm{e}$ (15 mg, 62\%) as a white solid: ${ }^{1} \mathrm{H}$ NMR (acetone- $\left.d_{6}, 400 \mathrm{MHz}\right) \delta 11.13(1 \mathrm{H}$, br s), 10.62 (1H, br s), $8.23(1 \mathrm{H}$, br s), 7.58-7.63 $(3 \mathrm{H}, \mathrm{m}), 7.33-7.45(3 \mathrm{H}, \mathrm{m}), 7.32(1 \mathrm{H}, \mathrm{d}, J=2.0$ $\mathrm{Hz}), 7.15(1 \mathrm{H}, \mathrm{d}, J=1.8 \mathrm{~Hz}), 7.09(1 \mathrm{H}, \mathrm{d}, J=1.8 \mathrm{~Hz}), 6.78(1 \mathrm{H}, \mathrm{dd}, J=2.4,8.8 \mathrm{~Hz})$, $5.30(2 \mathrm{H}, \mathrm{s}), 4.84(1 \mathrm{H}, \mathrm{t}, J=10.8 \mathrm{~Hz}), 4.65(1 \mathrm{H}, \mathrm{dd}, J=4.1,10.8 \mathrm{~Hz}), 4.21-4.28(1 \mathrm{H}$, m), $4.19(1 \mathrm{H}, \mathrm{dd}, J=3.7,11.0 \mathrm{~Hz}), 3.98(1 \mathrm{H}, \mathrm{dd}, J=7.8,11.0 \mathrm{~Hz}), 3.88(3 \mathrm{H}, \mathrm{s}), 3.85$ $(3 \mathrm{H}, \mathrm{s})$; IR (film) $v_{\max } 3282,2950,1713,1606,1505,1435,1300,1224,1162 \mathrm{~cm}^{-1}$; ESITOF-HRMS $m / z$ 544.1636 $\left(\mathrm{M}+\mathrm{H}^{+}, \mathrm{C}_{30} \mathrm{H}_{26} \mathrm{ClN}_{3} \mathrm{O}_{5}\right.$ requires 544.1634).

7e: $[\alpha]^{23}+6(c 0.2, \mathrm{THF})$.

ent-7e: $[\alpha]^{23}-4(c 0.2, \mathrm{THF})$.

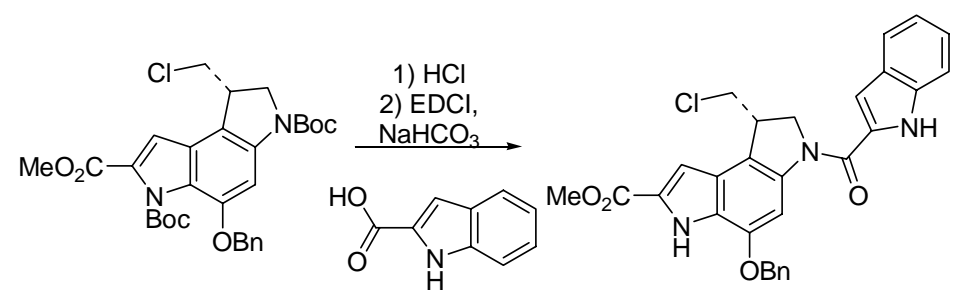

\section{Methyl 3-[(Indol-2-yl)carbonyl]-1-(chloromethyl)-5-benzyloxy-1,2-dihydro-3H-} pyrrolo[3,2-e ]indole-7-carboxylate (7f). Compound $6(31.8 \mathrm{mg}, 0.0557 \mathrm{mmol})$ was dissolved in $4 \mathrm{~N} \mathrm{HCl}-\mathrm{EtOAc}(3 \mathrm{~mL})$ and the solution was stirred for $1 \mathrm{~h}$ at $70{ }^{\circ} \mathrm{C}$. The solvent was removed under a stream of $\mathrm{N}_{2}$ and the sample was dried under vacuum for 3 h. The crude residue was dissolved in DMF $(0.6 \mathrm{~mL})$ and treated with carboxylic acid $\mathbf{5 f}$ (13.5 mg, $0.0835 \mathrm{mmol}$ ), EDCI (42.7 mg, $0.2228 \mathrm{mmol}$ ) and $\mathrm{NaHCO}_{3}$ (9.4 mg, 0.1114) and stirred for $16 \mathrm{~h}$ at $25^{\circ} \mathrm{C}$. The reaction mixture was diluted with THF, applied to a silica gel plug, and eluted with THF. The THF was removed by a $\mathrm{N}_{2}$ stream and the residue was purified by flash chromatography $\left(\mathrm{SiO}_{2}, 50 \%\right.$ EtOAc-hexanes) to provide $7 \mathbf{f}$ (21.6 mg, 75\%) as a white solid: ${ }^{1} \mathrm{H}$ NMR (acetone- $\left.d_{6}, 400 \mathrm{MHz}\right) \delta 11.17(1 \mathrm{H}, \mathrm{br} \mathrm{s})$, $10.83(1 \mathrm{H}$, br s), 8.22 (1H, br s), $7.73(1 \mathrm{H}, \mathrm{d}, J=8.1 \mathrm{~Hz}), 7.58-7.63(3 \mathrm{H}, \mathrm{m}), 7.35-7.45$ $(3 \mathrm{H}, \mathrm{m}), 7.33(1 \mathrm{H}, \mathrm{s}), 7.28(1 \mathrm{H}, \mathrm{ddd}, J=1.1,7.0,8.2 \mathrm{~Hz}), 7.22(1 \mathrm{H}, \mathrm{m}), 7.12(1 \mathrm{H}, \mathrm{ddd}, J$ $=1.0,7.0,8.0 \mathrm{~Hz}), 5.30(2 \mathrm{H}, \mathrm{s}), 4.88(1 \mathrm{H}, \mathrm{dd}, J=9.5,10.7 \mathrm{~Hz}), 4.68(1 \mathrm{H}, \mathrm{dd}, J=4.1$, $10.9 \mathrm{~Hz}), 4.45-4.60(1 \mathrm{H}, \mathrm{m}), 4.19(1 \mathrm{H}, \mathrm{dd}, J=3.6,10.9 \mathrm{~Hz}), 3.99(1 \mathrm{H}, \mathrm{dd}, J=7.7,11.0$ 
Hz), 3.88 (3H, s); IR (film) $v_{\max } 3289,2952,1716,1615,1516,1418,1326,1246,1163$

$\mathrm{cm}^{-1}$; ESITOF-HRMS $m / z 514.1522\left(\mathrm{M}+\mathrm{H}^{+}, \mathrm{C}_{29} \mathrm{H}_{24} \mathrm{ClN}_{3} \mathrm{O}_{4}\right.$ requires 514.1528).

7f: $[\alpha]^{23}{ }_{D}+2(c 0.2, \mathrm{THF})$.

ent-7f: $[\alpha]^{23}-1(c 0.2, \mathrm{THF})$.

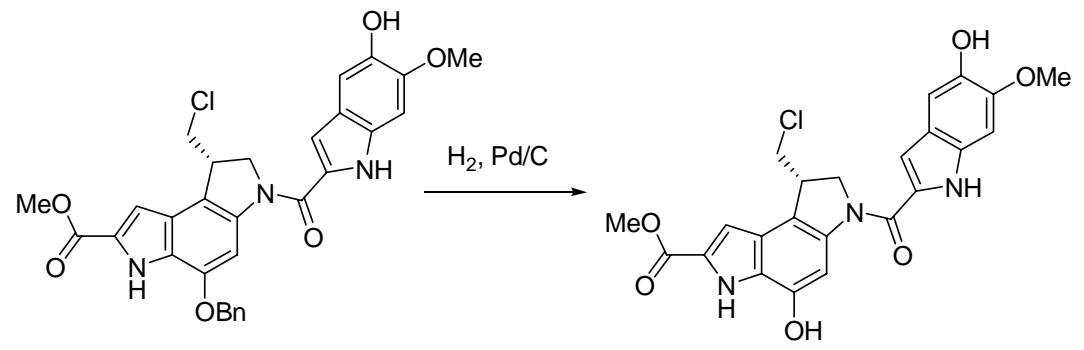

Methyl 3-[(5-Hydroxy-6-methoxyindol-2-yl)carbonyl]-1-(chloromethyl)-5-hydroxy1,2-dihydro-3H-pyrrolo[3,2-e]indole-7-carboxylate (8a). Compound 7a $(9.4 \mathrm{mg}$, $0.0168 \mathrm{mmol})$ was dissolved in 9:1 THF-MeOH $(3.0 \mathrm{~mL})$, treated with $10 \% \mathrm{Pd} / \mathrm{C}(5$ $\mathrm{mg}$ ), and the solution was stirred under $\mathrm{H}_{2}(1 \mathrm{~atm})$ at $25{ }^{\circ} \mathrm{C}$ for $2 \mathrm{~h}$. The mixture was filtered through Celite and concentrated in vacuo. The residue was purified by flash chromatography $\left(\mathrm{SiO}_{2}, 5 \% \mathrm{MeOH}-\mathrm{CH}_{2} \mathrm{Cl}_{2}\right)$ to afford $\mathbf{8 a}(6.3 \mathrm{mg}, 80 \%)$ as a beige solid: ${ }^{1} \mathrm{H}$ NMR (acetone- $\left.d_{6}, 600 \mathrm{MHz}\right) \delta 10.47(1 \mathrm{H}, \mathrm{s}), 8.01(1 \mathrm{H}, \mathrm{s}), 7.27(1 \mathrm{H}, \mathrm{s}), 7.10(1 \mathrm{H}, \mathrm{s})$, $7.08(1 \mathrm{H}, \mathrm{s}), 7.01(1 \mathrm{H}, \mathrm{s}), 4.79(1 \mathrm{H}, \mathrm{t}, J=9.2 \mathrm{~Hz}), 4.61(1 \mathrm{H}, \mathrm{dd}, J=7.0,3.5 \mathrm{~Hz}), 4.20$ $(1 \mathrm{H}, \mathrm{m}), 4.16(1 \mathrm{H}, \mathrm{m}), 3.93(1 \mathrm{H}, \mathrm{dd}, J=4.8,10.8 \mathrm{~Hz}), 3.90(3 \mathrm{H}, \mathrm{s}), 3.89(3 \mathrm{H}, \mathrm{s}) ; \mathrm{IR}$ (film) $v_{\max } 3301,1698,1503,1318 \mathrm{~cm}^{-1}$; ESITOF-HRMS $\mathrm{m} / z 470.1104\left(\mathrm{M}+\mathrm{H}^{+}\right.$, $\mathrm{C}_{23} \mathrm{H}_{20} \mathrm{ClN}_{3} \mathrm{O}_{6}$ requires 470.1113).

8a: $[\alpha]^{23}{ }_{D}+4(c$ 0.2, DMF).

ent-8a: $[\alpha]^{23}{ }_{D}-7$ (c 0.2, DMF).

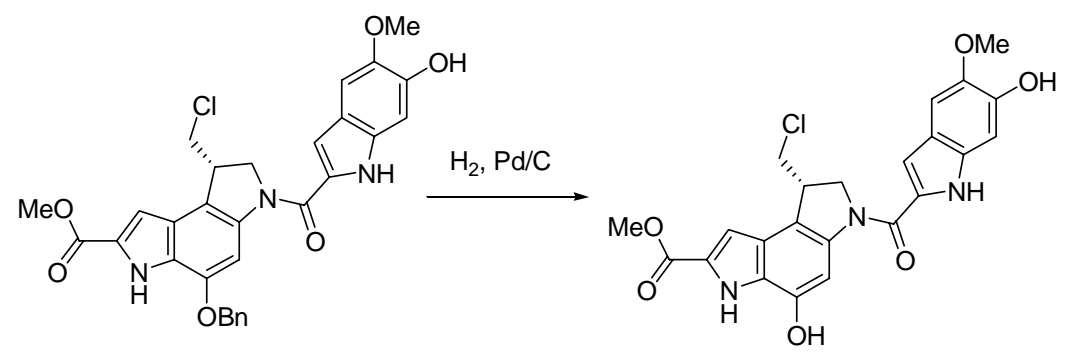


Methyl 3-[(6-Hydroxy-5-methoxyindol-2-yl)carbonyl]-1-(chloromethyl)-5-hydroxy1,2-dihydro-3H-pyrrolo[3,2-e]indole-7-carboxylate $(\mathbf{8 b})$. Compound $7 \mathrm{~b}$ (3.6 mg, $0.0064 \mathrm{mmol})$ was dissolved in 9:1 THF-MeOH $(2 \mathrm{~mL})$, treated with $10 \% \mathrm{Pd} / \mathrm{C}(10 \mathrm{mg})$, and the solution was stirred under $\mathrm{H}_{2}(1 \mathrm{~atm})$ at $25{ }^{\circ} \mathrm{C}$ for $1 \mathrm{~h}$. The mixture was filtered through Celite and concentrated in vacuo. The residue was purified by flash chromatography $\left(\mathrm{SiO}_{2}, 2-4 \% \mathrm{MeOH}-\mathrm{CH}_{2} \mathrm{Cl}_{2}\right)$ to afford $\mathbf{8 b}(2.7 \mathrm{mg}, 89 \%)$ as a beige solid: ${ }^{1} \mathrm{H}$ NMR (acetone- $\left.d_{6}, 600 \mathrm{MHz}\right) \delta 10.44(1 \mathrm{H}, \mathrm{br} \mathrm{s}), 8.00(1 \mathrm{H}, \mathrm{s}), 7.27(1 \mathrm{H}, \mathrm{s}), 7.18$ $(1 \mathrm{H}, \mathrm{s}), 7.05(1 \mathrm{H}, \mathrm{s}), 7.02(1 \mathrm{H}, \mathrm{s}), 4.78(1 \mathrm{H}, \mathrm{t}, J=10.1 \mathrm{~Hz}), 4.61(1 \mathrm{H}, \mathrm{dd}, J=7.1,4.0$ Hz), 4.15-4.18 (2H, m), $3.903(3 \mathrm{H}, \mathrm{s}), 3.901$ (3H, s), 3.89 (1H, m); IR (film) $v_{\max } 3392$, 1713, 1435, $1317 \mathrm{~cm}^{-1}$; MALDIFT-HRMS (DHB) $\mathrm{m} / z 469.1036\left(\mathrm{M}^{+}, \mathrm{C}_{23} \mathrm{H}_{20} \mathrm{ClN}_{3} \mathrm{O}_{6}\right.$ requires 469.1035$)$.

8b: $[\alpha]^{23}-9$ ( $c 0.2$, acetone).

ent-8b: $[\alpha]^{23}{ }_{D}+11(c 0.2$, acetone).

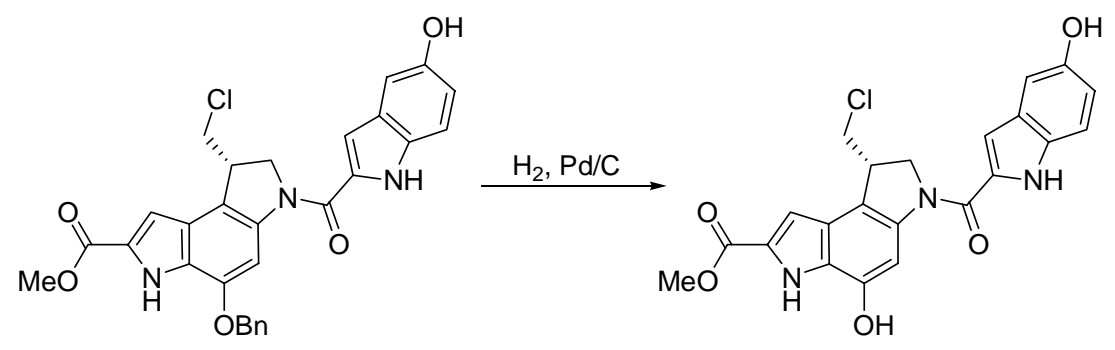

Methyl 3-[(5-Hydroxyindol-2-yl)carbonyl]-1-(chloromethyl)-5-hydroxy-1,2-dihydro3H-pyrrolo[3,2-e $]$ indole-7-carboxylate (8d). Compound 7d (5.9 mg, $0.0111 \mathrm{mmol})$ was dissolved in 9:1 THF-MeOH $(3.0 \mathrm{~mL})$, treated with $10 \% \mathrm{Pd} / \mathrm{C}(8.5 \mathrm{mg})$ and the solution was stirred under $\mathrm{H}_{2}(1 \mathrm{~atm})$ at $25^{\circ} \mathrm{C}$ for $4 \mathrm{~h}$. The mixture was filtered through Celite and concentrated in vacuo. The residue was purified by flash chromatography $\left(\mathrm{SiO}_{2}, 5 \% \mathrm{MeOH}-\mathrm{CH}_{2} \mathrm{Cl}_{2}\right)$ to afford $\mathbf{8 d}(4.2 \mathrm{mg}, 86 \%)$ as a tan solid: ${ }^{1} \mathrm{H}$ NMR (acetone$\left.d_{6}, 500 \mathrm{MHz}\right) \delta 10.50(1 \mathrm{H}, \mathrm{s}), 7.99(1 \mathrm{H}, \mathrm{s}), 7.42(1 \mathrm{H}, \mathrm{d}, J=8.8 \mathrm{~Hz}), 7.28(1 \mathrm{H}, \mathrm{s}), 7.09$ $(1 \mathrm{H}, \mathrm{d}, J=2.6 \mathrm{~Hz}), 7.02(1 \mathrm{H}, \mathrm{s}), 6.89(1 \mathrm{H}, \mathrm{dd}, J=6.6,2.2 \mathrm{~Hz}), 4.80(1 \mathrm{H}, \mathrm{t}, J=10.6 \mathrm{~Hz})$, $4.62(1 \mathrm{H}, \mathrm{dd}, J=7.0,4.0 \mathrm{~Hz}), 4.19(1 \mathrm{H}, \mathrm{m}), 4.16(1 \mathrm{H}, \mathrm{dd}, J=8.4,3.7 \mathrm{~Hz}), 3.91(1 \mathrm{H}, \mathrm{m})$, $3.90(3 \mathrm{H}, \mathrm{s})$; IR (film) $v_{\max } 3353,1437,1180 \mathrm{~cm}^{-1}$; MALDIFT-HRMS (DHB) $\mathrm{m} / z$ $440.1007\left(\mathrm{M}+\mathrm{H}^{+}, \mathrm{C}_{22} \mathrm{H}_{18} \mathrm{ClN}_{3} \mathrm{O}_{5}\right.$ requires 440.1008). 
8d: $[\alpha]^{23}+8(c 0.1, \mathrm{DMF})$

ent-8d: $[\alpha]^{23}-10(c 0.1, \mathrm{DMF})$

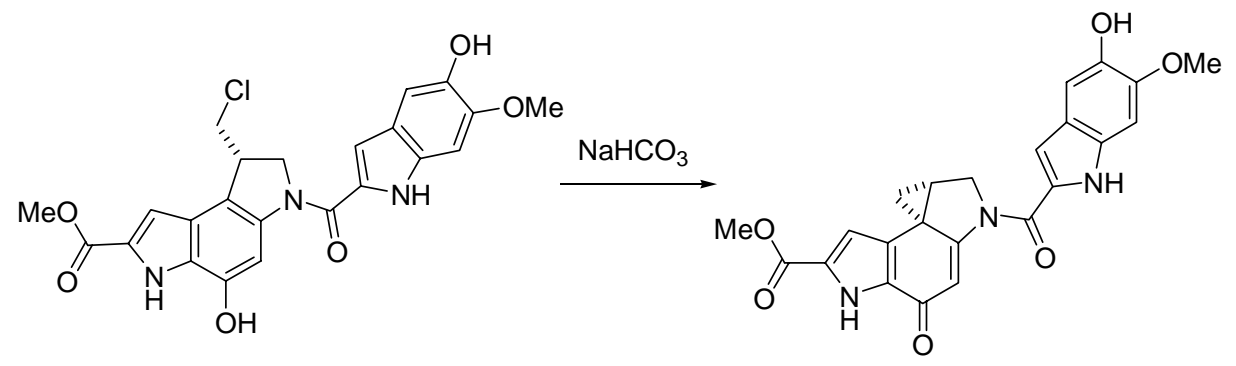

\section{Methyl}

2-[(5-Hydroxy-6-methoxyindol-2-yl)carbonyl]-1,2,8,8a-

tetrahydrocyclopropa[c]pyrrolo[3,2-e]indole-4-one-6-carboxylate (9a). Compound 8a $(2.05 \mathrm{mg}, 0.00436 \mathrm{mmol})$ was dissolved in DMF $(0.66 \mathrm{~mL})$, treated with a solution of $\mathrm{NaHCO}_{3}$ in $\mathrm{H}_{2} \mathrm{O}\left(0.33 \mathrm{~mL}, 15 \mathrm{mg} / \mathrm{mL} \mathrm{NaHCO}_{3}\right)$, and the mixture was stirred vigorously for $1 \mathrm{~h}$ at $25{ }^{\circ} \mathrm{C}$. THF $(2 \mathrm{~mL})$ was added, and the precipitated base was removed by filtration through a pad of silica gel. The solvent was removed by a $\mathrm{N}_{2}$ stream, and the residue was purified by flash chromatography $\left(\mathrm{SiO}_{2}, 2.5 \% \mathrm{MeOH}-\mathrm{CHCl}_{3}\right)$ to afford $9 \mathbf{a}$ $\left(1.69 \mathrm{mg}, 89 \%\right.$ ) as a yellow solid: ${ }^{1} \mathrm{H}$ NMR (acetone- $\left.d_{6}, 600 \mathrm{MHz}\right) \delta 10.60(1 \mathrm{H}, \mathrm{s}), 8.02$ $(1 \mathrm{H}, \mathrm{s}), 7.07(1 \mathrm{H}, \mathrm{s}), 7.05(1 \mathrm{H}, \mathrm{s}), 7.04(1 \mathrm{H}, \mathrm{s}), 6.96(1 \mathrm{H}, \mathrm{s}), 6.76(1 \mathrm{H}, \mathrm{s}), 4.59(1 \mathrm{H}, \mathrm{m})$, $4.51(1 \mathrm{H}, \mathrm{d}, J=10.1 \mathrm{~Hz}), 3.91(3 \mathrm{H}, \mathrm{s}), 3.84(3 \mathrm{H}, \mathrm{s}), 3.06(1 \mathrm{H}, \mathrm{dt}, J=4.8,3.1 \mathrm{~Hz}), 1.80$ $(1 \mathrm{H}, \mathrm{dd}, J=4.0,3.5 \mathrm{~Hz}), 1.60(1 \mathrm{H}, \mathrm{t}, J=4.4 \mathrm{~Hz})$; IR (film) $v_{\max } 2920,1709,1260 \mathrm{~cm}^{-1}$; ESITOF-HRMS $m / z$ 434.1351 ( $\mathrm{M}+\mathrm{H}^{+}, \mathrm{C}_{23} \mathrm{H}_{19} \mathrm{~N}_{3} \mathrm{O}_{6}$ requires 434.1347).

9a: $[\alpha]^{23}{ }_{D}+168$ ( $c 0.05$, acetone).

ent-9a: $[\alpha]_{\mathrm{D}}^{23}-174$ (c 0.1 , acetone).

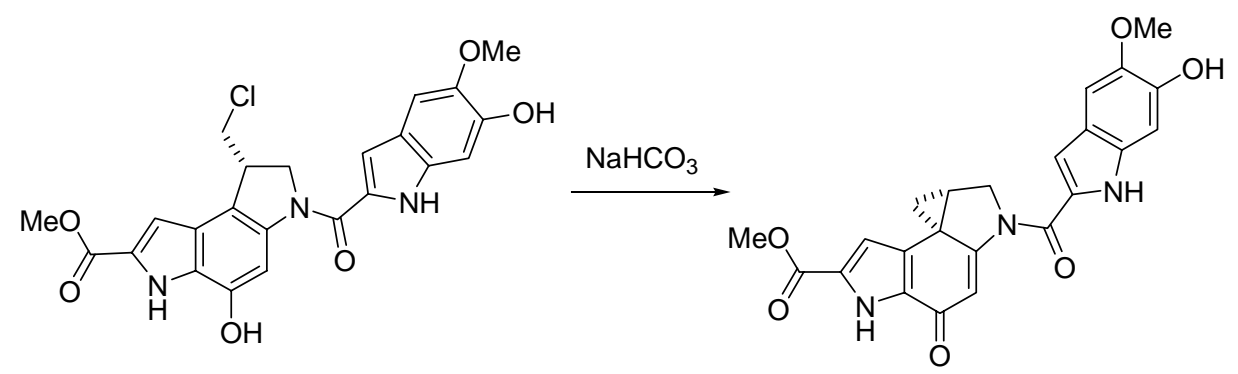


tetrahydrocyclopropa[c]pyrrolo[3,2-e]indole-4-one-6-carboxylate (9b). Compound $\mathbf{8 b}(4.0 \mathrm{mg}, 0.00851 \mathrm{mmol})$ was dissolved in DMF $(0.66 \mathrm{~mL})$, treated with a solution of $\mathrm{NaHCO}_{3}$ in $\mathrm{H}_{2} \mathrm{O}\left(0.33 \mathrm{~mL}, 15 \mathrm{mg} / \mathrm{mL} \mathrm{NaHCO}_{3}\right)$, and the mixture was stirred vigorously for $1 \mathrm{~h}$ at $25{ }^{\circ} \mathrm{C}$. THF $(2 \mathrm{~mL})$ was added, and the precipitated base was removed by filtration through a pad of silica gel. The solvent was removed by a $\mathrm{N}_{2}$ stream, and the residue was purified by flash chromatography $\left(\mathrm{SiO}_{2}, 2.5 \% \mathrm{MeOH}-\mathrm{CH}_{2} \mathrm{Cl}_{2}\right)$ to afford $\mathbf{9 b}$ $\left(2.36 \mathrm{mg}, 64 \%\right.$ ) as a yellow solid: ${ }^{1} \mathrm{H}$ NMR (acetone- $\left.d_{6}, 500 \mathrm{MHz}\right) \delta 7.13(1 \mathrm{H}, \mathrm{s}), 7.10$ $(1 \mathrm{H}, \mathrm{s}), 7.00(1 \mathrm{H}, \mathrm{s}), 6.93(1 \mathrm{H}, \mathrm{s}), 6.76(1 \mathrm{H}, \mathrm{s}), 4.59(1 \mathrm{H}, \mathrm{dd}, J=5.1,4.9 \mathrm{~Hz}), 4.50(1 \mathrm{H}$, d, $J=9.9 \mathrm{~Hz}), 3.89(3 \mathrm{H}, \mathrm{s}), 3.85(3 \mathrm{H}, \mathrm{s}), 3.05(1 \mathrm{H}, \mathrm{dt}, J=5.1,2.9 \mathrm{~Hz}), 1.81(1 \mathrm{H}, \mathrm{dd}, J=$ 4.0, 3.7 Hz), $1.60(1 \mathrm{H}, \mathrm{t}, J=4.4 \mathrm{~Hz})$; IR (film) $v_{\max } 1636,1269 \mathrm{~cm}^{-1}$; MALDIFT-HRMS (DHB) $m / z$ 434.1333 $\left(\mathrm{M}+\mathrm{H}^{+}, \mathrm{C}_{23} \mathrm{H}_{19} \mathrm{~N}_{3} \mathrm{O}_{6}\right.$ requires 434.1347).

9b: $[\alpha]^{23}+109(c 0.1$, acetone).

ent-9b: $[\alpha]^{23}-112$ (c 0.1 , acetone).

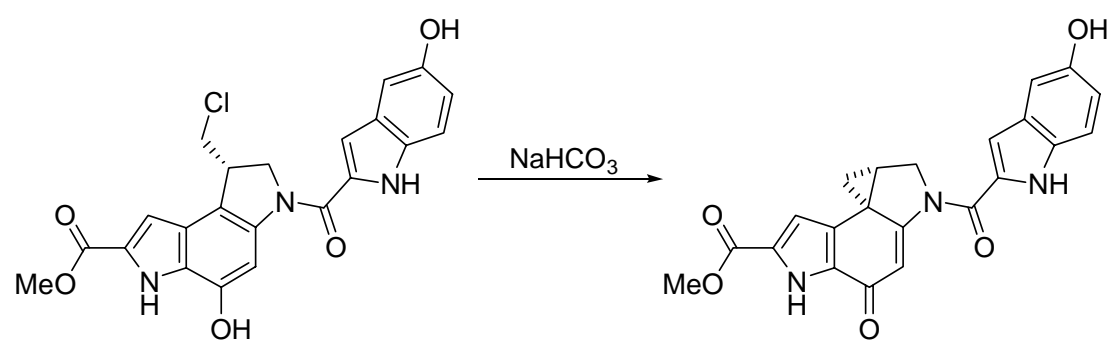

Methyl

2-[(5-Hydroxyindol-2-yl)

carbonyl]-1,2,8,8a-

tetrahydrocyclopropa[c]pyrrolo[3,2-e]indole-4-one-6-carboxylate (9d). Compound 8d $(1.70 \mathrm{mg}, 0.00386 \mathrm{mmol})$ was dissolved in DMF $(0.66 \mathrm{~mL})$, treated with a solution of $\mathrm{NaHCO}_{3}$ in $\mathrm{H}_{2} \mathrm{O}\left(0.33 \mathrm{~mL}, 15 \mathrm{mg} / \mathrm{mL} \mathrm{NaHCO}_{3}\right)$, and the mixture was stirred vigorously for $1 \mathrm{~h}$ at $25{ }^{\circ} \mathrm{C}$. THF ( $\left.2 \mathrm{~mL}\right)$ was added, and the precipitated base was removed by filtration through a pad of silica gel. The solvent was removed by a $\mathrm{N}_{2}$ stream, and the residue was purified by flash chromatography $\left(\mathrm{SiO}_{2}, 5 \% \mathrm{MeOH}-\mathrm{CH}_{2} \mathrm{Cl}_{2}\right)$ to afford $9 d$ $\left(1.33 \mathrm{mg}, 85 \%\right.$ ) as a yellow solid: ${ }^{1} \mathrm{H}$ NMR (acetone- $\left.d_{6}, 400 \mathrm{MHz}\right) \delta 7.42(1 \mathrm{H}, \mathrm{d}, J=8.7$ Hz), $7.06(1 \mathrm{H}, \mathrm{s}), 7.05(1 \mathrm{H}, \mathrm{s}), 6.93(1 \mathrm{H}, \mathrm{s}), 6.77(1 \mathrm{H}, \mathrm{s}), 6.68(1 \mathrm{H}, \mathrm{d}, J=1.0 \mathrm{~Hz}), 4.62$ $(1 \mathrm{H}, \mathrm{dd}, J=5.3,4.8 \mathrm{~Hz}), 4.53(1 \mathrm{H}, \mathrm{d}, J=10.3 \mathrm{~Hz}), 3.84(3 \mathrm{H}, \mathrm{s}), 3.07(1 \mathrm{H}, \mathrm{dt}, J=4.8,1.9$ $\mathrm{Hz}), 1.82(1 \mathrm{H}, \mathrm{dd}, J=4.1,3.7 \mathrm{~Hz}), 1.63(1 \mathrm{H}, \mathrm{t}, J=4.6 \mathrm{~Hz})$; IR (film) $v_{\max } 3383,1384$, 
$1264 \mathrm{~cm}^{-1}$; MALDIFT-HRMS (DHB) $\mathrm{m} / z 404.1239\left(\mathrm{M}+\mathrm{H}^{+}, \mathrm{C}_{22} \mathrm{H}_{17} \mathrm{~N}_{3} \mathrm{O}_{5}\right.$ requires 404.1241).

9d: $[\alpha]^{23}+180(c 0.1, \mathrm{DMF})$

ent-9d: $[\alpha]^{23}-176(c 0.1, \mathrm{DMF})$<smiles>COC(=O)c1cc2c([nH]1)C(=O)C=C(C1CCCC1)N(C(=O)c1cc3ccc(OC)cc3[nH]1)C2</smiles>

Methyl

2-[(6-Methoxyindol-2-yl)

carbonyl]-1,2,8,8a-

tetrahydrocyclopropa $[c]$ pyrrolo[3,2-e]indole-4-one-6-carboxylate (9e). Compound 9e was prepared according to our previously reported procedure. ${ }^{14 \mathrm{~b}}$<smiles>COC(=O)c1cc2c([nH]1)C(=O)C=C1N(C(=O)c3cc4ccccc4[nH]3)CC[C@@]12C</smiles>

Methyl 2-[(Indol-2-yl) carbonyl]-1,2,8,8a-tetrahydrocyclopropa[c]pyrrolo[3,2$\boldsymbol{e}$ ]indole-4-one-6-carboxylate (9f). Compound 9f was prepared according to our previously reported procedure. ${ }^{14 \mathrm{~b}}$

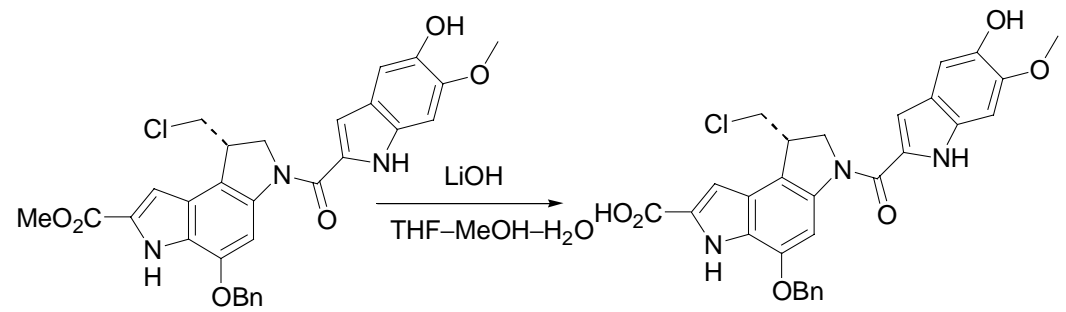

\section{3-[(5-Hydroxy-6-methoxyindol-2-yl)carbonyl]-1-(chloromethyl)-5-benzyloxy-1,2-}

dihydro-3H-pyrrolo[3,2-e]indole-7-carboxylic acid (11a). Compound 7a (28.5 mg, $0.0509 \mathrm{mmol})$ was dissolved in 3:2:1 THF-MeOH- $\mathrm{H}_{2} \mathrm{O}(3.0 \mathrm{~mL})$, treated with $4 \mathrm{~N}$ aq. $\mathrm{LiOH}(0.1 \mathrm{~mL}, 0.4 \mathrm{mmol})$, and the mixture was stirred for $14 \mathrm{~h}$ at $25^{\circ} \mathrm{C}$. The reaction was quenched with $1 \mathrm{~N}$ aq. $\mathrm{HCl}(20 \mathrm{~mL})$ and the solution was extracted with EtOAc $(3 \times$ $20 \mathrm{~mL}$ ). The combined organic extracts were washed with saturated aqueous $\mathrm{NaCl}$ (5 $\mathrm{mL})$, dried $\left(\mathrm{Na}_{2} \mathrm{SO}_{4}\right)$, and concentrated in vacuo. The crude residue was purified by flash 
chromatography $\left(\mathrm{SiO}_{2}, 50 \%\right.$ EtOAc-hexanes containing 1\% $\left.\mathrm{HOAc}\right)$, and azeotropically dried with toluene to afford 11a (25.6 mg, 92\%) as an off-white solid: ${ }^{1} \mathrm{H}$ NMR (acetone$\left.d_{6}, 400 \mathrm{MHz}\right) \delta 10.99(1 \mathrm{H}, \mathrm{s}), 10.49(1 \mathrm{H}, \mathrm{s}), 8.23(1 \mathrm{H}, \mathrm{s}), 7.61(2 \mathrm{H}, \mathrm{d}, J=7.5 \mathrm{~Hz}), 7.41$ $(2 \mathrm{H}, \mathrm{t}, J=7.1 \mathrm{~Hz}), 7.34(1 \mathrm{H}, \mathrm{t}, J=7.2 \mathrm{~Hz}), 7.32(1 \mathrm{H}, \mathrm{s}), 7.10(1 \mathrm{H}, \mathrm{s}), 7.09(1 \mathrm{H}, \mathrm{s}), 7.03$ $(1 \mathrm{H}, \mathrm{s}), 5.30(2 \mathrm{H}, \mathrm{s}), 4.82(1 \mathrm{H}, \mathrm{t}, J=9.5 \mathrm{~Hz}), 4.63(1 \mathrm{H}, \mathrm{dd}, J=6.9,4.0 \mathrm{~Hz}), 4.24(1 \mathrm{H}$, m), $4.19(1 \mathrm{H}, \mathrm{dd}, J=7.4,3.5 \mathrm{~Hz}), 3.97(1 \mathrm{H}, \mathrm{m}), 3.90(3 \mathrm{H}, \mathrm{s}) ;{ }^{13} \mathrm{C}$ NMR (acetone- $d_{6}, 100$ MHz) $\delta 162.7,153.0,149.0,146.5,143.7,140.1,138.1,132.1,130.7,130.2,129.3$ (2C), 128.8 (2C), 128.7, 127.4, 125.1, 122.7, 115.3, 107.0, 106.2, 105.8, 99.4, 94.6, 70.9, 60.6, 56.3, 48.1, 43.8; IR (film) $v_{\max }$ 3255, 1700, $1308 \mathrm{~cm}^{-1}$; ESITOF-HRMS $\mathrm{m} / \mathrm{z} 546.1418$ $\left(\mathrm{M}+\mathrm{H}^{+}, \mathrm{C}_{29} \mathrm{H}_{24} \mathrm{ClN}_{3} \mathrm{O}_{6}\right.$ requires 546.1426).

11a: $[\alpha]^{23}{ }_{\mathrm{D}}+14(c$ 0.04, THF).

ent-11a: $[\alpha]^{23}{ }_{D}-15$ (c 0.04, THF).

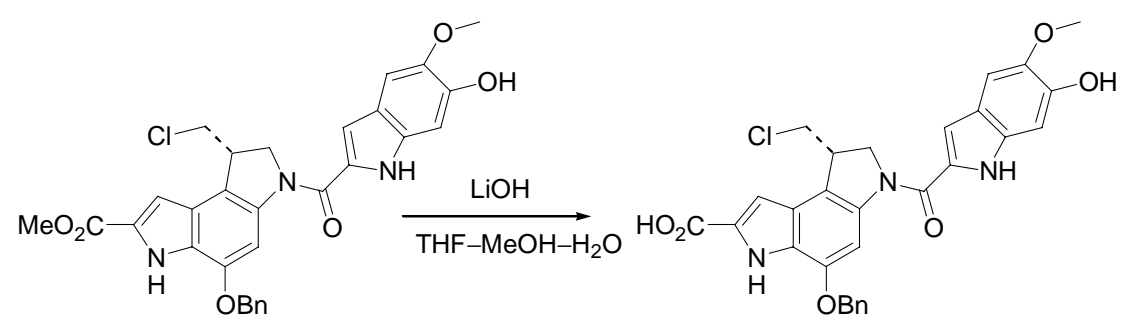

3-[(6-Hydroxy-5-methoxyindol-2-yl)carbonyl]-1-(chloromethyl)-5-benzyloxy-1,2dihydro-3H-pyrrolo[3,2-e]indole-7-carboxylic acid (11b). Compound 7b $(30.2 \mathrm{mg}$, $0.0541 \mathrm{mmol})$ was dissolved in $3: 2: 1 \mathrm{THF}-\mathrm{MeOH}-\mathrm{H}_{2} \mathrm{O}(1.0 \mathrm{~mL})$, treated with $\mathrm{LiOH} \cdot \mathrm{H}_{2} \mathrm{O}(6.9 \mathrm{mg}, 0.168 \mathrm{mmol})$, and the mixture was stirred for $14 \mathrm{~h}$ at $25^{\circ} \mathrm{C} .1 \mathrm{~N}$ aqueous $\mathrm{HCl}(1.0 \mathrm{~mL})$ was added and the solution was extracted with EtOAc $(3 \times 5 \mathrm{~mL})$. The combined organic extracts were washed with saturated aqueous $\mathrm{NaCl}(5 \mathrm{~mL})$, dried $\left(\mathrm{Na}_{2} \mathrm{SO}_{4}\right)$, and concentrated in vacuo. The crude residue was purified by flash chromatography $\left(\mathrm{SiO}_{2}, 50 \%\right.$ EtOAc-hexanes containing 1\% $\left.\mathrm{HOAc}\right)$, and azeotropically dried with toluene to afford 11b $(23.0 \mathrm{mg}, 78 \%)$ as an off-white solid: ${ }^{1} \mathrm{H}$ NMR (acetone$\left.d_{6}, 400 \mathrm{MHz}\right) \delta 11.00(1 \mathrm{H}, \mathrm{br} \mathrm{s}), 10.50(1 \mathrm{H}, \mathrm{br} \mathrm{s}), 8.22(1 \mathrm{H}, \mathrm{s}), 7.60(2 \mathrm{H}, \mathrm{d}, J=7.2 \mathrm{~Hz})$, $7.41(2 \mathrm{H}, \mathrm{t}, J=7.0 \mathrm{~Hz}), 7.34(1 \mathrm{H}, \mathrm{t}, J=7.3 \mathrm{~Hz}), 7.31(1 \mathrm{H}, \mathrm{s}), 7.18(1 \mathrm{H}, \mathrm{s}), 7.00(1 \mathrm{H}, \mathrm{s})$, $7.03(1 \mathrm{H}, \mathrm{s}), 5.30(2 \mathrm{H}, \mathrm{s}), 4.80(1 \mathrm{H}, \mathrm{t}, J=9.4 \mathrm{~Hz}), 4.64(1 \mathrm{H}, \mathrm{dd}, J=6.8,3.8 \mathrm{~Hz})$, 
4.18-4.21 (2H, m), $3.98(1 \mathrm{H}, \mathrm{dd}, J=7.8,2.9 \mathrm{~Hz}), 3.90(3 \mathrm{H}, \mathrm{s}) ;{ }^{13} \mathrm{C}$ NMR (acetone- $d_{6}$, $100 \mathrm{MHz}) \delta 162.6,160.7,147.6,146.5,145.5,140.1,138.1,133.0,130.4,130.1,129.3$ (2C), 128.84 (2C), 128.79, 127.4, 125.1, 121.9, 115.2, 107.1, 106.8, 103.2, 99.4, 97.6, 70.9, 56.6, 55.8, 48.0, 43.9; IR (film) $v_{\max }$ 3385, 1692, 1308, $1195 \mathrm{~cm}^{-1}$; MALDIFT-HRMS (DHB) $m / z 545.1340\left(\mathrm{M}^{+}, \mathrm{C}_{29} \mathrm{H}_{24} \mathrm{ClN}_{3} \mathrm{O}_{6}\right.$ requires 545.1353).

11b: $[\alpha]^{23} \mathrm{D}+8(c 0.20$, acetone $)$.

ent-11b: $[\alpha]^{23}-8(c 0.20$, acetone $)$.
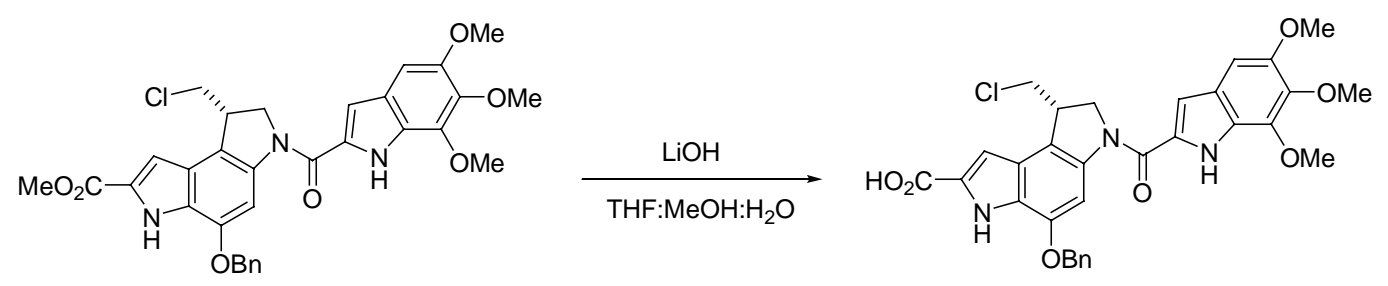

3-[(5,6,7-Trimethoxyindole-2-yl)carbonyl]-1-(chloromethyl)-5-benzyloxy-1,2-

dihydro-3H-pyrrolo[3,2-e]indole-7-carboxylic Acid (11c). Compound 7c (26.3 mg, $0.0435 \mathrm{mmol})$ was dissolved in 3:2:1 THF-MeOH- $\mathrm{H}_{2} \mathrm{O}(1.5 \mathrm{~mL})$, treated with $4 \mathrm{~N} \mathrm{LiOH}$ $(100 \mu \mathrm{L}, 0.4 \mathrm{mmol})$, and the mixture was stirred at $25^{\circ} \mathrm{C}$ for $14 \mathrm{~h}$. The reaction mixture was diluted with $\mathrm{H}_{2} \mathrm{O}(20 \mathrm{~mL})$, treated with $1 \mathrm{~N}$ aqueous $\mathrm{HCl}(2 \mathrm{~mL})$, and extracted with EtOAc $(3 \times 20 \mathrm{~mL})$. The combined organic extracts were washed with saturated aqueous $\mathrm{NaCl}(5 \mathrm{~mL})$, dried $\left(\mathrm{Na}_{2} \mathrm{SO}_{4}\right)$, and concentrated in vacuo, and the residue was azeotropically dried with toluene evaporation to afford 11c $(22.8 \mathrm{mg}, 89 \%)$ as an offwhite solid: ${ }^{1} \mathrm{H}$ NMR (acetone- $\left.d_{6}, 500 \mathrm{MHz}\right) \delta 10.27(1 \mathrm{H}, \mathrm{br} \mathrm{s}), 8.18(1 \mathrm{H}, \mathrm{br} \mathrm{s}), 7.58(2 \mathrm{H}$, d, $J=7.3 \mathrm{~Hz}), 7.39(2 \mathrm{H}, \mathrm{t}, J=7.0 \mathrm{~Hz}), 7.33(1 \mathrm{H}, \mathrm{t}, J=7.3 \mathrm{~Hz}), 7.32(1 \mathrm{H}, \mathrm{s}), 7.09(1 \mathrm{H}, \mathrm{s})$, $6.98(1 \mathrm{H}, \mathrm{s}), 5.27(2 \mathrm{H}, \mathrm{s}), 4.79(1 \mathrm{H}, \mathrm{t}, J=10.2 \mathrm{~Hz}), 4.60(1 \mathrm{H}, \mathrm{dd}, J=3.7,7.0 \mathrm{~Hz})$, 4.16-4.21 (2H, m), $4.04(3 \mathrm{H}, \mathrm{s}), 3.93(1 \mathrm{H}, \mathrm{dd}, J=7.7,2.9 \mathrm{~Hz}), 3.87(3 \mathrm{H}, \mathrm{s}), 3.86(3 \mathrm{H}, \mathrm{s})$; ${ }^{13} \mathrm{C}$ NMR (acetone- $\left.d_{6}, 125 \mathrm{MHz}\right) \delta 162.6,160.5,151.1,146.6,141.5,140.1,139.8$, 138.0, 132.1, 130.1, 129.3 (2C), 128.8 (2C), 128.7, 127.6, 126.4, 125.1, 124.9, 115.6, 107.1, 106.9, 99.4, 99.1, 71.0, 61.6, 61.5, 56.6, 55.8, 48.0, 43.9; IR (film) $v_{\max } 3254$, 2937, $1311 \mathrm{~cm}^{-1}$; ESITOF-HRMS m/z $590.1700\left(\mathrm{M}+\mathrm{H}^{+}, \mathrm{C}_{31} \mathrm{H}_{28} \mathrm{ClN}_{3} \mathrm{O}_{7}\right.$ requires 590.1700).

11c: $[\alpha]^{23}-7(c 0.2, \mathrm{THF})$. 
ent-11c: $[\alpha]^{23}{ }_{\mathrm{D}}+7(c 0.2, \mathrm{THF})$.

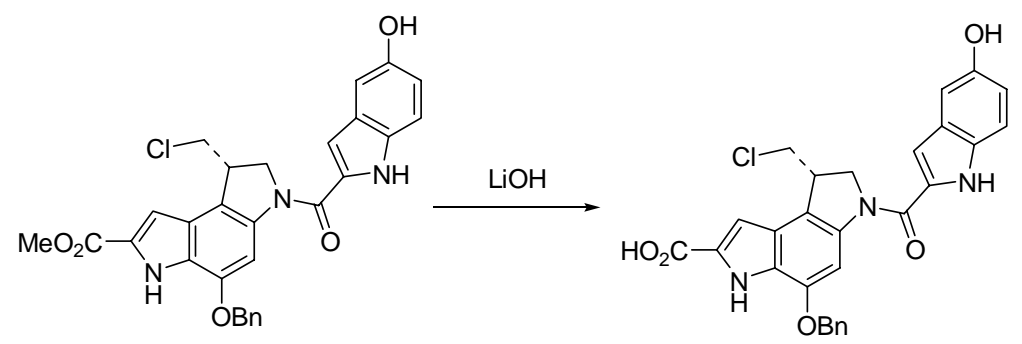

3-[(5-Hydroxyindol-2-yl)carbonyl]-1-(chloromethyl)-5-benzyloxy-1,2-dihydro-3Hpyrrolo[3,2-e]indole-7-carboxylic acid (11d). Compound 7d (15.5 mg, $0.0293 \mathrm{mmol})$ was dissolved in 3:2:1 THF-MeOH- $\mathrm{H}_{2} \mathrm{O}(1.5 \mathrm{~mL})$, treated with $4 \mathrm{~N}$ aqueous $\mathrm{LiOH}(150$ $\mu \mathrm{L}, 0.6 \mathrm{mmol}$ ), and the mixture was stirred at $25{ }^{\circ} \mathrm{C}$ for $14 \mathrm{~h}$. The reaction mixture was diluted with $\mathrm{H}_{2} \mathrm{O}(20 \mathrm{~mL})$, treated with $1 \mathrm{~N}$ aqueous $\mathrm{HCl}(2 \mathrm{~mL})$, and extracted with EtOAc $(3 \times 20 \mathrm{~mL})$. The combined organic extracts were washed with saturated aqueous $\mathrm{NaCl}(5 \mathrm{~mL})$, dried $\left(\mathrm{Na}_{2} \mathrm{SO}_{4}\right)$, concentrated in vacuo, and precipitated by the addition of $\mathrm{CH}_{2} \mathrm{Cl}_{2}$ to afford 11d (13.6 mg, 90\%) as a white solid: ${ }^{1} \mathrm{H}$ NMR (acetone- $\left.d_{6}, 400 \mathrm{MHz}\right) \delta$ $10.98(1 \mathrm{H}$, br s), $10.58(1 \mathrm{H}$, br s), $8.21(1 \mathrm{H}$, br s), $7.89(1 \mathrm{H}$, br s), $7.62(2 \mathrm{H}, \mathrm{d}, J=7.3$ $\mathrm{Hz}), 7.33-7.45(4 \mathrm{H}, \mathrm{m}), 7.32(1 \mathrm{H}, \mathrm{d}, J=2.0 \mathrm{~Hz}), 7.10(1 \mathrm{H}, \mathrm{d}, J=2.0 \mathrm{~Hz}), 7.04(1 \mathrm{H}, \mathrm{d}, J$ $=1.5 \mathrm{~Hz}), 6.91(1 \mathrm{H}, \mathrm{dd}, J=2.5,8.8 \mathrm{~Hz}), 5.31(2 \mathrm{H}, \mathrm{s}), 4.84(1 \mathrm{H}, \mathrm{t}, J=10.0 \mathrm{~Hz}), 4.66$ $(1 \mathrm{H}, \mathrm{dd}, J=4.2,11.3 \mathrm{~Hz}), 4.21-4.28(1 \mathrm{H}, \mathrm{m}), 4.19(1 \mathrm{H}, \mathrm{dd}, J=3.7,10.8 \mathrm{~Hz}), 3.98(1 \mathrm{H}$, $\mathrm{dd}, J=7.8,10.8 \mathrm{~Hz}$ ); IR (film) $v_{\max } 1699,1602,1520,1435,1304,1218,1178 \mathrm{~cm}^{-1}$; ESITOF-HRMS $m / z$ 516.1321 $\left(\mathrm{M}+\mathrm{H}^{+}, \mathrm{C}_{28} \mathrm{H}_{22} \mathrm{ClN}_{3} \mathrm{O}_{5}\right.$ requires 516.1321).

11d: $[\alpha]^{23}{ }_{\mathrm{D}}+6(c 0.1, \mathrm{THF})$.

ent-11d: $[\alpha]^{23}-8(c 0.1, \mathrm{THF})$.

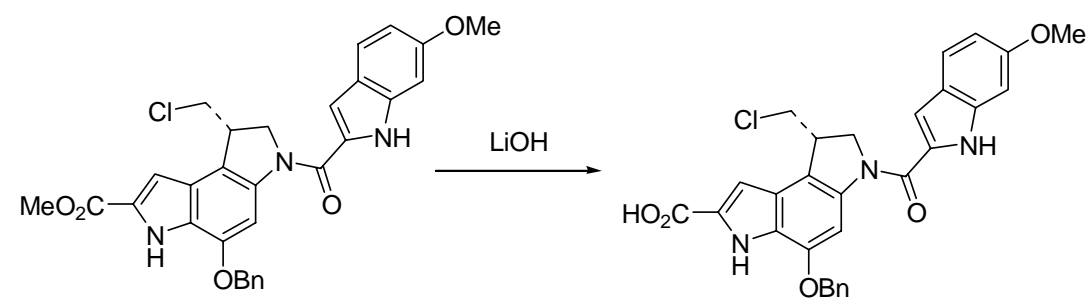

3-[(6-Methoxyindol-2-yl)carbonyl]-1-(chloromethyl)-5-benzyloxy-1,2-dihydro-3Hpyrrolo[3,2-e ]indole-7-carboxylic acid (11e). Compound 7e (11.7 mg, $0.0215 \mathrm{mmol})$ 
was dissolved in 3:2:1 THF- $\mathrm{MeOH}-\mathrm{H}_{2} \mathrm{O}(1.0 \mathrm{~mL})$, treated with $4 \mathrm{~N}$ aqueous $\mathrm{LiOH}(100$ $\mu \mathrm{L}, 0.4 \mathrm{mmol}$ ), and the mixture was stirred at $25^{\circ} \mathrm{C}$ for $14 \mathrm{~h}$. The reaction mixture was diluted with $\mathrm{H}_{2} \mathrm{O}(20 \mathrm{~mL})$, treated with $1 \mathrm{~N}$ aqueous $\mathrm{HCl}(2 \mathrm{~mL})$, and extracted with EtOAc $(3 \times 20 \mathrm{~mL})$. The combined organic extracts were washed with saturated aqueous $\mathrm{NaCl}(5 \mathrm{~mL})$, dried $\left(\mathrm{Na}_{2} \mathrm{SO}_{4}\right)$, concentrated in vacuo, and precipitated by the addition of $\mathrm{CH}_{2} \mathrm{Cl}_{2}$ an afford 11e (10.4 mg, 91\%) as a tan solid: ${ }^{1} \mathrm{H}$ NMR (acetone- $\left.d_{6}, 400 \mathrm{MHz}\right) \delta$ $10.99(1 \mathrm{H}, \mathrm{br} \mathrm{s}), 10.62(1 \mathrm{H}, \mathrm{br} \mathrm{s}), 8.23(1 \mathrm{H}, \mathrm{br} \mathrm{s}), 7.57-7.65(3 \mathrm{H}, \mathrm{m}), 7.34-7.45(3 \mathrm{H}, \mathrm{m})$, $7.33(1 \mathrm{H}, \mathrm{d}, J=1.8 \mathrm{~Hz}), 7.15(1 \mathrm{H}, \mathrm{d}, J=1.8 \mathrm{~Hz}), 7.09(1 \mathrm{H}, \mathrm{d}, J=1.4 \mathrm{~Hz}), 6.78(1 \mathrm{H}, \mathrm{dd}$, $J=2.4,8.8 \mathrm{~Hz}), 5.31(2 \mathrm{H}, \mathrm{s}), 4.85(1 \mathrm{H}, \mathrm{t}, J=10.8 \mathrm{~Hz}), 4.65(1 \mathrm{H}, \mathrm{dd}, J=4.1,10.8 \mathrm{~Hz})$, $4.22-4.29(1 \mathrm{H}, \mathrm{m}), 4.19(1 \mathrm{H}, \mathrm{dd}, J=3.5,10.8 \mathrm{~Hz}), 3.98(1 \mathrm{H}, \mathrm{dd}, J=7.8,11.1 \mathrm{~Hz}), 3.86$ (3H，s); IR (film) $v_{\max }$ 3257, 2923, 1693, 1602, 1511, 1298, 1233, $1162 \mathrm{~cm}^{-1}$; ESITOF-HRMS $m / z 530.1480\left(\mathrm{M}+\mathrm{H}^{+}, \mathrm{C}_{29} \mathrm{H}_{24} \mathrm{ClN}_{3} \mathrm{O}_{5}\right.$ requires 530.1477).

11e: $[\alpha]^{23}{ }_{D}+2(c 0.1, \mathrm{THF})$.

ent-11e: $[\alpha]^{23}{ }_{\mathrm{D}}-4(c 0.1, \mathrm{THF})$.

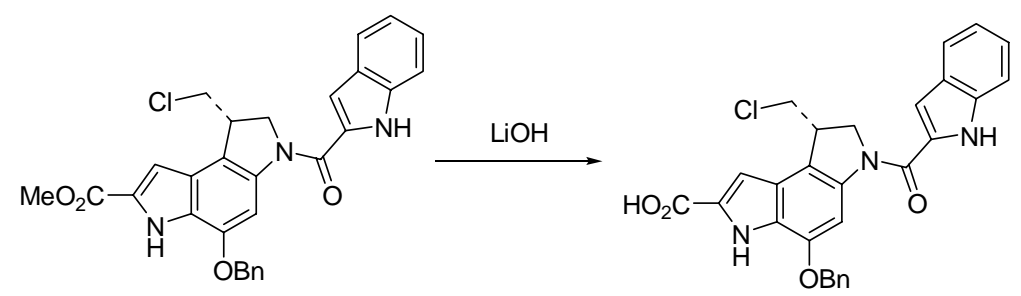

3-[(Indol-2-yl)carbonyl]-1-(chloromethyl)-5-benzyloxy-1,2-dihydro-3H-pyrrolo[3,2$\boldsymbol{e}$ ]indole-7-carboxylic acid (11f). Compound $7 \mathbf{f}(10.3 \mathrm{mg}, 0.0200 \mathrm{mmol})$ was dissolved in 3:2:1 THF- $\mathrm{MeOH}-\mathrm{H}_{2} \mathrm{O}(2.5 \mathrm{~mL})$, treated with $4 \mathrm{~N}$ aqueous $\mathrm{LiOH}(80 \mu \mathrm{L}, 0.32$ $\mathrm{mmol}$ ), and the mixture was stirred at $25{ }^{\circ} \mathrm{C}$ for $1.5 \mathrm{~h}$. The reaction mixture was diluted with $\mathrm{H}_{2} \mathrm{O}(20 \mathrm{~mL})$, treated with $1 \mathrm{~N}$ aqueous $\mathrm{HCl}(2 \mathrm{~mL})$, and extracted with EtOAc $(3 \times$ $20 \mathrm{~mL}$ ). The combined organic extracts were washed with saturated aqueous $\mathrm{NaCl}$ (5 $\mathrm{mL})$, dried $\left(\mathrm{Na}_{2} \mathrm{SO}_{4}\right)$, concentrated in vacuo, and precipitated by the addition of $\mathrm{CH}_{2} \mathrm{Cl}_{2}$ to afford $11 \mathrm{f}(9.4 \mathrm{mg}, 94 \%)$ as a white solid: ${ }^{1} \mathrm{H}$ NMR (DMSO- $\left.d_{6}, 500 \mathrm{MHz}\right) \delta 12.01$ $(1 \mathrm{H}, \mathrm{s}), 11.72(1 \mathrm{H}, \mathrm{s}), 8.06(1 \mathrm{H}, \mathrm{br} \mathrm{s}), 7.70(1 \mathrm{H}, \mathrm{d}, J=7.8 \mathrm{~Hz}), 7.60-7.70(2 \mathrm{H}, \mathrm{m}), 7.48$ $(1 \mathrm{H}, \mathrm{dd}, J=0.7,8.3 \mathrm{~Hz}), 7.41(2 \mathrm{H}, \mathrm{t}, J=7.5 \mathrm{~Hz}), 7.33(1 \mathrm{H}, \mathrm{m}), 7.26(1 \mathrm{H}, \mathrm{d}, J=2.0 \mathrm{~Hz})$, $7.24(1 \mathrm{H}, \mathrm{m}), 7.14(1 \mathrm{H}, \mathrm{s}), 7.08(1 \mathrm{H}, \mathrm{ddd}, J=0.9,7.1,8.1 \mathrm{~Hz}), 5.28(2 \mathrm{H}, \mathrm{s}), 4.78(1 \mathrm{H}, \mathrm{t}$, $J=10.8 \mathrm{~Hz}), 4.46(1 \mathrm{H}, \mathrm{dd}, J=4.3,10.8 \mathrm{~Hz}), 4.16(1 \mathrm{H}, \mathrm{m}), 4.11(1 \mathrm{H}, \mathrm{dd}, J=3.4,11.0$ 
Hz), $4.02(1 \mathrm{H}, \mathrm{dd}, J=6.6,11.0 \mathrm{~Hz})$; IR (film) $v_{\max } 3274,2937,1694,1651,1505,1324$, $1205 \mathrm{~cm}^{-1}$; ESITOF-HRMS m/z $500.1377\left(\mathrm{M}+\mathrm{H}^{+}, \mathrm{C}_{28} \mathrm{H}_{22} \mathrm{ClN}_{3} \mathrm{O}_{4}\right.$ requires 500.1377). 11f: $[\alpha]^{23}{ }_{\mathrm{D}}+2(c 0.1, \mathrm{THF})$. ent-11f: $[\alpha]^{23}-2$ (c 0.1, THF).

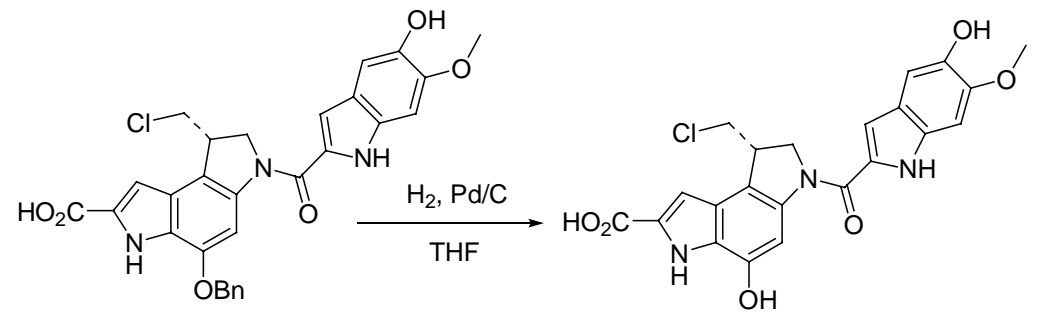

3-[(5-Hydroxy-6-methoxyindol-2-yl)carbonyl]-1-(chloromethyl)-5-hydroxy-1,2dihydro-3H-pyrrolo[3,2-e]indole-7-carboxylic acid (12a). Compound 11a $(17.1 \mathrm{mg}$, $0.0313 \mathrm{mmol})$ was dissolved in 9:1 THF-MeOH $(4.0 \mathrm{~mL})$, treated with $10 \% \mathrm{Pd} / \mathrm{C}(9$ $\mathrm{mg}$ ), and the mixture was stirred under $\mathrm{H}_{2}(1 \mathrm{~atm})$ at $25^{\circ} \mathrm{C}$ for $8 \mathrm{~h}$. The mixture was filtered through Celite, concentrated in vacuo, and precipitated by the addition of $\mathrm{CH}_{2} \mathrm{Cl}_{2}$ to afford 12a (14.2 mg, 100\%) as a white solid: ${ }^{1} \mathrm{H}$ NMR (acetone- $\left.d_{6}, 400 \mathrm{MHz}\right) \delta 10.60$ $(1 \mathrm{H}, \mathrm{s}), 10.50(1 \mathrm{H}, \mathrm{s}), 8.06(1 \mathrm{H}, \mathrm{s}), 7.303(1 \mathrm{H}, \mathrm{s}), 7.297(1 \mathrm{H}, \mathrm{s}), 7.16(1 \mathrm{H}, \mathrm{s}), 7.09(1 \mathrm{H}$, s), $7.08(1 \mathrm{H}, \mathrm{s}), 7.02(1 \mathrm{H}, \mathrm{s}), 4.80(1 \mathrm{H}, \mathrm{t}, J=9.8 \mathrm{~Hz}), 4.62(1 \mathrm{H}, \mathrm{dd}, J=6.6,3.7 \mathrm{~Hz}), 4.22$ $(1 \mathrm{H}, \mathrm{m}), 4.17(1 \mathrm{H}, \mathrm{m}), 3.93(1 \mathrm{H}, \mathrm{m}), 3.89(3 \mathrm{H}, \mathrm{s}) ;{ }^{13} \mathrm{C}$ NMR (acetone- $\left.d_{6}, 400 \mathrm{MHz}\right) \delta$ 162.7, 160.5, 149.0, 144.4, 143.7, 140.1, 132.1, 130.8, 129.9, 129.7, 126.8, 125.5, 122.7, 114.2, 107.0, 106.1, 105.8, 94.6, 56.3, 55.7, 48.1, 43.9; IR (film) $v_{\max } 3285,1694,1312$ $\mathrm{cm}^{-1}$; ESITOF-HRMS $m / z 454.0815\left([\mathrm{M}-\mathrm{H}]^{-}, \mathrm{C}_{22} \mathrm{H}_{18} \mathrm{ClN}_{3} \mathrm{O}_{6}\right.$ requires 454.0811).

12a: $[\alpha]^{23}{ }_{D}-8(c 0.2, \mathrm{THF})$.

ent-12a: $[\alpha]_{\mathrm{D}}^{23}+7(c 0.2$, THF $)$.

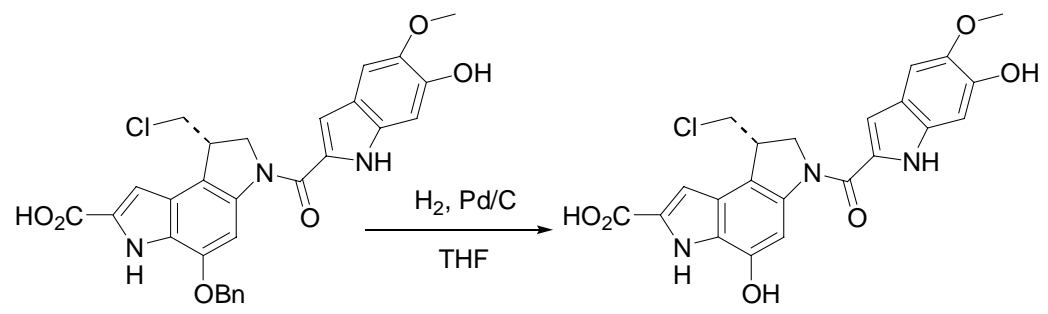




\section{3-[(6-Hydroxy-5-methoxyindol-2-yl)carbonyl]-1-(chloromethyl)-5-hydroxy-1,2-}

dihydro-3H-pyrrolo[3,2-e]indole-7-carboxylic acid (12b). Compound 11b (23.0 mg, $0.0421 \mathrm{mmol})$ was dissolved in THF $(2.0 \mathrm{~mL})$, treated with $10 \% \mathrm{Pd} / \mathrm{C}(5 \mathrm{mg})$, and the mixture was stirred under $\mathrm{H}_{2}(1 \mathrm{~atm})$ at $25^{\circ} \mathrm{C}$ for $2 \mathrm{~h}$. The mixture was filtered through Celite, concentrated in vacuo, and then precipitated by the addition of $\mathrm{CH}_{2} \mathrm{Cl}_{2}$ to afford 12b $\left(16.2 \mathrm{mg}, 85 \%\right.$ ) as a beige solid: ${ }^{1} \mathrm{H}$ NMR (acetone- $\left.d_{6}, 500 \mathrm{MHz}\right) \delta 10.46(1 \mathrm{H}$, br s), $8.01(1 \mathrm{H}, \mathrm{s}), 7.29(1 \mathrm{H}, \mathrm{s}), 7.18(1 \mathrm{H}, \mathrm{s}), 7.05(1 \mathrm{H}, \mathrm{d}, J=1.8 \mathrm{~Hz}), 7.02(1 \mathrm{H}, \mathrm{s}), 4.79(1 \mathrm{H}, \mathrm{t}$, $J=10.3 \mathrm{~Hz}), 4.62(1 \mathrm{H}, \mathrm{dd}, J=6.6,4.0 \mathrm{~Hz}), 4.19(2 \mathrm{H}, \mathrm{m}), 3.90(3 \mathrm{H}, \mathrm{s}), 3.88(1 \mathrm{H}, \mathrm{m}) ;{ }^{13} \mathrm{C}$ NMR (acetone- $\left.d_{6}, 125 \mathrm{MHz}\right) \delta 162.7,160.6,147.6,145.5,144.5,140.1,132.9,130.5$, 128.8, 126.8, 125.5, 121.9, 114.1, 106.9, 106.7, 103.2, 102.1, 97.7, 56.6, 55.8, 48.1, 44.0; IR (film) $v_{\max } 3353,1599,1310 \mathrm{~cm}^{-1}$; MALDIFT-HRMS (DHB) $\mathrm{m} / z, 456.0949\left(\mathrm{M}+\mathrm{H}^{+}\right.$, $\mathrm{C}_{22} \mathrm{H}_{18} \mathrm{ClN}_{3} \mathrm{O}_{6}$ requires 456.0957).

12b: $[\alpha]_{D}^{23}-3.5(c 0.29, \mathrm{THF})$.

ent-12b: $[\alpha]^{23}{ }_{\mathrm{D}}+3.4(c 0.32, \mathrm{THF})$.
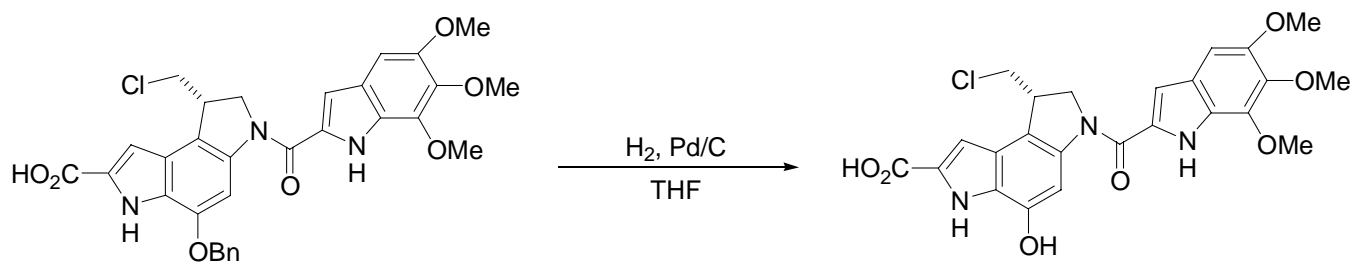

3-[(5,6,7-Trimethoxyindole-2-yl)carbonyl]-1-(chloromethyl)-5-hydroxy-1,2-dihydro3H-pyrrolo[3,2-e]indole-7-carboxylic acid (12c). Compound 11c (14.5 mg, 0.0246 mmol) was dissolved in THF (1.0 mL), treated with $10 \% \mathrm{Pd} / \mathrm{C}(10 \mathrm{mg})$, and the solution was stirred under $\mathrm{H}_{2}(1 \mathrm{~atm})$ at $25{ }^{\circ} \mathrm{C}$ for $2 \mathrm{~h}$. The mixture was filtered through Celite, concentrated in vacuo, and precipitated by the addition of $1: 1 \mathrm{CH}_{2} \mathrm{Cl}_{2}$-hexanes to afford 12c $(10.3 \mathrm{mg}, 84 \%)$ as a beige solid: ${ }^{1} \mathrm{H}$ NMR (THF- $\left.d_{8}, 600 \mathrm{MHz}\right) \delta 10.90(1 \mathrm{H}, \mathrm{s}), 10.51$ $(1 \mathrm{H}, \mathrm{s}), 8.95(1 \mathrm{H}, \mathrm{br} \mathrm{s}), 7.88(1 \mathrm{H}, \mathrm{s}), 7.13(1 \mathrm{H}, \mathrm{d}, J=2.2 \mathrm{~Hz}), 6.96(1 \mathrm{H}, \mathrm{d}, J=2.2 \mathrm{~Hz})$, $6.89(1 \mathrm{H}, \mathrm{s}), 4.70(1 \mathrm{H}, \mathrm{t}, J=10.1 \mathrm{~Hz}), 4.55(1 \mathrm{H}, \mathrm{dd}, J=4.0,6.6 \mathrm{~Hz}), 4.10(1 \mathrm{H}, \mathrm{dd}, J=$ 3.5, $7.5 \mathrm{~Hz}), 4.04(1 \mathrm{H}, \mathrm{m}), 4.02(3 \mathrm{H}, \mathrm{s}), 3.84(3 \mathrm{H}, \mathrm{s}), 3.83(3 \mathrm{H}, \mathrm{s}), 3.65(1 \mathrm{H}, \mathrm{t}, J=10.5$ $\mathrm{Hz}$ ); IR (film) $v_{\max }$ 3252, 2938, $1700 \mathrm{~cm}^{-1}$; ESITOF-HRMS m/z $500.1204\left(\mathrm{M}+\mathrm{H}^{+}\right.$, $\mathrm{C}_{24} \mathrm{H}_{22} \mathrm{ClN}_{3} \mathrm{O}_{7}$ requires 500.1219).

12c: $[\alpha]^{23}{ }_{\mathrm{D}}+4.2(c 0.2, \mathrm{THF})$. 
ent-12c: $[\alpha]^{23}{ }_{\mathrm{D}}-4.2(c 0.2, \mathrm{THF})$.

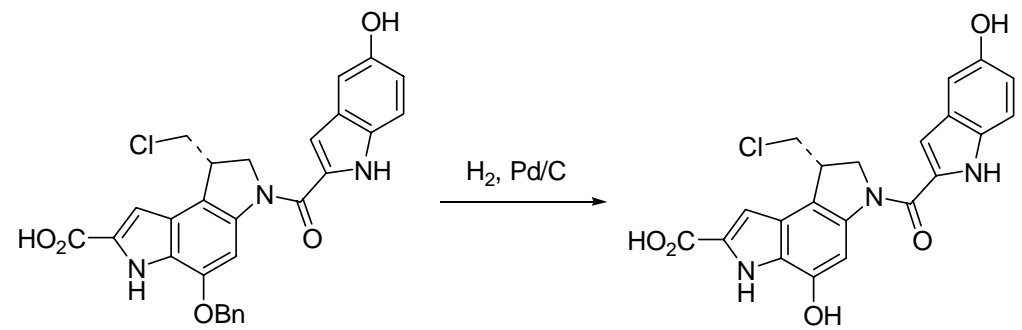

3-[(5-Hydroxyindol-2-yl)carbonyl]-1-(chloromethyl)-5-hydroxy-1,2-dihydro-3H-

pyrrolo[3,2-e]indole-7-carboxylic acid (12d). A solution of 11d (12.2 mg, 0.0236 mmol) in 9:1 THF-MeOH (1.5 mL) was treated with $10 \% \mathrm{Pd} / \mathrm{C}(5.5 \mathrm{mg})$ and the solution was stirred under $\mathrm{H}_{2}(1 \mathrm{~atm})$ at $25{ }^{\circ} \mathrm{C}$ for $3 \mathrm{~h}$. The mixture was filtered through Celite, concentrated in vacuo, and precipitated by the addition of $\mathrm{CH}_{2} \mathrm{Cl}_{2}$ to afford $\mathbf{1 2 d}(8.9 \mathrm{mg}$, $89 \%$ ) as a white solid: ${ }^{1} \mathrm{H}$ NMR (acetone- $\left.d_{6}, 500 \mathrm{MHz}\right) \delta 10.77(1 \mathrm{H}, \mathrm{br}$ ) $), 10.55(1 \mathrm{H}$, br s), $7.99(1 \mathrm{H}$, br s), $7.42(1 \mathrm{H}, \mathrm{d}, J=8.8 \mathrm{~Hz}), 7.29(1 \mathrm{H}, \mathrm{d}, J=2.0 \mathrm{~Hz}), 7.09(1 \mathrm{H}, \mathrm{d}, J=2.0$ $\mathrm{Hz}), 7.02(1 \mathrm{H}, \mathrm{d}, J=2.0 \mathrm{~Hz}), 6.90(1 \mathrm{H}, \mathrm{dd}, J=2.5,8.8 \mathrm{~Hz}), 4.81(1 \mathrm{H}, \mathrm{t}, J=9.8 \mathrm{~Hz}), 4.63$ $(1 \mathrm{H}, \mathrm{dd}, J=3.9,10.8 \mathrm{~Hz}), 4.15-4.24(2 \mathrm{H}, \mathrm{m}), 3.93(1 \mathrm{H}, \mathrm{dd}, J=7.8,10.8 \mathrm{~Hz})$; IR (film) $v_{\max } 1690,1601,1523,1439,1175 \mathrm{~cm}^{-1}$; ESITOF-HRMS m/z $426.0845\left(\mathrm{M}+\mathrm{H}^{+}\right.$, $\mathrm{C}_{21} \mathrm{H}_{16} \mathrm{ClN}_{3} \mathrm{O}_{5}$ requires 426.0851).

12d: $[\alpha]^{23} \mathrm{D}+5(c 0.2, \mathrm{THF})$.

ent-12d: $[\alpha]^{23}-4(c 0.2, \mathrm{THF})$.

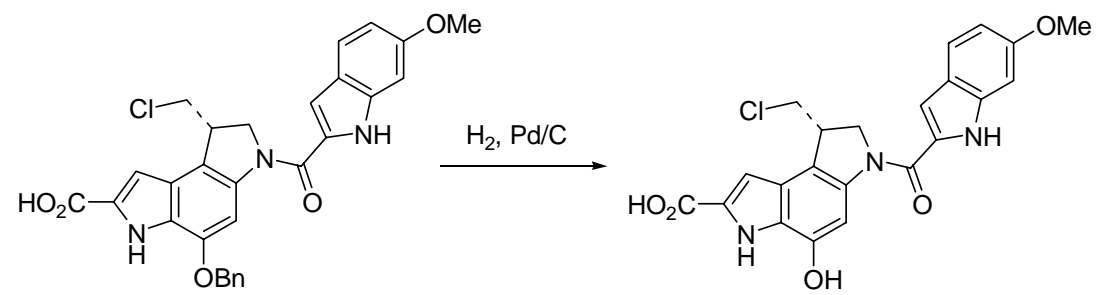

3-[(6-Methoxyindol-2-yl)carbonyl]-1-(chloromethyl)-5-hydroxy-1,2-dihydro-3H-

pyrrolo[3,2-e ]indole-7-carboxylic acid (12e). A solution of $11 e(9.8 \mathrm{mg}, 0.18 \mathrm{mmol})$ in 9:1 THF-MeOH (1.0 mL) was treated with $10 \% \mathrm{Pd} / \mathrm{C}(5 \mathrm{mg})$ and the solution was stirred under $\mathrm{H}_{2}(1 \mathrm{~atm})$ at $25^{\circ} \mathrm{C}$ for $4 \mathrm{~h}$. The mixture was filtered through Celite, concentrated in vacuo, and precipitated by the addition of $\mathrm{CH}_{2} \mathrm{Cl}_{2}$ to afford $12 \mathrm{e}(7.2 \mathrm{mg}, 88 \%)$ as a white solid: ${ }^{1} \mathrm{H}$ NMR (acetone- $\left.d_{6}, 500 \mathrm{MHz}\right) \delta 10.60(1 \mathrm{H}$, br s), $10.57(1 \mathrm{H}$, br s), 8.02 $(1 \mathrm{H}, \mathrm{s}), 7.59(1 \mathrm{H}, \mathrm{d}, J=8.7 \mathrm{~Hz}), 7.30(1 \mathrm{H}, \mathrm{d}, J=2.1 \mathrm{~Hz}), 7.13(1 \mathrm{H}, \mathrm{d}, J=2.0 \mathrm{~Hz}), 7.08$ 
$(1 \mathrm{H}, \mathrm{d}, J=2.2 \mathrm{~Hz}), 6.78(1 \mathrm{H}, \mathrm{dd}, J=2.1,8.7 \mathrm{~Hz}), 4.82(1 \mathrm{H}, \mathrm{dd}, J=9.3,10.6 \mathrm{~Hz}), 4.64$ $(1 \mathrm{H}, \mathrm{dd}, J=4.0,10.8 \mathrm{~Hz}), 4.22(1 \mathrm{H}, \mathrm{m}), 4.18(1 \mathrm{H}, \mathrm{dd}, J=3.6,10.9 \mathrm{~Hz}), 3.93(1 \mathrm{H}, \mathrm{dd}, J$ $=7.9,10.9 \mathrm{~Hz}$ ), 3.84 (3H, s); IR (film) $v_{\max } 3300,2956,1694,1601,1514,1435,1302$, 1232, $1160 \mathrm{~cm}^{-1}$; ESITOF-HRMS $\mathrm{m} / z 440.1006\left(\mathrm{M}+\mathrm{H}^{+}, \mathrm{C}_{22} \mathrm{H}_{18} \mathrm{ClN}_{3} \mathrm{O}_{5}\right.$ requires 440.1008).

12e: $[\alpha]^{23}{ }_{\mathrm{D}}+5(c 0.2, \mathrm{THF})$.

ent-12e: $[\alpha]^{23}{ }_{\mathrm{D}}-4$ (c 0.2, THF).

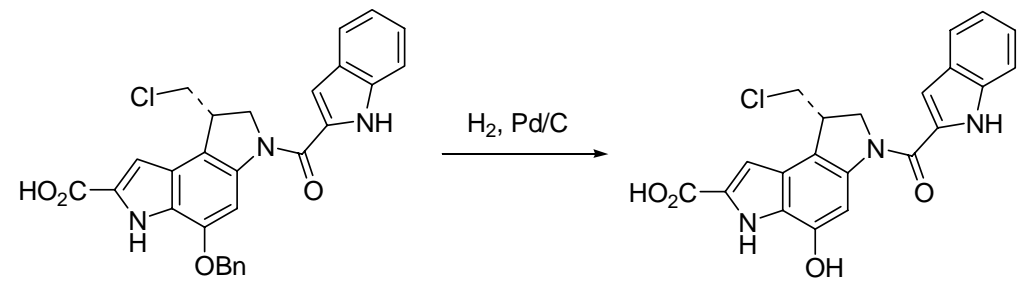

\section{3-[(Indol-2-yl)carbonyl]-1-(chloromethyl)-5-hydroxy-1,2-dihydro-3H-pyrrolo[3,2-}

$\boldsymbol{e}$ ]indole-7-carboxylic acid (12f). A solution of 11f $(10.1 \mathrm{mg}, 0.0202 \mathrm{mmol})$ in 9:1 THF-MeOH $(4.5 \mathrm{~mL})$ was treated with $10 \% \mathrm{Pd} / \mathrm{C}(12.2 \mathrm{mg})$ and the solution was stirred under $\mathrm{H}_{2}(1 \mathrm{~atm})$ at $25^{\circ} \mathrm{C}$ for $8 \mathrm{~h}$. The mixture was filtered through Celite, concentrated in vacuo, and precipitated by the addition of $\mathrm{CH}_{2} \mathrm{Cl}_{2}$ to afford $\mathbf{1 2 f}(7.5 \mathrm{mg}, 91 \%)$ as a white solid: ${ }^{1} \mathrm{H}$ NMR (acetone- $\left.d_{6}, 500 \mathrm{MHz}\right) \delta 10.80(1 \mathrm{H}, \mathrm{br} \mathrm{s}), 10.60(1 \mathrm{H}, \mathrm{br} \mathrm{s}), 8.84$ $(1 \mathrm{H}, \mathrm{br} \mathrm{s}), 7.73(1 \mathrm{H}, \mathrm{d}, J=8.1 \mathrm{~Hz}), 7.59(1 \mathrm{H}, \mathrm{dd}, J=0.7,8.3 \mathrm{~Hz}), 7.30(1 \mathrm{H}, \mathrm{s}), 7.27(1 \mathrm{H}$, ddd, $J=1.1,7.0,8.3 \mathrm{~Hz}), 7.20(1 \mathrm{H}, \mathrm{s}), 7.12(1 \mathrm{H}, \mathrm{t}, J=7.1 \mathrm{~Hz}), 4.85(1 \mathrm{H}, \mathrm{dd}, J=9.3$, $10.5 \mathrm{~Hz}), 4.67(1 \mathrm{H}, \mathrm{dd}, J=4.0,10.8 \mathrm{~Hz}), 4.20-4.26(1 \mathrm{H}, \mathrm{m}), 4.18(1 \mathrm{H}, \mathrm{dd}, J=3.6,10.9$ Hz), 3.94 (1H, dd, $J=7.9,10.9 \mathrm{~Hz}$ ); IR (film) $v_{\max } 3329,2959,1690,1601,1514,1435$, 1343, $1218 \mathrm{~cm}^{-1}$; ESITOF-HRMS $\mathrm{m} / z 410.0894\left(\mathrm{M}+\mathrm{H}^{+}, \mathrm{C}_{21} \mathrm{H}_{16} \mathrm{ClN}_{3} \mathrm{O}_{4}\right.$ requires 410.0902).

22: $[\alpha]^{23}{ }_{\mathrm{D}}+2(c 0.1, \mathrm{THF})$.

ent-22: $[\alpha]^{23}-2(c 0.1, \mathrm{THF})$. 


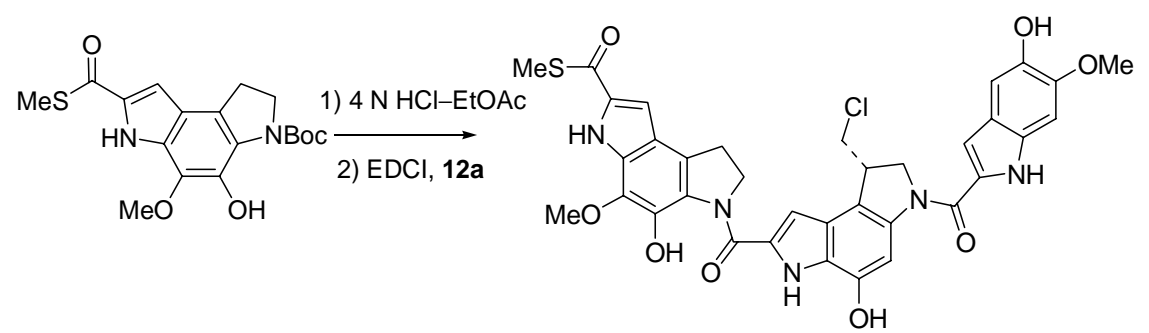

seco-yatakemycin (13a). Compound $10(13.4 \mathrm{mg}, 0.043 \mathrm{mmol})$ was dissolved in $4 \mathrm{~N}$ $\mathrm{HCl}-\mathrm{EtOAc}(0.5 \mathrm{~mL})$ and the solution was stirred for $0.5 \mathrm{~h}$ at $25{ }^{\circ} \mathrm{C}$. The solvent was removed by a $\mathrm{N}_{2}$ stream and the residue was dried for $3 \mathrm{~h}$ under high vacuum. The crude residue was dissolved in DMF (0.50 mL), treated with EDCI $(34 \mathrm{mg}, 0.179 \mathrm{mmol})$, carboxylic acid 12a $(16.3 \mathrm{mg}, 0.0358 \mathrm{mmol})$ and the mixture was stirred for $23 \mathrm{~h}$ at 25 ${ }^{\circ} \mathrm{C}$. The solvent was removed by a $\mathrm{N}_{2}$ stream, and the residue was purified by flash chromatography $\left(\mathrm{SiO}_{2}, 14 \% \mathrm{DMF}-\right.$ toluene) to afford 13a $(13.4 \mathrm{mg}, 52 \%)$ as a yellow solid: ${ }^{1} \mathrm{H}$ NMR $\left(\mathrm{DMF}-d_{6}, 500 \mathrm{MHz}\right) \delta 12.01(1 \mathrm{H}, \mathrm{s}), 11.44(1 \mathrm{H}, \mathrm{s}), 11.28(1 \mathrm{H}, \mathrm{s}), 11.21$ $(1 \mathrm{H}, \mathrm{s}), 10.04(1 \mathrm{H}, \mathrm{s}), 8.51(1 \mathrm{H}, \mathrm{s}), 8.01(1 \mathrm{H}, \mathrm{s}), 7.58(1 \mathrm{H}, \mathrm{d}, J=2.0 \mathrm{~Hz}), 7.35(1 \mathrm{H}, \mathrm{d}, J=$ $2.0 \mathrm{~Hz}), 7.12(2 \mathrm{H}, \mathrm{s}), 7.05(1 \mathrm{H}, \mathrm{s}), 4.88-4.96(2 \mathrm{H}, \mathrm{m}), 4.83(1 \mathrm{H}, \mathrm{t}, J=10.0 \mathrm{~Hz}), 4.62$ (1H, dd, $J=10.7,3.4 \mathrm{~Hz}), 4.33(1 \mathrm{H}, \mathrm{dd}, J=10.7,3.4 \mathrm{~Hz}), 4.22-4.29(1 \mathrm{H}, \mathrm{m}), 4.06(1 \mathrm{H}$, dd, $J=8.7,11.4 \mathrm{~Hz}), 3.97(3 \mathrm{H}, \mathrm{s}), 3.90(3 \mathrm{H}, \mathrm{s}), 3.49(2 \mathrm{H}, \mathrm{t}$, partially obscured $), 2.50(3 \mathrm{H}$, s); IR (film) $v_{\max } 3319,2929,1633,1503,1417,1310 \mathrm{~cm}^{-1}$; ESITOF-HRMS $\mathrm{m} / \mathrm{z}$ $716.1565\left(\mathrm{M}+\mathrm{H}^{+}, \mathrm{C}_{35} \mathrm{H}_{30} \mathrm{ClN}_{5} \mathrm{O}_{8} \mathrm{~S}\right.$ requires 716.1576).

13a: $[\alpha]^{23}-24(c 0.2, \mathrm{DMF})$.

ent-13a: $[\alpha]^{23}{ }_{\mathrm{D}}+25(c 0.2, \mathrm{DMF})$.

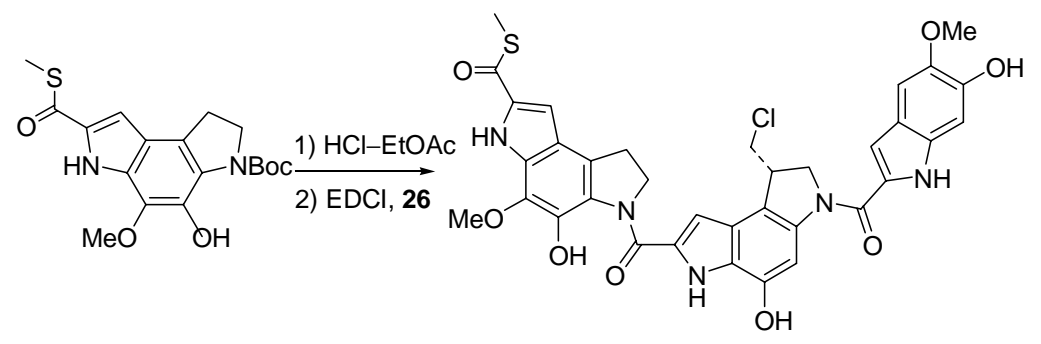

Analogue 13b. Compound $10(3.64 \mathrm{mg}, 9.6 \mu \mathrm{mol})$ was dissolved in $4 \mathrm{~N} \mathrm{HCl}$-EtOAc $(0.5 \mathrm{~mL})$, the resulting solution was stirred for $0.5 \mathrm{~h}$ at $25^{\circ} \mathrm{C}$, and the solvent was removed by a $\mathrm{N}_{2}$ stream. The crude residue was dissolved in DMF $(0.15 \mathrm{~mL})$, treated 
with EDCI (7.4 mg, $38 \mu \mathrm{mol})$, carboxylic acid 12b $(4.38 \mathrm{mg}, 9.6 \mu \mathrm{mol})$ and the mixture was stirred for $16 \mathrm{~h}$ at $25{ }^{\circ} \mathrm{C}$. The solvent was removed by a $\mathrm{N}_{2}$ stream and the residue was purified by flash chromatography $\left(\mathrm{SiO}_{2}, 40 \% \mathrm{THF}-\mathrm{C}_{6} \mathrm{H}_{6}\right)$ to afford $\mathbf{1 3 b}(2.43 \mathrm{mg}$, $42 \%$ ) as a tan solid: ${ }^{1} \mathrm{H}$ NMR (acetone- $\left.d_{6}, 500 \mathrm{MHz}\right) \delta 10.82(1 \mathrm{H}, \mathrm{s}), 10.71(1 \mathrm{H}$, br s), $10.50(1 \mathrm{H}, \mathrm{s}), 8.95(1 \mathrm{H}$, br s), $8.04(1 \mathrm{H}, \mathrm{s}), 7.56(1 \mathrm{H}, \mathrm{s}), 7.50(1 \mathrm{H}, \mathrm{s}), 7.27(1 \mathrm{H}, \mathrm{s}), 7.18$ $(1 \mathrm{H}, \mathrm{s}), 7.06(1 \mathrm{H}, \mathrm{s}), 7.04(1 \mathrm{H}, \mathrm{s}), 4.86-4.94(2 \mathrm{H}, \mathrm{m}), 4.81(1 \mathrm{H}, \mathrm{t}, J=10.1 \mathrm{~Hz}), 4.64(1 \mathrm{H}$, dd, $J=11.0,4.0 \mathrm{~Hz}), 4.17-4.27(2 \mathrm{H}, \mathrm{m}), 3.95(3 \mathrm{H}, \mathrm{s}), 3.91(3 \mathrm{H}, \mathrm{s}), 3.87-3.91(1 \mathrm{H}, \mathrm{m})$, $3.47(2 \mathrm{H}, \mathrm{t}, J=8.1 \mathrm{~Hz}), 2.46(3 \mathrm{H}, \mathrm{s})$; IR (film) $v_{\max } 3345,2925,1634,1504,1311 \mathrm{~cm}^{-1}$; ESITOF-HRMS m/z $716.1589\left(\mathrm{M}+\mathrm{H}^{+}, \mathrm{C}_{35} \mathrm{H}_{30} \mathrm{ClN}_{5} \mathrm{O}_{8} \mathrm{~S}\right.$ requires 716.1576).

13b: $[\alpha]_{D}^{23}-3.3(c 0.24, \mathrm{THF})$.

ent-13b: $[\alpha]^{23}{ }_{\mathrm{D}}+4.1($ c $0.24, \mathrm{THF})$.

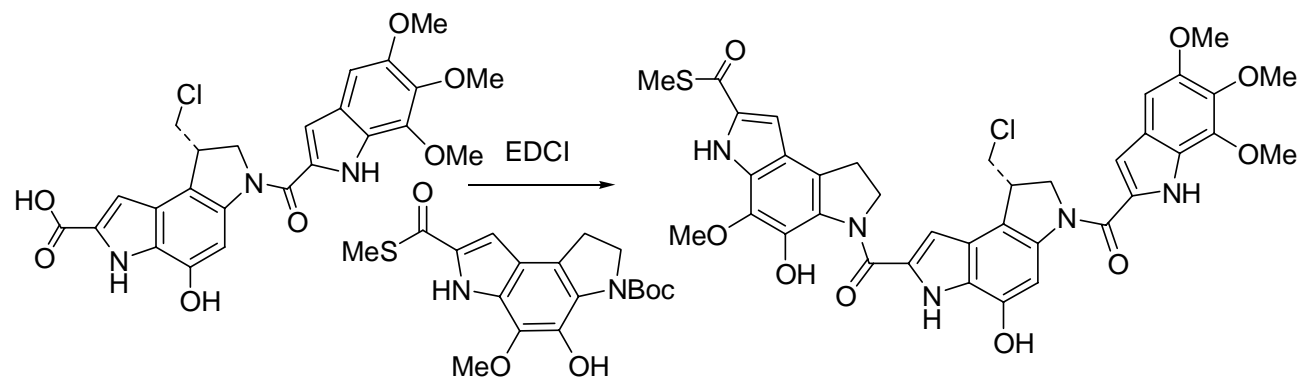

Analogue 13c. Compound 10 (5.3 mg, $0.014 \mathrm{mmol})$ was dissolved in $4 \mathrm{~N} \mathrm{HCl-EtOAc} \mathrm{(2}$ $\mathrm{mL}$ ) and the solution was stirred for $0.5 \mathrm{~h}$ at $25^{\circ} \mathrm{C}$. The solvent was removed by a $\mathrm{N}_{2}$ stream and the residue was dried for $3 \mathrm{~h}$ under high vacuum. The crude residue was dissolved in DMF $(0.15 \mathrm{~mL})$, treated with EDCI $(9.6 \mathrm{mg}, 0.050 \mathrm{mmol})$, carboxylic acid 12c $(5.0 \mathrm{mg}, 0.010 \mathrm{mmol})$ and the mixture was stirred for $20 \mathrm{~h}$ at $25^{\circ} \mathrm{C}$. The solvent was removed by a $\mathrm{N}_{2}$ stream, and the residue was purified by flash chromatography $\left(\mathrm{SiO}_{2}\right.$, $10 \%$ DMF-toluene) to afford $13 \mathrm{c}(5.1 \mathrm{mg}, 74 \%)$ as a yellow solid: ${ }^{1} \mathrm{H}$ NMR (DMF- $d_{6}$, $500 \mathrm{MHz}) \delta 12.00(1 \mathrm{H}, \mathrm{s}), 11.50(1 \mathrm{H}, \mathrm{s}), 11.29(1 \mathrm{H}, \mathrm{s}), 11.27(1 \mathrm{H}, \mathrm{s}), 10.11(1 \mathrm{H}, \mathrm{s}), 7.92$ $(1 \mathrm{H}$, br s), $7.58(1 \mathrm{H}, \mathrm{s}), 7.35(1 \mathrm{H}, \mathrm{d}, J=2.0 \mathrm{~Hz}), 7.12(1 \mathrm{H}, \mathrm{d}, J=2.0 \mathrm{~Hz}), 7.06(1 \mathrm{H}, \mathrm{s})$, $4.91(2 \mathrm{H}, \mathrm{dt}, J=2.7,10.7 \mathrm{~Hz}), 4.83(1 \mathrm{H}, \mathrm{s}), 4.58(1 \mathrm{H}, \mathrm{dd}, J=3.9,10.9 \mathrm{~Hz}), 4.33(1 \mathrm{H}, \mathrm{dd}$, $J=3.5,10.8 \mathrm{~Hz}), 4.22(1 \mathrm{H}, \mathrm{m}), 4.04(3 \mathrm{H}, \mathrm{s}), 4.03(1 \mathrm{H}, \mathrm{m}), 3.97(3 \mathrm{H}, \mathrm{s}), 3.91(3 \mathrm{H}, \mathrm{s})$, $3.89(3 \mathrm{H}, \mathrm{s}), 3.49(2 \mathrm{H}, \mathrm{t}, J=7.9 \mathrm{~Hz}), 2.50(3 \mathrm{H}, \mathrm{s})$; IR (film) $v_{\max } 3317,2933,1634,1524$, 
1494, 1422, 1311, $1226 \mathrm{~cm}^{-1}$; ESITOF-HRMS $m / z 760.1847\left(\mathrm{M}+\mathrm{H}^{+}, \mathrm{C}_{37} \mathrm{H}_{34} \mathrm{ClN}_{5} \mathrm{O}_{9} \mathrm{~S}\right.$ requires 760.1838$)$.

13c: $[\alpha]^{23}{ }_{D}-23(c 0.2, D M F)$.

ent-13c: $[\alpha]^{23}+24(c 0.2, \mathrm{DMF})$.

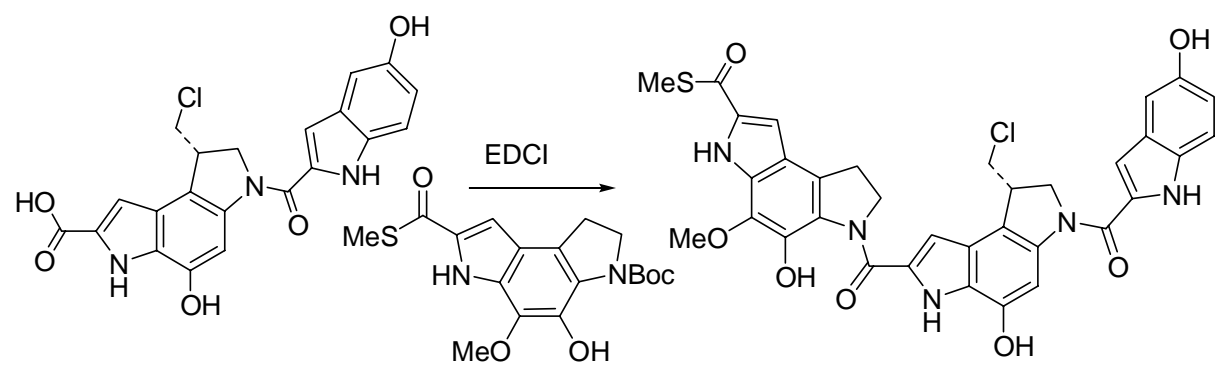

Analogue 13d. Compound 10 (4.2 mg, $0.011 \mathrm{mmol}$ ) was dissolved in $4 \mathrm{~N} \mathrm{HCl-EtOAc} \mathrm{(2}$ $\mathrm{mL}$ ) and the solution was stirred for $0.5 \mathrm{~h}$ at $25^{\circ} \mathrm{C}$. The solvent was removed by a $\mathrm{N}_{2}$ stream and the residue was dried for $3 \mathrm{~h}$ under high vacuum. The crude residue was dissolved in DMF (0.15 mL), treated with EDCI $(8.0 \mathrm{mg}, 0.042 \mathrm{mmol})$, carboxylic acid $12 \mathrm{~d}(3.19 \mathrm{mg}, 0.00749 \mathrm{mmol})$ and the mixture was stirred for $16 \mathrm{~h}$ at $25^{\circ} \mathrm{C}$. The solvent was removed by a $\mathrm{N}_{2}$ stream, and the residue was purified by flash chromatography $\left(\mathrm{SiO}_{2}, 14 \%\right.$ DMF-toluene) to afford $\mathbf{1 3 d}(4.0 \mathrm{mg}, 77 \%)$ as a yellow solid: ${ }^{1} \mathrm{H}$ NMR $\left(\right.$ DMF- $\left.d_{6}, 500 \mathrm{MHz}\right) \delta 12.03(1 \mathrm{H}, \mathrm{s}), 11.48(1 \mathrm{H}, \mathrm{s}), 11.39(1 \mathrm{H}, \mathrm{s}), 11.27(1 \mathrm{H}, \mathrm{s}), 10.09$ $(1 \mathrm{H}, \mathrm{s}), 9.07(1 \mathrm{H}, \mathrm{s}), 7.96(1 \mathrm{H}, \mathrm{s}), 7.59(1 \mathrm{H}, \mathrm{d}, J=2.1 \mathrm{~Hz}), 7.45(1 \mathrm{H}, \mathrm{d}, J=8.8 \mathrm{~Hz}), 7.35$ $(1 \mathrm{H}, \mathrm{d} J=2.1 \mathrm{~Hz}), 7.12(1 \mathrm{H}, \mathrm{d}, J=2.1 \mathrm{~Hz}), 7.06(1 \mathrm{H}, \mathrm{d}, J=2.1 \mathrm{~Hz}), 6.91(1 \mathrm{H}, \mathrm{dd}, J=$ $2.2,8.8 \mathrm{~Hz}), 4.82-4.96(3 \mathrm{H}, \mathrm{m}), 4.63(1 \mathrm{H}, \mathrm{dd}, J=3.9,10.9 \mathrm{~Hz}), 4.33(1 \mathrm{H}, \mathrm{dd}, J=3.5$, $10.8 \mathrm{~Hz}), 4.25(1 \mathrm{H}, \mathrm{m}), 4.06(1 \mathrm{H}, \mathrm{dd}, J=8.0,10.7 \mathrm{~Hz}), 3.97(3 \mathrm{H}, \mathrm{s}), 3.46(2 \mathrm{H}$, partially obscured), 2.50 (3H, s); IR (film) $v_{\max } 3329,2965,1757,1612,1420,1240 \mathrm{~cm}^{-1}$; ESITOF-HRMS $m / z, 686.1471\left(\mathrm{M}+\mathrm{H}^{+}, \mathrm{C}_{34} \mathrm{H}_{28} \mathrm{ClN}_{5} \mathrm{O}_{7} \mathrm{~S}\right.$ requires 686.1471).

13d: $[\alpha]^{23}{ }_{\mathrm{D}}-20(c 0.1, \mathrm{DMF})$.

ent-13d: $[\alpha]_{D}^{23}+20(c$ 0.1, DMF). 


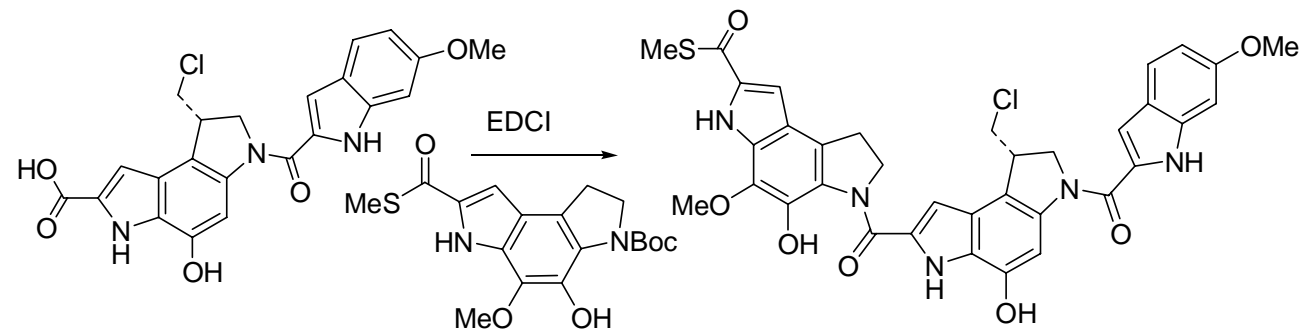

Analogue 13e. Compound 10 (4.8 $\mathrm{mg}, 0.0127 \mathrm{mmol})$ was dissolved in $4 \mathrm{~N} \mathrm{HCl}$-EtOAc $(2 \mathrm{~mL})$ and the solution was stirred for $0.5 \mathrm{~h}$ at $25^{\circ} \mathrm{C}$. The solvent was removed by a $\mathrm{N}_{2}$ stream and the residue was dried for $3 \mathrm{~h}$ under high vacuum. The crude residue was dissolved in DMF $(0.15 \mathrm{~mL})$, treated with EDCI $(7.0 \mathrm{mg}, 0.036 \mathrm{mmol})$, carboxylic acid 12e $(4.0 \mathrm{mg}, 0.0091 \mathrm{mmol})$ and the mixture was stirred for $16 \mathrm{~h}$ at $25{ }^{\circ} \mathrm{C}$. The solvent was removed by a $\mathrm{N}_{2}$ stream, and the residue was purified by flash chromatography $\left(\mathrm{SiO}_{2}, 11 \%\right.$ DMF-toluene) to afford $13 \mathrm{e}(3.8 \mathrm{mg}, 60 \%)$ as a yellow solid: ${ }^{1} \mathrm{H} \mathrm{NMR}$ $\left(\mathrm{DMF}-d_{6}, 500 \mathrm{MHz}\right) \delta 12.01(1 \mathrm{H}, \mathrm{s}), 11.50(1 \mathrm{H}, \mathrm{s}), 11.44(1 \mathrm{H}, \mathrm{s}), 11.27(1 \mathrm{H}, \mathrm{s}), 10.09$ $(1 \mathrm{H}, \mathrm{s}), 8.01(1 \mathrm{H}, \mathrm{s}), 7.65(1 \mathrm{H}, \mathrm{d}, J=8.7 \mathrm{~Hz}), 7.59(1 \mathrm{H}, \mathrm{d}, J=2.1 \mathrm{~Hz}), 7.35(1 \mathrm{H}, \mathrm{d}, J=$ $2.2 \mathrm{~Hz}), 7.19(1 \mathrm{H}, \mathrm{d}, J=2.1 \mathrm{~Hz}), 7.12(1 \mathrm{H}, \mathrm{d}, J=2.1 \mathrm{~Hz}), 6.81(1 \mathrm{H}, \mathrm{dd}, J=2.3,8.7 \mathrm{~Hz})$, 4.84-4.98 (3H, m), 4.63 (1H, dd, $J=4.0,10.9 \mathrm{~Hz}), 4.33$ (1H, dd, $J=3.5,10.8 \mathrm{~Hz}), 4.26$ $(1 \mathrm{H}, \mathrm{m}), 4.07(1 \mathrm{H}, \mathrm{dd}, J=8.0,10.7 \mathrm{~Hz}), 3.97(3 \mathrm{H}, \mathrm{s}), 3.87(3 \mathrm{H}, \mathrm{s}), 3.49(2 \mathrm{H}, \mathrm{t}, J=8.0$ $\mathrm{Hz}$ ), 2.50 (3H, s); IR (film) $v_{\max }$ 3332, 2934, 1633, 1505, 1417, 1235, $1164 \mathrm{~cm}^{-1}$; ESITOF-HRMS $m / z 700.1627\left(\mathrm{M}+\mathrm{H}^{+}, \mathrm{C}_{35} \mathrm{H}_{30} \mathrm{ClN}_{5} \mathrm{O}_{7} \mathrm{~S}\right.$ requires 700.1627).

13e: $[\alpha]^{23}-32(c 0.1, \mathrm{DMF})$.

ent-13e: $[\alpha]^{23}+34(c 0.1, \mathrm{DMF})$.

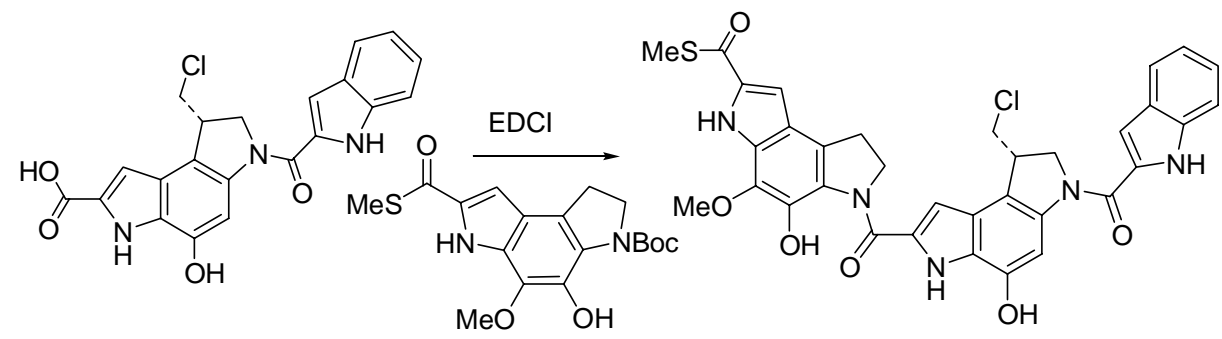

Analogue 13f. Compound 10 (5.3 mg, $0.014 \mathrm{mmol})$ was dissolved in $4 \mathrm{~N} \mathrm{HCl-EtOAc} \mathrm{(2}$ $\mathrm{mL}$ ) and the solution was stirred for $0.75 \mathrm{~h}$ at $25^{\circ} \mathrm{C}$. The solvent was removed by a $\mathrm{N}_{2}$ stream and the residue was dried for $3 \mathrm{~h}$ under high vacuum. The crude residue was 
dissolved in DMF (0.15 mL), treated with EDCI $(8.0 \mathrm{mg}, 0.042 \mathrm{mmol})$, carboxylic acid $12 \mathrm{f}(4.11 \mathrm{mg}, 0.0100 \mathrm{mmol})$ and the mixture was stirred for $24 \mathrm{~h}$ at $25^{\circ} \mathrm{C}$. The solvent was removed by a $\mathrm{N}_{2}$ stream, and the residue was purified by flash chromatography $\left(\mathrm{SiO}_{2}, 8 \% \mathrm{DMF}\right.$-toluene) to afford $\mathbf{1 3 f}(3.7 \mathrm{mg}, 55 \%)$ as a yellow solid: ${ }^{1} \mathrm{H}$ NMR (acetone- $\left.d_{6}, 500 \mathrm{MHz}\right) \delta 10.81(1 \mathrm{H}, \mathrm{br} \mathrm{s}), 10.79(1 \mathrm{H}, \mathrm{br} \mathrm{s}), 10.70(1 \mathrm{H}, \mathrm{br} \mathrm{s}), 8.04(1 \mathrm{H}, \mathrm{br}$ s), $7.73(1 \mathrm{H}, \mathrm{d}, J=7.7 \mathrm{~Hz}), 7.60(1 \mathrm{H}, \mathrm{d}, J=8.2 \mathrm{~Hz}), 7.50(1 \mathrm{H}, \mathrm{s}), 7.28(1 \mathrm{H}, \mathrm{m}), 7.26$ $(1 \mathrm{H}, \mathrm{s}), 7.20(1 \mathrm{H}, \mathrm{d}, J=1.9 \mathrm{~Hz}), 7.11(1 \mathrm{H}, \mathrm{dt}, J=3.6,7.2), 4.84-4.94(3 \mathrm{H}, \mathrm{m}), 4.69(1 \mathrm{H}$, dd, $J=3.7,10.9 \mathrm{~Hz}), 4.19-4.27(2 \mathrm{H}, \mathrm{m}), 3.96(3 \mathrm{H}, \mathrm{s}), 3.93(1 \mathrm{H}, \mathrm{dd}, J=9.2,11.7 \mathrm{~Hz})$, 3.47 (2H, t, $J=7.9 \mathrm{~Hz}$ ), 2.46 (3H, s); IR (film) $v_{\max } 3328,2925,1633,1520,1417,1318$, $1142 \mathrm{~cm}^{-1}$; ESITOF-HRMS $m / z 670.1508\left(\mathrm{M}+\mathrm{H}^{+}, \mathrm{C}_{34} \mathrm{H}_{28} \mathrm{ClN}_{5} \mathrm{O}_{6} \mathrm{~S}\right.$ requires 670.1521). 13f: $[\alpha]^{23}-8(c 0.1, \mathrm{DMF})$.

ent-13f: $[\alpha]^{23}{ }_{D}+10(c 0.1, \mathrm{DMF})$.

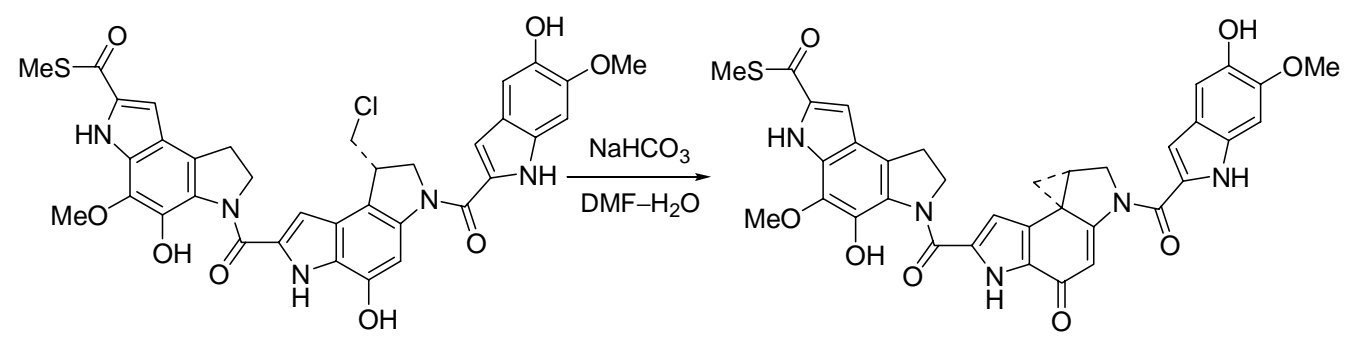

Yatakemycin (1). Compound 13a $(4.3 \mathrm{mg}, 6.0 \mu \mathrm{mol})$ was dissolved in DMF (0.66 mL), treated with a solution of $\mathrm{NaHCO}_{3}$ in $\mathrm{H}_{2} \mathrm{O}\left(0.33 \mathrm{~mL}, 15 \mathrm{mg} / \mathrm{mL} \mathrm{NaHCO}_{3}\right)$, and the mixture was stirred vigorously for $1 \mathrm{~h}$ at $25{ }^{\circ} \mathrm{C}$. THF $(2 \mathrm{~mL})$ was added and the precipitated base was removed by filtration through a pad of silica gel. The solvent was removed by a $\mathrm{N}_{2}$ stream and the residue was purified by flash chromatography $\left(\mathrm{SiO}_{2}\right.$, 14\% DMF-toluene) to afford $\mathbf{1}$ (4.0 mg 98\%) as a yellow solid: ${ }^{1} \mathrm{H}$ NMR (pyridine- $d_{5}$, $500 \mathrm{MHz}) \delta 13.74(1 \mathrm{H}, \mathrm{br} \mathrm{s}), 12.76(1 \mathrm{H}$, br s), $11.71(1 \mathrm{H}, \mathrm{br} \mathrm{s}), 10.73(1 \mathrm{H}, \mathrm{br} \mathrm{s}), 7.73$ $(1 \mathrm{H}, \mathrm{s}), 7.64(1 \mathrm{H}, \mathrm{s}), 7.52(1 \mathrm{H}, \mathrm{s}), 7.24(1 \mathrm{H}, \mathrm{s}), 6.74(1 \mathrm{H}, \mathrm{s}), 4.42-4.54(4 \mathrm{H}, \mathrm{m}), 4.03$ $(3 \mathrm{H}, \mathrm{s}), 3.85(3 \mathrm{H}, \mathrm{s}), 3.22(2 \mathrm{H}, \mathrm{t}, J=7.8 \mathrm{~Hz}), 2.98(1 \mathrm{H}, \mathrm{dd}, J=4.8,8.0 \mathrm{~Hz}), 2.49(3 \mathrm{H}, \mathrm{s})$, $1.77(1 \mathrm{H}, \mathrm{dd}, J=4.4,7.5 \mathrm{~Hz}), 1.44(1 \mathrm{H}, \mathrm{t}, J=4.8 \mathrm{~Hz}) ;{ }^{1} \mathrm{H}$ NMR $\left(\mathrm{DMF}-d_{6}, 500 \mathrm{MHz}\right) \delta$ $12.35(1 \mathrm{H}, \mathrm{br} \mathrm{s}), 12.04(1 \mathrm{H}, \mathrm{s}), 11.39(1 \mathrm{H}, \mathrm{s}), 11.11(1 \mathrm{H}, \mathrm{s}), 8.65(1 \mathrm{H}, \mathrm{s}), 7.33(1 \mathrm{H}, \mathrm{d}, J=$ $2.0 \mathrm{~Hz}), 7.10(1 \mathrm{H}, \mathrm{s}, J=2.0 \mathrm{~Hz}), 7.09(2 \mathrm{H}, \mathrm{s}), 7.03(1 \mathrm{H}, \mathrm{s}), 6.91(1 \mathrm{H}, \mathrm{s}), 4.68-4.74(2 \mathrm{H}$, 
m), $4.66(1 \mathrm{H}, \mathrm{dd}, J=5.0,10.7 \mathrm{~Hz}), 4.52(1 \mathrm{H}, \mathrm{d}, J=10.7 \mathrm{~Hz}), 3.95(3 \mathrm{H}, \mathrm{s}), 3.90(3 \mathrm{H}, \mathrm{s})$, $3.43(2 \mathrm{H}, \mathrm{t}, J=8.0 \mathrm{~Hz}), 3.15(1 \mathrm{H}, \mathrm{dd}, J=7.4,5.0 \mathrm{~Hz}), 1.94(1 \mathrm{H}, \mathrm{dd}, J=4.0,8.0 \mathrm{~Hz})$, $1.70(1 \mathrm{H}, \mathrm{t}, J=4.0 \mathrm{~Hz})$; IR (film) $v_{\max } 1623,1498,1381,1251 \mathrm{~cm}^{-1}$; ESITOF-HRMS $m / z \quad 680.1812\left(\mathrm{M}+\mathrm{H}^{+}, \mathrm{C}_{35} \mathrm{H}_{29} \mathrm{~N}_{5} \mathrm{O}_{8} \mathrm{~S}\right.$ requires 680.1810).

1: $[\alpha]^{23}+100(c 0.1, \mathrm{DMF})$.

ent-1: $[\alpha]_{\mathrm{D}}^{23}-94(c 0.1, \mathrm{DMF})$.
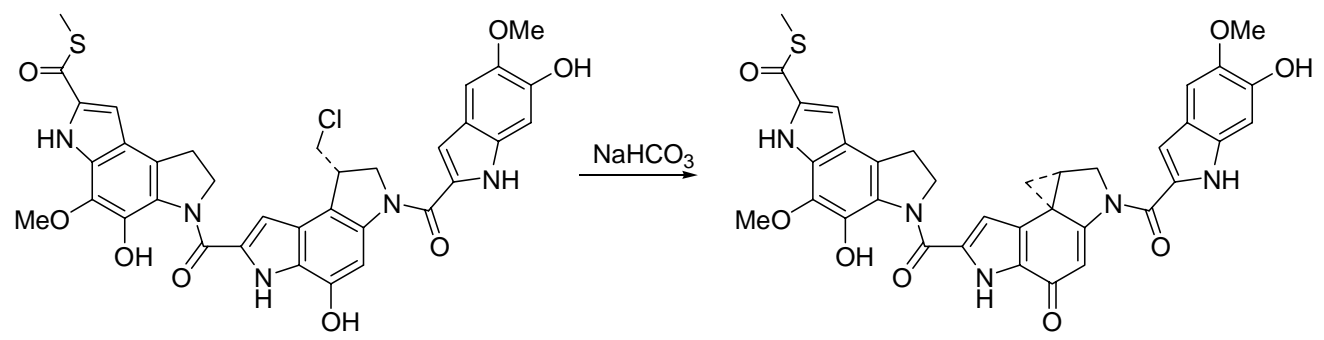

Analogue 14b. Compound 13b $(0.80 \mathrm{mg}, 1.1 \mu \mathrm{mol})$ was dissolved in 1:1:1 $\mathrm{CH}_{3} \mathrm{CN}-\mathrm{H}_{2} \mathrm{O}-\mathrm{THF}(1.5 \mathrm{~mL})$, treated with $\mathrm{NaHCO}_{3}(5.0 \mathrm{mg}, 60 \mu \mathrm{mol})$, and the mixture was stirred for $2 \mathrm{~h}$ at $25^{\circ} \mathrm{C}$. Acetic acid $(50 \mu \mathrm{L})$ was added and the solvent was removed by a $\mathrm{N}_{2}$ stream. The residue was purified by flash chromatography $\left(\mathrm{SiO}_{2}, 2-5 \%\right.$ $\left.\mathrm{MeOH}-\mathrm{CHCl}_{3}\right)$ afforded $\mathbf{1 4 b}(0.6 \mathrm{mg} 75 \%)$ as a yellow solid: ${ }^{1} \mathrm{H}$ NMR (pyridine- $d_{5}, 500$ MHz) $\delta 13.75$ (1H, br s), 12.88 (1H, br s), $11.72(1 \mathrm{H}$, br s), 11.35 (1H, br s), $7.71(1 \mathrm{H}, \mathrm{s})$, $7.51(1 \mathrm{H}, \mathrm{s}), 7.48(1 \mathrm{H}, \mathrm{s}), 7.34(1 \mathrm{H}, \mathrm{s}), 7.25(1 \mathrm{H}, \mathrm{s}), 6.74(1 \mathrm{H}, \mathrm{s}), 4.44-4.56(4 \mathrm{H}, \mathrm{m})$, $4.03(3 \mathrm{H}, \mathrm{s}), 3.87(3 \mathrm{H}, \mathrm{s}), 3.22(2 \mathrm{H}, \mathrm{t}, J=7.7 \mathrm{~Hz}), 2.97(1 \mathrm{H}, \mathrm{m}), 2.49(3 \mathrm{H}, \mathrm{s}), 1.78(1 \mathrm{H}$, dd, $J=3.7,7.3 \mathrm{~Hz}$ ), $1.47\left(1 \mathrm{H}, \mathrm{t}, J=4.4 \mathrm{~Hz}\right.$ ); IR (film) $v_{\max } 3336,2924,1631,1500$, 1383, $1233 \mathrm{~cm}^{-1}$; ESITOF-HRMS $\mathrm{m} / z 678.1653\left(\mathrm{M}-\mathrm{H}^{-}, \mathrm{C}_{35} \mathrm{H}_{29} \mathrm{~N}_{5} \mathrm{O}_{8} \mathrm{~S}\right.$ requires 678.1664).

14b: $[\alpha]_{\mathrm{D}}^{23}+76(c 0.1, \mathrm{DMF})$.

ent-14b: $[\alpha]^{23}{ }_{D}-84$ (c 0.1, DMF). 


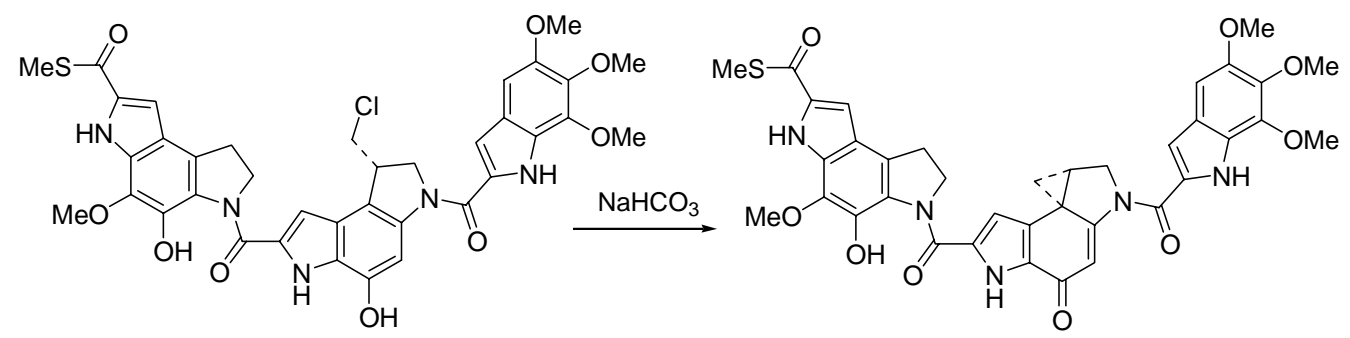

Analogue 14c. Compound 13c (2.3 mg, $0.0030 \mathrm{mmol})$ was dissolved in DMF (0.66 mL), treated with a solution of $\mathrm{NaHCO}_{3}$ in $\mathrm{H}_{2} \mathrm{O}\left(0.33 \mathrm{~mL}, 15 \mathrm{mg} / \mathrm{mL} \mathrm{NaHCO}_{3}\right)$, and the mixture was stirred vigorously for $1 \mathrm{~h}$ at $25{ }^{\circ} \mathrm{C}$. THF $(2 \mathrm{~mL})$ was added and the precipitated base was removed by filtration through a pad of silica gel. The solvent was removed by a $\mathrm{N}_{2}$ stream and the residue was purified by flash chromatography $\left(\mathrm{SiO}_{2}\right.$, $10 \% \mathrm{DMF}-$ toluene) to afford $\mathbf{1 4 c}(1.9 \mathrm{mg}, 87 \%)$ as a yellow solid: ${ }^{1} \mathrm{H}$ NMR (pyridine- $d_{5}$, $500 \mathrm{MHz}) \delta 14.65(1 \mathrm{H}, \mathrm{br} \mathrm{s}), 13.69(1 \mathrm{H}, \mathrm{s}), 13.32(1 \mathrm{H}, \mathrm{s}), 11.69(1 \mathrm{H}, \mathrm{s}), 7.57(1 \mathrm{H}, \mathrm{s})$, $7.50(1 \mathrm{H}, \mathrm{d}, J=2.0 \mathrm{~Hz}), 7.26(1 \mathrm{H}, \mathrm{d}, J=2.1 \mathrm{~Hz}), 7.09(1 \mathrm{H}, \mathrm{s}), 6.74(1 \mathrm{H}, \mathrm{s}), 4.43-4.57$ $(4 \mathrm{H}, \mathrm{m}), 4.03(3 \mathrm{H}, \mathrm{s}), 4.00(3 \mathrm{H}, \mathrm{s}), 3.94(3 \mathrm{H}, \mathrm{s}), 3.85(3 \mathrm{H}, \mathrm{s}), 3.22(2 \mathrm{H}, \mathrm{t}, J=7.9 \mathrm{~Hz})$, $2.95(1 \mathrm{H}, \mathrm{td}, J=4.9,7.5 \mathrm{~Hz}), 2.49(3 \mathrm{H}, \mathrm{s}), 1.80(1 \mathrm{H}, \mathrm{dd}, J=4.2,7.6 \mathrm{~Hz}), 1.49(1 \mathrm{H}, \mathrm{t}, J=$ $4.6 \mathrm{~Hz}$ ); IR (film) $v_{\max } 3279,2935,1633,1383,1241 \mathrm{~cm}^{-1}$; ESITOF-HRMS m/z $724.2076\left(\mathrm{M}+\mathrm{H}^{+}, \mathrm{C}_{37} \mathrm{H}_{33} \mathrm{~N}_{5} \mathrm{O}_{9} \mathrm{~S}\right.$ requires 724.2072).

14c: $[\alpha]^{23}{ }_{\mathrm{D}}+124(c$ 0.2, DMF).

ent-14c: $[\alpha]^{23}-115(c 0.2, \mathrm{DMF})$.

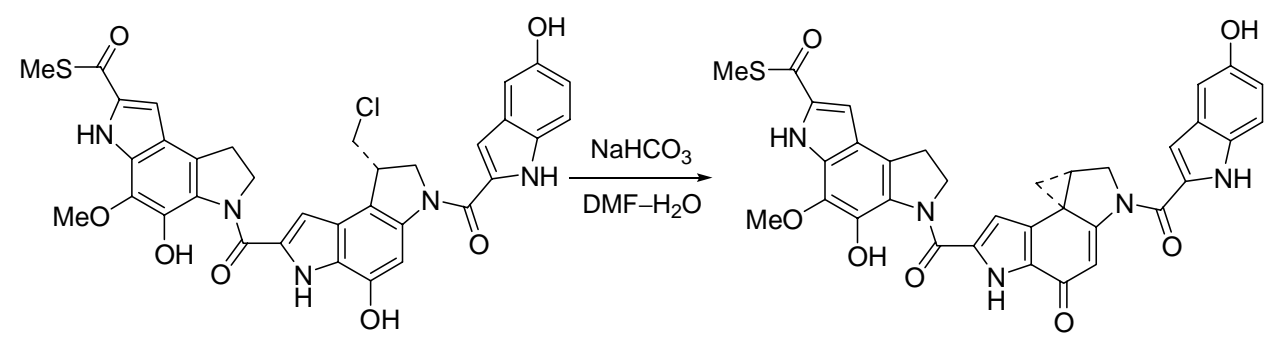

Analogue 14d. Compound 13d (1.25 mg, $0.00182 \mathrm{mmol})$ was dissolved in DMF (0.66 $\mathrm{mL})$, treated with a solution of $\mathrm{NaHCO}_{3}$ in $\mathrm{H}_{2} \mathrm{O}\left(0.33 \mathrm{~mL}, 15 \mathrm{mg} / \mathrm{mL} \mathrm{NaHCO}_{3}\right)$, and the mixture was stirred vigorously for $1 \mathrm{~h}$ at $25{ }^{\circ} \mathrm{C}$. THF $(2 \mathrm{~mL})$ was added and the precipitated base was removed by filtration through a pad of silica gel. The solvent was removed by a $\mathrm{N}_{2}$ stream and the residue was purified by flash chromatography $\left(\mathrm{SiO}_{2}\right.$, 
14\% DMF-toluene) to afford $\mathbf{1 4 d}(0.75 \mathrm{mg}, 63 \%)$ as a yellow solid: ${ }^{1} \mathrm{H}$ NMR (pyridine$\left.d_{5}, 500 \mathrm{MHz}\right) \delta 14.70(1 \mathrm{H}, \mathrm{br} \mathrm{s}), 13.73(1 \mathrm{H}, \mathrm{s}), 13.08(1 \mathrm{H}, \mathrm{s}), 11.70(1 \mathrm{H}, \mathrm{s}), 11.23(1 \mathrm{H}$, s), $7.70(1 \mathrm{H}, \mathrm{d}$, partially obscured), $7.69(1 \mathrm{H}, \mathrm{s}), 7.62(1 \mathrm{H}, \mathrm{d}, J=1.9 \mathrm{~Hz}), 7.51(1 \mathrm{H}, \mathrm{d}, J=$ $1.7 \mathrm{~Hz}), 7.44(1 \mathrm{H}, \mathrm{dd}, J=2.0,8.7 \mathrm{~Hz}), 7.18(1 \mathrm{H}, \mathrm{s}), 6.73(1 \mathrm{H}, \mathrm{s}), 4.43-4.54(4 \mathrm{H}, \mathrm{m})$, $4.03(3 \mathrm{H}, \mathrm{s}), 3.22(2 \mathrm{H}, \mathrm{t}, J=7.9 \mathrm{~Hz}), 2.98(1 \mathrm{H}, \mathrm{td}, J=5.0,8.3 \mathrm{~Hz}), 2.49(3 \mathrm{H}, \mathrm{s}), 1.78$ $(1 \mathrm{H}, \mathrm{dd}, J=4.2,7.6 \mathrm{~Hz}), 1.46(1 \mathrm{H}, \mathrm{t}, J=4.5 \mathrm{~Hz})$; IR (film) $v_{\max } 3284,1636,1507,1379$, $1233 \mathrm{~cm}^{-1}$; ESITOF-HRMS m/z $650.1689\left(\mathrm{M}+\mathrm{Na}^{+}, \mathrm{C}_{34} \mathrm{H}_{27} \mathrm{~N}_{5} \mathrm{O}_{7} \mathrm{~S}\right.$ requires 650.1704).

14d: $[\alpha]^{23}{ }_{D}+132(c 0.1, \mathrm{DMF})$.

ent-14d: $[\alpha]_{D}^{23}-132$ (c 0.1, DMF).

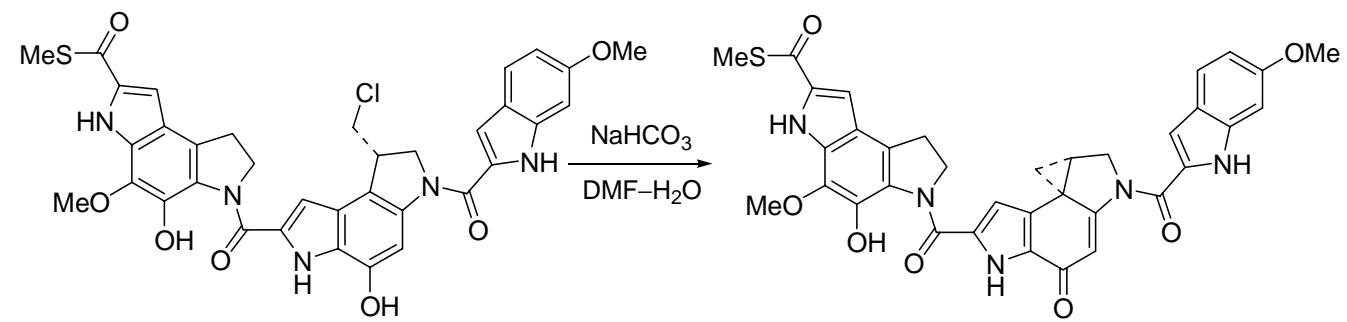

Analogue 14e. Compound 13e (1.10 mg, $0.00157 \mathrm{mmol})$ was dissolved in DMF (0.66 $\mathrm{mL})$, treated with a solution of $\mathrm{NaHCO}_{3}$ in $\mathrm{H}_{2} \mathrm{O}\left(0.33 \mathrm{~mL}, 15 \mathrm{mg} / \mathrm{mL} \mathrm{NaHCO}_{3}\right)$, and the mixture was stirred vigorously for $1 \mathrm{~h}$ at $25{ }^{\circ} \mathrm{C}$. THF $(2 \mathrm{~mL})$ was added and the precipitated base was removed by filtration through a pad of silica gel. The solvent was removed by a $\mathrm{N}_{2}$ stream and the residue was purified by flash chromatography $\left(\mathrm{SiO}_{2}, 8 \%\right.$ DMF-toluene) to afford $\mathbf{1 4 e}(0.98 \mathrm{mg}, 94 \%)$ as a yellow solid: ${ }^{1} \mathrm{H}$ NMR (pyridine- $d_{5}$, $500 \mathrm{MHz}) \delta 13.69(1 \mathrm{H}, \mathrm{s}), 12.93(1 \mathrm{H}, \mathrm{s}), 11.69(1 \mathrm{H}, \mathrm{s}), 7.79(1 \mathrm{H}, \mathrm{d}, J=8.7 \mathrm{~Hz}), 7.70$ $(1 \mathrm{H}, \mathrm{s}), 7.51(1 \mathrm{H}, \mathrm{s}), 7.25(1 \mathrm{H}, \mathrm{s}), 7.20(1 \mathrm{H}, \mathrm{s}), 7.08(1 \mathrm{H}, \mathrm{dd}, J=8.7,1.9 \mathrm{~Hz}), 6.74(1 \mathrm{H}$, s), $4.43-4.55(4 \mathrm{H}, \mathrm{m}), 4.03(3 \mathrm{H}, \mathrm{s}), 3.78(3 \mathrm{H}, \mathrm{s}), 3.23(2 \mathrm{H}, \mathrm{t}, J=7.9 \mathrm{~Hz}), 2.99(1 \mathrm{H}, \mathrm{td}, J$ $=4.9,7.7 \mathrm{~Hz}), 2.49(3 \mathrm{H}, \mathrm{s}), 1.79(1 \mathrm{H}, \mathrm{dd}, J=4.1,7.6 \mathrm{~Hz}), 1.47(1 \mathrm{H}, \mathrm{t}, J=4.5 \mathrm{~Hz})$; IR (film) $v_{\max } 3309,2924,1634,1505,1382,1254 \mathrm{~cm}^{-1}$; ESITOF-HRMS $\mathrm{m} / z 686.1683(\mathrm{M}$ $+\mathrm{Na}^{+}, \mathrm{C}_{35} \mathrm{H}_{29} \mathrm{~N}_{5} \mathrm{O}_{7} \mathrm{~S}$ requires 686.1680).

14e: $[\alpha]^{23}{ }_{D}+144(c$ 0.1, DMF).

ent-14e: $[\alpha]^{23}-138(c 0.1, \mathrm{DMF})$. 

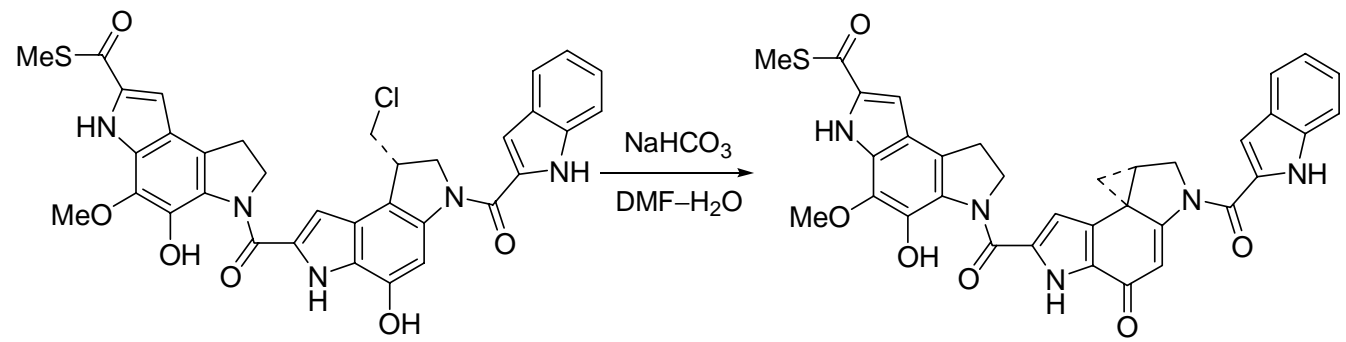

Analogue 14f. Compound 13f (2.3 mg, $0.0034 \mathrm{mmol})$ was dissolved in DMF (0.66 mL), treated with a solution of $\mathrm{NaHCO}_{3}$ in $\mathrm{H}_{2} \mathrm{O}\left(0.33 \mathrm{~mL}, 15 \mathrm{mg} / \mathrm{mL} \mathrm{NaHCO}_{3}\right)$, and the mixture was stirred vigorously for $1 \mathrm{~h}$ at $25{ }^{\circ} \mathrm{C}$. THF $(2 \mathrm{~mL})$ was added and the precipitated base was removed by filtration through a pad of silica gel. The solvent was removed by a $\mathrm{N}_{2}$ stream and the residue was purified by flash chromatography $\left(\mathrm{SiO}_{2}, 8 \%\right.$ DMF-toluene) to afford $\mathbf{1 4 f}(1.9 \mathrm{mg}, 87 \%)$ as a yellow solid: ${ }^{1} \mathrm{H}$ NMR (pyridine- $d_{5}, 500$ MHz) $\delta 14.67(1 \mathrm{H}$, br s), $13.69(1 \mathrm{H}, \mathrm{s}), 13.26(1 \mathrm{H}, \mathrm{s}), 11.69(1 \mathrm{H}, \mathrm{s}), 7.91(1 \mathrm{H}, \mathrm{d}, J=8.0$ $\mathrm{Hz}), 7.74(1 \mathrm{H}, \mathrm{d}, J=8.9 \mathrm{~Hz}), 7.67(1 \mathrm{H}, \mathrm{s}), 7.51(1 \mathrm{H}, \mathrm{d}, J=1.9 \mathrm{~Hz}), 7.44(1 \mathrm{H}, \mathrm{t}, J=7.6$ Hz), 7.25-7.32 (2H, m), $6.74(1 \mathrm{H}, \mathrm{s}), 4.45-4.56(4 \mathrm{H}, \mathrm{m}), 4.03(3 \mathrm{H}, \mathrm{s}), 3.22(2 \mathrm{H}, \mathrm{t}, J=$ $8.0 \mathrm{~Hz}), 2.99(1 \mathrm{H}, \mathrm{td}, J=4.8,7.6 \mathrm{~Hz}), 2.49(3 \mathrm{H}, \mathrm{s}), 1.79(1 \mathrm{H}, \mathrm{dd}, J=4.3,7.7 \mathrm{~Hz}), 1.49$ $(1 \mathrm{H}, \mathrm{t}, J=4.6 \mathrm{~Hz})$; IR (film) $v_{\max } 3286,2928,1635,1507,1387,1255 \mathrm{~cm}^{-1}$; ESITOF-HRMS $m / z 634.1744\left(\mathrm{M}+\mathrm{H}^{+}, \mathrm{C}_{34} \mathrm{H}_{27} \mathrm{~N}_{5} \mathrm{O}_{6} \mathrm{~S}\right.$ requires 634.1755).

14f: $[\alpha]^{23}+130(c 0.1, \mathrm{DMF})$.

ent-14f: $[\alpha]_{D}^{23}-122(c 0.1, \mathrm{DMF})$.
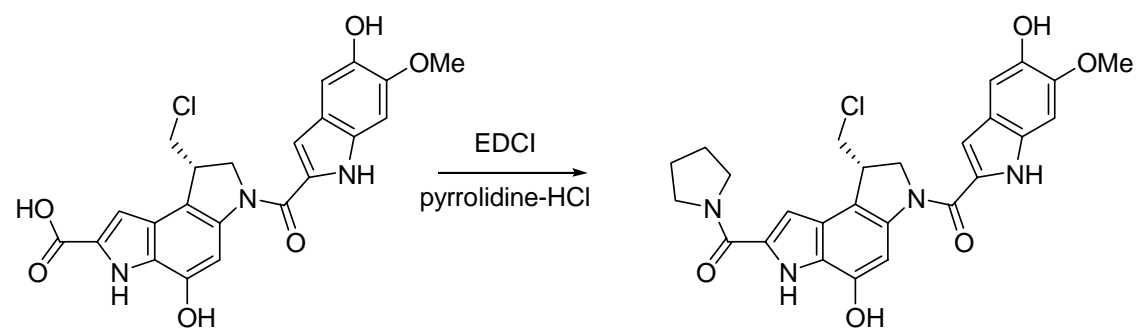

[[3-[(5-hydroxy-6-methoxyindole-2-yl)carbonyl]-1-(chloromethyl)-5-hydroxy-1,2dihydro-3H-pyrrolo[3,2-e]indol-7-yl]carbonyl]pyrrolidine (15a). Compound 12a (4.2 $\mathrm{mg}, 0.0092 \mathrm{mmol})$ was dissolved in DMF $(0.15 \mathrm{~mL})$, treated with EDCI $(9.0 \mathrm{mg}, 0.046$ $\mathrm{mmol})$, and pyrrolidine- $\mathrm{HCl}(3.3 \mathrm{mg}, 0.031 \mathrm{mmol})$, and the mixture was stirred for $16 \mathrm{~h}$ at $25{ }^{\circ} \mathrm{C}$. The solvent was removed by a $\mathrm{N}_{2}$ stream, and the residue was purified by flash 
chromatography ( $\mathrm{SiO}_{2}, 12 \%$ DMF-toluene) to afford 15a (2.3 $\left.\mathrm{mg}, 49 \%\right)$ as a yellow solid: ${ }^{1} \mathrm{H}$ NMR (DMF- $\left.d_{6}, 500 \mathrm{MHz}\right) \delta 7.97(1 \mathrm{H}, \mathrm{s}), 7.15(1 \mathrm{H}, \mathrm{s}), 7.11(1 \mathrm{H}, \mathrm{s}), 7.08(1 \mathrm{H}$, s), $6.99(1 \mathrm{H}, \mathrm{s}), 4.78(1 \mathrm{H}, \mathrm{t}, J=10 \mathrm{~Hz}), 4.61(1 \mathrm{H}, \mathrm{dd}, J=3.5,10.7 \mathrm{~Hz}), 4.19(1 \mathrm{H}, \mathrm{dd}, J=$ 3.0, $11.6 \mathrm{~Hz}), 4.16(1 \mathrm{H}, \mathrm{m}), 3.97(3 \mathrm{H}, \mathrm{m}), 3.91(3 \mathrm{H}, \mathrm{s}), 3.85(1 \mathrm{H}, \mathrm{dd}, J=3.8,10.5 \mathrm{~Hz})$, $3.65(2 \mathrm{H}, \mathrm{m}), 2.09(2 \mathrm{H}, \mathrm{m}), 1.95(2 \mathrm{H}, \mathrm{m})$; IR (film) $v_{\max } 3295,2931,1620,1502,1384$, $1255 \mathrm{~cm}^{-1}$; ESITOF-HRMS m/z $509.1569\left(\mathrm{M}+\mathrm{H}^{+}, \mathrm{C}_{26} \mathrm{H}_{25} \mathrm{ClN}_{4} \mathrm{O}_{5}\right.$ requires 509.1586). 15a: $[\alpha]^{23}{ }_{D}+6(c$ 0.1, DMF). ent-15a: $[\alpha]^{23}-4(c 0.1, \mathrm{DMF})$.

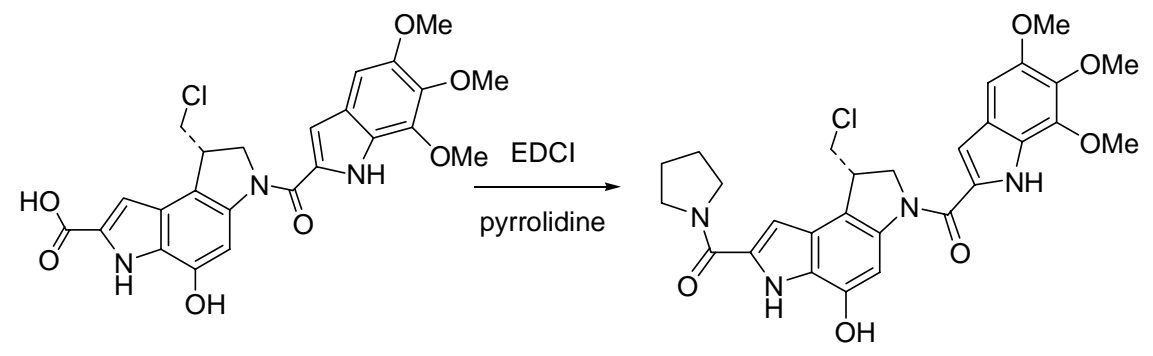

[[3-[(5,6,7-Trimethoxyindole-2-yl)carbonyl]-1-(chloromethyl)-5-hydroxy-1,2dihydro-3H-pyrrolo[3,2-e]indol-7-yl]carbonyl]pyrrolidine (15b). Compound 12c (4.88 mg, $0.0098 \mathrm{mmol})$ was dissolved in DMF $(0.15 \mathrm{~mL})$, treated with EDCI $(9.4 \mathrm{mg}$, $0.049 \mathrm{mmol})$, and pyrrolidine- $\mathrm{HCl}(2.7 \mathrm{mg}, 0.025 \mathrm{mmol})$ and the mixture was stirred for $16 \mathrm{~h}$ at $25{ }^{\circ} \mathrm{C}$. The solvent was removed by a $\mathrm{N}_{2}$ stream, and the residue was purified by flash chromatography $\left(\mathrm{SiO}_{2}, 10 \% \mathrm{DMF}\right.$-toluene) to afford $\mathbf{1 5 b}(3.5 \mathrm{mg}, 65 \%)$ as a yellow solid: ${ }^{1} \mathrm{H}$ NMR (DMF- $\left.d_{6}, 500 \mathrm{MHz}\right) \delta 11.31(1 \mathrm{H}, \mathrm{s}), 11.03(1 \mathrm{H}, \mathrm{s}), 9.97(1 \mathrm{H}, \mathrm{s})$, $7.85(1 \mathrm{H}, \mathrm{br} \mathrm{s}), 7.24(1 \mathrm{H}, \mathrm{d}, J=2.1 \mathrm{~Hz}), 7.10(1 \mathrm{H}, \mathrm{d}, J=2.1 \mathrm{~Hz}), 7.05(1 \mathrm{H}, \mathrm{s}), 4.79(1 \mathrm{H}$, t, $J=10.0 \mathrm{~Hz}), 4.55(1 \mathrm{H}, \mathrm{dd}, J=3.9,10.9 \mathrm{~Hz}), 4.27(1 \mathrm{H}, \mathrm{dd}, J=3.6,10.8 \mathrm{~Hz}), 4.14-4.20$ $(1 \mathrm{H}, \mathrm{m}), 4.03(3 \mathrm{H}, \mathrm{s}), 3.92-4.00(3 \mathrm{H}, \mathrm{m}), 3.91(3 \mathrm{H}, \mathrm{s}), 3.88(3 \mathrm{H}, \mathrm{s}), 3.55-3.67(2 \mathrm{H}, \mathrm{m})$, 2.02-2.09 (2H, m), 1.85-1.96 (2H, m); IR (film) $v_{\max } 2925,1568,1423,1307,1221$ $\mathrm{cm}^{-1}$; ESITOF-HRMS m/z 553.1830 $\left(\mathrm{M}+\mathrm{H}^{+}, \mathrm{C}_{28} \mathrm{H}_{29} \mathrm{ClN}_{4} \mathrm{O}_{6}\right.$ requires 553.1848).

15b: $[\alpha]^{23}{ }_{D}+8(c 0.1, \mathrm{DMF})$.

ent-15b: $[\alpha]^{23}-4(c 0.1, \mathrm{DMF})$. 


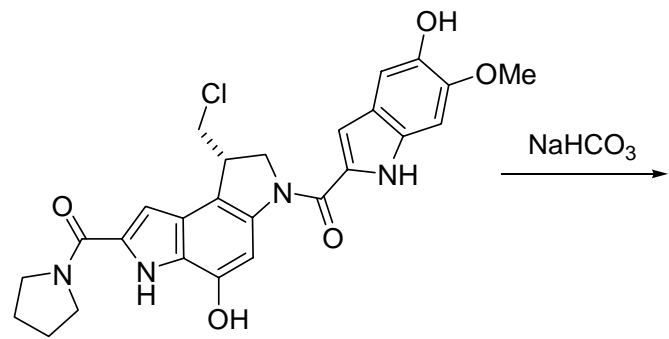

[[2-[(5-Hydroxy-6-methoxyindole-2-yl)

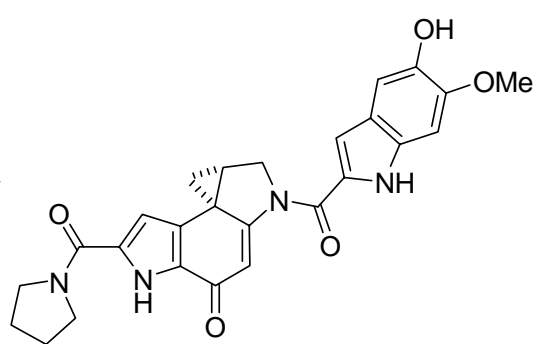

carbonyl]-1,2,8,8a-

tetrahydrocyclopropa[c]pyrrolo[3,2-e]indol-4-one-6-yl]carbonyl]pyrrolidine (16a). Compound 15a $(1.5 \mathrm{mg}, 0.0029 \mathrm{mmol})$ was dissolved in DMF $(0.66 \mathrm{~mL})$, treated with a solution of $\mathrm{NaHCO}_{3}$ in $\mathrm{H}_{2} \mathrm{O}\left(0.33 \mathrm{~mL}, 15 \mathrm{mg} / \mathrm{mL} \mathrm{NaHCO}_{3}\right)$, and the mixture was stirred vigorously for $1 \mathrm{~h}$ at $25{ }^{\circ} \mathrm{C}$. THF $(2 \mathrm{~mL})$ was added and the precipitated base was removed by filtration through a pad of silica gel. The solvent was removed by a $\mathrm{N}_{2}$ stream and the residue was purified by flash chromatography $\left(\mathrm{SiO}_{2}, 3-5 \%\right.$ $\left.\mathrm{MeOH}-\mathrm{CH}_{2} \mathrm{Cl}_{2}\right)$ to afford $\mathbf{1 6 a}(0.8 \mathrm{mg}, 58 \%)$ as a yellow solid: ${ }^{1} \mathrm{H}$ NMR (pyridine- $d_{5}$, $500 \mathrm{MHz}) \delta 10.66(1 \mathrm{H}, \mathrm{s}), 8.06(1 \mathrm{H}, \mathrm{s}), 7.69(1 \mathrm{H}, \mathrm{s}), 7.62(1 \mathrm{H}, \mathrm{s}), 7.22(1 \mathrm{H}, \mathrm{s}), 7.15(1 \mathrm{H}$, s), $6.53(1 \mathrm{H}, \mathrm{s}), 4.42(1 \mathrm{H}, \mathrm{dd}, J=4.7,10.0 \mathrm{~Hz}), 4.39(1 \mathrm{H}, \mathrm{d}, J=10.1 \mathrm{~Hz}), 3.84(3 \mathrm{H}, \mathrm{s})$, $3.69(2 \mathrm{H}, \mathrm{m}), 3.56(2 \mathrm{H}, \mathrm{m}), 2.89(1 \mathrm{H}, \mathrm{m}), 1.68(3 \mathrm{H}, \mathrm{m}), 1.61(2 \mathrm{H}, \mathrm{m}), 1.37(1 \mathrm{H}, \mathrm{t}, J=4.4$ Hz); IR (film) $v_{\max } 3319,2931,1649,1518,1431 \mathrm{~cm}^{-1}$; ESITOF-HRMS m/z 473.1815 $\left(\mathrm{M}+\mathrm{H}^{+}, \mathrm{C}_{26} \mathrm{H}_{24} \mathrm{~N}_{4} \mathrm{O}_{5}\right.$ requires 473.1819).

16a: $[\alpha]^{23}{ }_{D}+112(c 0.1, \mathrm{DMF})$.

ent-16a: $[\alpha]^{23}{ }_{D}-132$ (c 0.1, DMF).

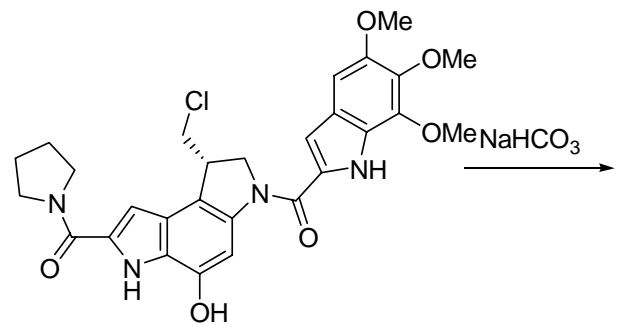

[[2-[(5,6,7-Trimethoxyindole-2-yl)

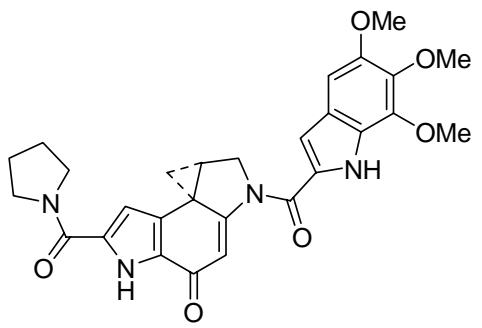

carbonyl]-1,2,8,8a-

tetrahydrocyclopropa[c]pyrrolo[3,2-e]indol-4-one-6-yl]carbonyl]pyrrolidine (16b). Compound 15b (1.6 mg, $0.0029 \mathrm{mmol})$ was dissolved in DMF $(0.66 \mathrm{~mL})$, treated with a solution of $\mathrm{NaHCO}_{3}$ in $\mathrm{H}_{2} \mathrm{O}\left(0.33 \mathrm{~mL}, 15 \mathrm{mg} / \mathrm{mL} \mathrm{NaHCO}_{3}\right)$, and the mixture was stirred vigorously for $1 \mathrm{~h}$ at $25^{\circ} \mathrm{C}$. THF $(2 \mathrm{~mL})$ was added and the precipitated base was 
removed by filtration through a pad of silica gel. The solvent was removed by a $\mathrm{N}_{2}$ stream and the residue was purified by flash chromatography $\left(\mathrm{SiO}_{2}, 11 \% \mathrm{DMF}\right.$-toluene) to afford $\mathbf{1 6 b}\left(1.3 \mathrm{mg}, 87 \%\right.$ ) as a yellow solid: ${ }^{1} \mathrm{H}$ NMR (pyridine- $\left.d_{5}, 500 \mathrm{MHz}\right) \delta 14.37$ $(1 \mathrm{H}, \mathrm{br} \mathrm{s}), 13.35(1 \mathrm{H}, \mathrm{s}), 7.53(1 \mathrm{H}, \mathrm{s}), 7.22(1 \mathrm{H}, \mathrm{d}, J=2.0 \mathrm{~Hz}), 7.07(1 \mathrm{H}, \mathrm{s}), 6.54(1 \mathrm{H}, \mathrm{s})$, $4.46(1 \mathrm{H}, \mathrm{dd}, J=4.8,10.3 \mathrm{~Hz}), 4.39(1 \mathrm{H}, \mathrm{d}, J=10.3 \mathrm{~Hz}), 3.99(3 \mathrm{H}, \mathrm{s}), 3.93(3 \mathrm{H}, \mathrm{s}), 3.84$ $(3 \mathrm{H}, \mathrm{s}), 3.70(2 \mathrm{H}, \mathrm{m}), 3.55(2 \mathrm{H}, \mathrm{m}), 2.87(1 \mathrm{H}, \mathrm{dt}, J=4.8,7.6 \mathrm{~Hz}), 1.71(1 \mathrm{H}, \mathrm{dd}, J=4.1$, $7.6 \mathrm{~Hz}), 1.67(2 \mathrm{H}, \mathrm{m}), 1.60(2 \mathrm{H}, \mathrm{m}), 1.41(1 \mathrm{H}, \mathrm{t}, J=4.4 \mathrm{~Hz})$; IR (film) $v_{\max } 3188,2932$, 1636, 1617, 1382, 1309, 1245, $1108 \mathrm{~cm}^{-1}$; ESITOF-HRMS $\mathrm{m} / z 517.2078\left(\mathrm{M}+\mathrm{H}^{+}\right.$, $\mathrm{C}_{28} \mathrm{H}_{28} \mathrm{~N}_{4} \mathrm{O}_{6}$ requires 517.2082).

16b: $[\alpha]^{23}{ }_{\mathrm{D}}+180$ (c 0.1, DMF).

ent-16b: $[\alpha]_{D}^{23}-186$ (c 0.1, DMF).

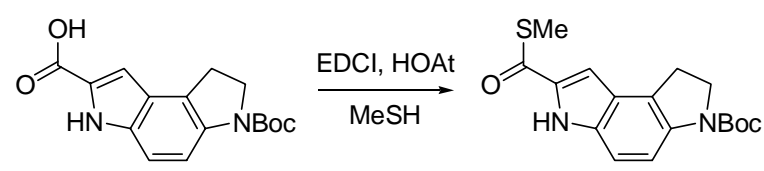

Methyl 3-((tert-Butyloxy)carbonyl)-1,2-dihydro-3H-pyrrolo[3,2-e]indole-7-

thiocarboxylate (18). 3-((tert-Butyloxy)carbonyl)-1,2-dihydro-3H-pyrrolo[3,2-e]indole7-carboxylic acid (17.0 mg, $0.0562 \mathrm{mmol})$ was dissolved in DMF $(1.5 \mathrm{~mL})$, treated with EDCI (43.0 mg, $0.225 \mathrm{mmol}$ ), and HOAt (11.4 $\mathrm{mg}, 0.0843 \mathrm{mmol})$ at $0{ }^{\circ} \mathrm{C} \mathrm{CH}_{3} \mathrm{SH}$ gas (excess) was bubbled through the DMF for $1 \mathrm{~min}$, and the solution was stirred at $0{ }^{\circ} \mathrm{C}$ for $0.5 \mathrm{~h}$ then $25^{\circ} \mathrm{C}$ for $2 \mathrm{~h}$. The mixture was diluted with EtOAc $(20 \mathrm{~mL})$, washed with $1 \mathrm{~N}$ aqueous $\mathrm{HCl}(20 \mathrm{~mL}), \mathrm{H}_{2} \mathrm{O}(20 \mathrm{~mL})$, dried $\left(\mathrm{Na}_{2} \mathrm{SO}_{4}\right)$, and concentrated in vacuo. The crude residue was purified by flash chromatography $\left(\mathrm{SiO}_{2}, 5 \% \mathrm{Et}_{2} \mathrm{O}\right.$-toluene) to afford $18(15.6 \mathrm{mg}, 83 \%)$ as a white solid: ${ }^{1} \mathrm{H}$ NMR (DMSO- $\left.d_{6}, 600 \mathrm{MHz}\right) \delta 11.96(1 \mathrm{H}, \mathrm{s}), 7.89$ $(1 \mathrm{H}, \mathrm{br} \mathrm{s}), 7.26(1 \mathrm{H}, \mathrm{d}, J=8.9 \mathrm{~Hz}), 7.17(1 \mathrm{H}, \mathrm{s}), 4.00(2 \mathrm{H}, \mathrm{t}, J=8.8 \mathrm{~Hz}), 3.23(2 \mathrm{H}, \mathrm{t}, J=$ $8.8 \mathrm{~Hz}$ ), $2.46(3 \mathrm{H}, \mathrm{s}), 1.51(9 \mathrm{H}, \mathrm{s}) ;{ }^{13} \mathrm{C}$ NMR (DMSO- $\left.d_{6}, 600 \mathrm{MHz}\right) \delta 183.2,151.6$, 134.6, 134.4, 134.2, 123.8, 121.7 114.0, 110.9, 104.5, 79.3, 47.7, 28.0 (3C), 26.0, 10.6; IR (film) $v_{\max } 3317,1703,1615,1515,1433,1370,1347,1137 \mathrm{~cm}^{-1}$; ESITOF-HRMS $m / z 355.1086\left(\mathrm{M}+\mathrm{Na}^{+}, \mathrm{C}_{17} \mathrm{H}_{20} \mathrm{~N}_{2} \mathrm{O}_{3} \mathrm{~S}\right.$ requires 355.1087). 


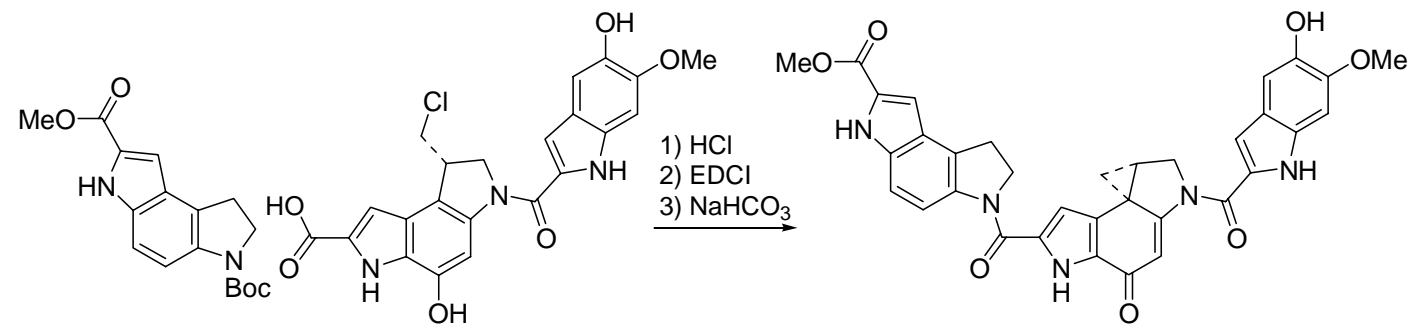

Analogue 20a. Compound $17^{18}(4.14 \mathrm{mg}, 0.0191 \mathrm{mmol})$ was dissolved in $4 \mathrm{~N}$ $\mathrm{HCl}-\mathrm{EtOAc}(2 \mathrm{~mL})$ and the solution was stirred for $0.5 \mathrm{~h}$ at $25{ }^{\circ} \mathrm{C}$. The solvent was removed by a $\mathrm{N}_{2}$ stream and the residue was dried for $3 \mathrm{~h}$ under high vacuum. The crude residue was dissolved in DMF $(0.250 \mathrm{~mL})$, treated with EDCI $(16.0 \mathrm{mg}, 0.0822 \mathrm{mmol})$, carboxylic acid 12a $(6.22 \mathrm{mg}, 0.0137 \mathrm{mmol})$ and the mixture was stirred for $16 \mathrm{~h}$ at 25 ${ }^{\circ} \mathrm{C}$. The solvent was removed by a $\mathrm{N}_{2}$ stream, and the residue was purified by flash chromatography $\left(\mathrm{SiO}_{2}, 15 \% \mathrm{DMF}\right.$-toluene) to afford $19 \mathrm{a}(3.5 \mathrm{mg}, 41 \%)$ as a yellow solid, contaminated with 20a. The product mixture $(1.25 \mathrm{mg}, 0.00191 \mathrm{mmol})$ was dissolved in DMF (1.0 mL), treated with a solution of $\mathrm{NaHCO}_{3}$ in $\mathrm{H}_{2} \mathrm{O}(0.5 \mathrm{~mL}, 15$ $\mathrm{mg} / \mathrm{mL} \mathrm{NaHCO}_{3}$ ), and the mixture was stirred vigorously for $40 \mathrm{~min}$ at $25{ }^{\circ} \mathrm{C}$. THF (2 $\mathrm{mL}$ ) was added, and the precipitated base was removed by filtration through a pad of silica gel. The solvent was removed by a $\mathrm{N}_{2}$ stream, and the residue was purified by flash chromatography $\left(\mathrm{SiO}_{2}, 15 \% \mathrm{DMF}-\right.$ toluene) to afford $\mathbf{2 0 a}(1.1 \mathrm{mg}, 91 \%)$ as a yellow solid: ${ }^{1} \mathrm{H}$ NMR (pyridine- $\left.d_{5}, 500 \mathrm{MHz}\right) \delta 13.40(1 \mathrm{H}, \mathrm{s}), 12.68(1 \mathrm{H}, \mathrm{s}), 10.64(1 \mathrm{H}, \mathrm{s}), 8.89$ $(1 \mathrm{H}$, br s), $7.71(1 \mathrm{H}, \mathrm{s}), 7.63(1 \mathrm{H}, \mathrm{s}), 7.61(1 \mathrm{H}, \mathrm{d}$, partially obscured $), 7.37(1 \mathrm{H}, \mathrm{s}), 7.23$ $(1 \mathrm{H}, \mathrm{s}), 7.17(1 \mathrm{H}, \mathrm{s}), 6.66(1 \mathrm{H}, \mathrm{s}), 4.36-4.50(4 \mathrm{H}, \mathrm{m}), 3.88(3 \mathrm{H}, \mathrm{s}), 3.84(3 \mathrm{H}, \mathrm{s}), 3.28$ $(2 \mathrm{H}, \mathrm{t}, J=8.2 \mathrm{~Hz}), 2.94(1 \mathrm{H}, \mathrm{m}), 1.74(1 \mathrm{H}, \mathrm{dd}, J=4.1,7.5 \mathrm{~Hz}), 1.41(1 \mathrm{H}, \mathrm{t}, J=4.4 \mathrm{~Hz})$; IR (film) $v_{\max } 3338,1701,1618,1371,1256,1192 \mathrm{~cm}^{-1}$; ESITOF-HRMS m/z 618.1981 $\left(\mathrm{M}+\mathrm{H}^{+}, \mathrm{C}_{34} \mathrm{H}_{27} \mathrm{~N}_{5} \mathrm{O}_{7}\right.$ requires 618.1983).

20a: $[\alpha]^{23}{ }_{D}+138$ (c 0.1, DMF).

ent-20a: $[\alpha]^{23}{ }_{D}-124$ (c 0.1, DMF). 


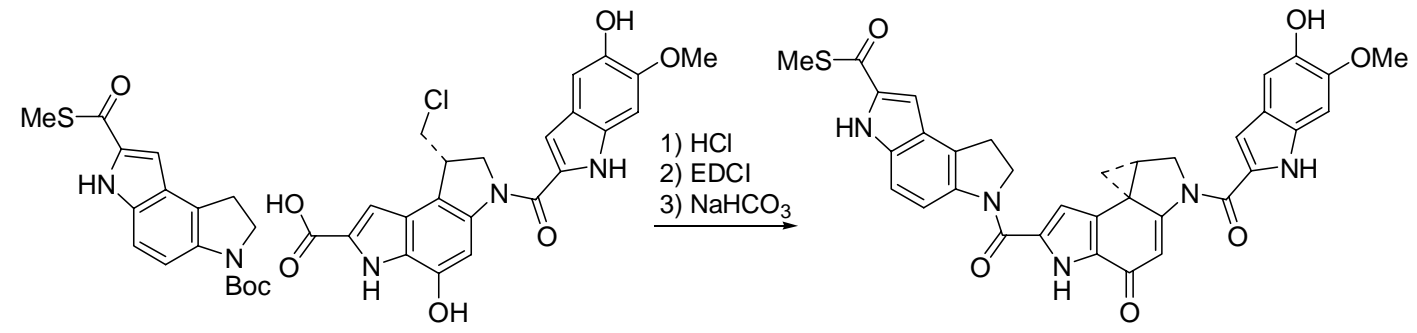

Analogue 20b. Compound 18 (5.5 mg, $0.017 \mathrm{mmol})$ was dissolved in $4 \mathrm{~N} \mathrm{HCl-EtOAc} \mathrm{(2}$ $\mathrm{mL}$ ) and the solution was stirred for $0.5 \mathrm{~h}$ at $25^{\circ} \mathrm{C}$. The solvent was removed by a $\mathrm{N}_{2}$ stream and the residue was dried for $3 \mathrm{~h}$ under high vacuum. The crude residue was dissolved in DMF (0.250 mL), treated with EDCI (11.3 mg, $0.0590 \mathrm{mmol})$, carboxylic acid 12a (5.38 mg, $0.0118 \mathrm{mmol})$ and the mixture was stirred for $16 \mathrm{~h}$ at $25^{\circ} \mathrm{C}$. The solvent was removed by a $\mathrm{N}_{2}$ stream, and the residue was purified by flash chromatography $\left(\mathrm{SiO}_{2}, 15 \% \mathrm{DMF}\right.$-toluene) to afford $\mathbf{1 9 b}(2.8 \mathrm{mg}, 37 \%)$ as a yellow solid, contaminated with 20b. The product mixture $(2.5 \mathrm{mg}, 0.00394 \mathrm{mmol})$ was dissolved in DMF (1.0 mL), treated with a solution of $\mathrm{NaHCO}_{3}$ in $\mathrm{H}_{2} \mathrm{O}(0.5 \mathrm{~mL}, 15$ $\mathrm{mg} / \mathrm{mL} \mathrm{NaHCO}_{3}$ ), and the mixture was stirred vigorously for $40 \mathrm{~min}$ at $25{ }^{\circ} \mathrm{C}$. $\mathrm{THF}(2$ $\mathrm{mL}$ ) was added, and the precipitated base was removed by filtration through a pad of silica gel. The solvent was removed by a $\mathrm{N}_{2}$ stream, and the residue was purified by flash chromatography $\left(\mathrm{SiO}_{2}, 15 \% \mathrm{DMF}\right.$-toluene) to afford $\mathbf{2 0 b}(1.6 \mathrm{mg}, 66 \%)$ as a yellow solid: ${ }^{1} \mathrm{H}$ NMR (pyridine- $\left.d_{5}, 500 \mathrm{MHz}\right) \delta 13.49(1 \mathrm{H}, \mathrm{s}), 12.89(1 \mathrm{H}, \mathrm{s}), 11.99(1 \mathrm{H}, \mathrm{s}), 9.64$ $(1 \mathrm{H}, \mathrm{s}), 8.89(1 \mathrm{H}, \mathrm{s}), 7.71(1 \mathrm{H}, \mathrm{s}), 7.63(1 \mathrm{H}, \mathrm{s}), 7.59(1 \mathrm{H}, \mathrm{d}, J=8.9 \mathrm{~Hz}), 7.50(1 \mathrm{H}, \mathrm{s})$, $7.23(1 \mathrm{H}, \mathrm{s}), 7.17(1 \mathrm{H}, \mathrm{s}), 6.66(1 \mathrm{H}, \mathrm{s}), 4.36-4.50(4 \mathrm{H}, \mathrm{m}), 3.48(3 \mathrm{H}, \mathrm{s}), 3.28(2 \mathrm{H}, \mathrm{t}, J=$ $8.2 \mathrm{~Hz}), 2.96(1 \mathrm{H}, \mathrm{m}), 2.49(3 \mathrm{H}, \mathrm{s}), 1.75(1 \mathrm{H}, \mathrm{dd}, J=4.0,7.5 \mathrm{~Hz}), 1.42(1 \mathrm{H}, \mathrm{t}, J=4.3$ $\mathrm{Hz}$ ); IR (film) $v_{\max } 3322,2924,1633,1504,1384,1254,1151 \mathrm{~cm}^{-1}$; ESITOF-HRMS $\mathrm{m} / z$ 634.1728 $\left(\mathrm{M}+\mathrm{H}^{+}, \mathrm{C}_{34} \mathrm{H}_{27} \mathrm{~N}_{5} \mathrm{O}_{6} \mathrm{~S}\right.$ requires 634.1755).

20b: $[\alpha]^{23}+136$ ( $c$ 0.1, DMF).

ent-20b: $[\alpha]^{23}{ }_{\mathrm{D}}-132$ (c 0.1, DMF). 


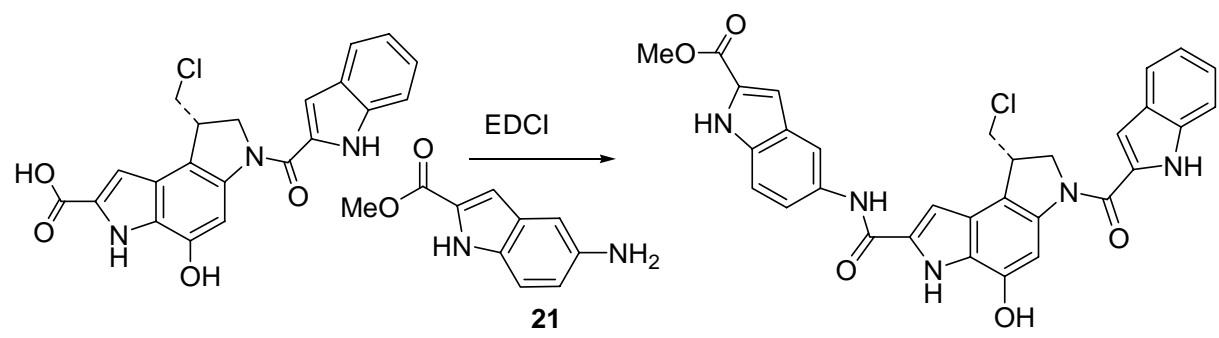

Analogue 22. Compound 21 (5.3 mg, $0.013 \mathrm{mmol})$ was dissolved in DMF $(0.15 \mathrm{~mL})$, treated with EDCI $(13.0 \mathrm{mg}, 0.0678 \mathrm{mmol})$, and $\mathbf{1 2 f}(4.1 \mathrm{mg}, 0.022 \mathrm{mmol})$ and the mixture was stirred for $24 \mathrm{~h}$ at $25^{\circ} \mathrm{C}$. The solvent was removed by a $\mathrm{N}_{2}$ stream, and the residue was purified by flash chromatography $\left(\mathrm{SiO}_{2}, 11 \% \mathrm{DMF}-\right.$ toluene) to afford 22 (4.0 mg, 53\%) as a yellow solid: ${ }^{1} \mathrm{H}$ NMR (DMF- $\left.d_{6}, 500 \mathrm{MHz}\right) \delta 11.92(1 \mathrm{H}, \mathrm{s}), 11.68$ $(1 \mathrm{H}, \mathrm{s}), 11.52(1 \mathrm{H}, \mathrm{s}), 10.37(1 \mathrm{H}, \mathrm{s}), 10.14(1 \mathrm{H}$, br s $), 8.37(1 \mathrm{H}, \mathrm{d}, J=1.5 \mathrm{~Hz}), 7.95(1 \mathrm{H}$, br s), $7.75(2 \mathrm{H}, \mathrm{m}), 7.62(1 \mathrm{H}, \mathrm{d}, J=8.8 \mathrm{~Hz}), 7.57(1 \mathrm{H}, \mathrm{d}, J=9.1 \mathrm{~Hz}), 7.54(1 \mathrm{H}, \mathrm{s}), 7.29$ $(1 \mathrm{H}, \mathrm{m}), 7.25(1 \mathrm{H}, \mathrm{m}), 7.13(1 \mathrm{H}, \mathrm{m}), 4.89(1 \mathrm{H}, \mathrm{t}, J=9.9 \mathrm{~Hz}), 4.63(1 \mathrm{H}, \mathrm{dd}, J=3.9,10.9$ Hz), 4.20-4.25 (2H, dd, $J=8.8,11.7 \mathrm{~Hz}), 4.03(1 \mathrm{H}, \mathrm{dd}, J=8.9,11.6 \mathrm{~Hz}) 3.50(3 \mathrm{H}, \mathrm{s})$; IR (film) $v_{\max } 3306,1698,1520,1435,1213 \mathrm{~cm}^{-1}$; ESITOF-HRMS $\mathrm{m} / z 582.1548\left(\mathrm{M}+\mathrm{H}^{+}\right.$, $\mathrm{C}_{31} \mathrm{H}_{24} \mathrm{ClN}_{5} \mathrm{O}_{5}$ requires 582.1539).

22: $[\alpha]^{23}{ }_{\mathrm{D}}+6(c$ 0.1, DMF).

ent-22: $[\alpha]^{23}-4$ (c 0.1, DMF).
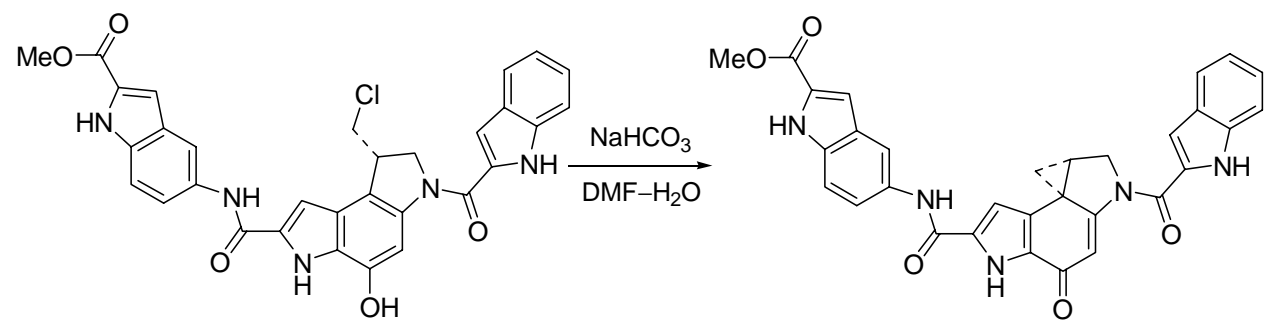

Analogue 23. Compound $22(2.1 \mathrm{mg}, 0.0036 \mathrm{mmol})$ was dissolved in DMF (0.66 mL), treated with a solution of aqueous $\mathrm{NaHCO}_{3}(0.33 \mathrm{~mL}, 15 \mathrm{mg} / \mathrm{mL} \mathrm{NaHCO} 3)$, and the mixture was stirred vigorously for $1 \mathrm{~h}$ at $25{ }^{\circ} \mathrm{C}$. THF $(2 \mathrm{~mL})$ was added, and the precipitated base was removed by filtration through a pad of silica. The solvent was removed by a $\mathrm{N}_{2}$ stream, and the residue was purified by flash chromatography $\left(\mathrm{SiO}_{2}\right.$, $11 \%$ DMF-toluene) to afford $23(1.9 \mathrm{mg}, 93 \%)$ as a yellow solid: ${ }^{1} \mathrm{H}$ NMR (pyridine- $d_{5}$, $500 \mathrm{MHz}) \delta 14.86(1 \mathrm{H}, \mathrm{br} \mathrm{s}), 13.37(1 \mathrm{H}, \mathrm{s}), 13.27(1 \mathrm{H}, \mathrm{s}), 10.81(1 \mathrm{H}, \mathrm{s}), 8.76(1 \mathrm{H}, \mathrm{s})$, 
$8.01(1 \mathrm{H}, \mathrm{dd}, J=1.7,8.8 \mathrm{~Hz}), 7.88(1 \mathrm{H}, \mathrm{d}, J=8.0 \mathrm{~Hz}), 7.72(2 \mathrm{H}, \mathrm{dd}, J=10.8,8.9 \mathrm{~Hz})$, $7.59(1 \mathrm{H}, \mathrm{s}), 7.41-7.45(2 \mathrm{H}, \mathrm{m}), 7.24-7.29(2 \mathrm{H}, \mathrm{m}), 6.91(1 \mathrm{H}, \mathrm{s}), 4.34-4.44(2 \mathrm{H}, \mathrm{m})$, $3.80(3 \mathrm{H}, \mathrm{s}), 2.64(1 \mathrm{H}, \mathrm{td}, J=4.6,7.5 \mathrm{~Hz}), 1.44(1 \mathrm{H}, \mathrm{dd}, J=4.3,7.6 \mathrm{~Hz}), 1.36(1 \mathrm{H}, \mathrm{t}, J=$ $4.5 \mathrm{~Hz}$ ); IR (film) $v_{\max } 3312,1704,1644,1591,1393,1255 \mathrm{~cm}^{-1}$; ESITOF-HRMS $\mathrm{m} / \mathrm{z}$ $568.1582\left(\mathrm{M}+\mathrm{Na}^{+}, \mathrm{C}_{31} \mathrm{H}_{23} \mathrm{~N}_{5} \mathrm{O}_{5}\right.$ requires 568.1591).

23: $[\alpha]^{23}+128(c 0.1, \mathrm{DMF})$.

ent-23: $[\alpha]_{\mathrm{D}}^{23}-118$ (c $\left.0.1, \mathrm{DMF}\right)$.

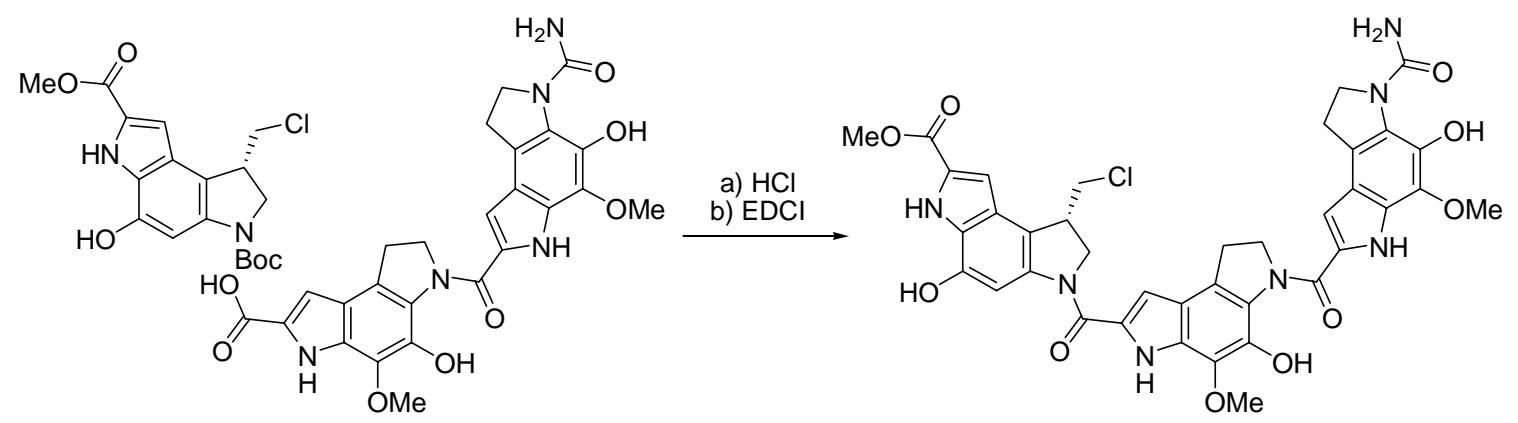

seco-DSA-PDE-PDE (29). Compound 27 (6.5 mg, $0.014 \mathrm{mmol})$ was dissolved in $4 \mathrm{~N}$ $\mathrm{HCl}-\mathrm{EtOAc}(2 \mathrm{~mL})$ and the solution was stirred for $3 \mathrm{~h}$ at $25{ }^{\circ} \mathrm{C}$. The solvent was removed by a $\mathrm{N}_{2}$ stream and the residue was dried for $3 \mathrm{~h}$ under high vacuum. The crude residue was dissolved in DMF $(0.25 \mathrm{~mL})$, treated with EDCI $(8.4 \mathrm{mg}, 0.044 \mathrm{mmol})$ and carboxylic acid $28^{22}(6.2 \mathrm{mg}, 0.011 \mathrm{mmol})$ and the mixture was stirred for $22 \mathrm{~h}$ at $25^{\circ} \mathrm{C}$. The solvent was removed by a $\mathrm{N}_{2}$ stream, and the residue was purified by flash chromatography $\left(\mathrm{SiO}_{2}, 17 \% \mathrm{DMF}-\right.$ toluene) to afford $29(3.1 \mathrm{mg}, 36 \%)$ as a yellow solid: ${ }^{1} \mathrm{H}$ NMR (DMF-d $\left.d_{7}, 500 \mathrm{MHz}\right) \delta 13.06(1 \mathrm{H}, \mathrm{s}), 11.76(1 \mathrm{H}, \mathrm{br}), 11.34(1 \mathrm{H}, \mathrm{s}), 11.28(1 \mathrm{H}$, s), $11.06(1 \mathrm{H}, \mathrm{s}), 10.19(1 \mathrm{H}, \mathrm{br} s), 7.92(1 \mathrm{H}, \mathrm{br} \mathrm{s}), 7.37(1 \mathrm{H}, \mathrm{s}), 7.20(1 \mathrm{H}, \mathrm{d}, J=2.1 \mathrm{~Hz})$, 7.19 (1H, br s), 6.99 (2H, br s), $4.83(3 \mathrm{H}, \mathrm{m}), 4.58(1 \mathrm{H}, \mathrm{dd}, J=3.6,11.0 \mathrm{~Hz}), 4.22(4 \mathrm{H}$, m), 4.05 (1H, dd, $J=8.2,11.7 \mathrm{~Hz}), 4.00(3 \mathrm{H}, \mathrm{s}), 3.94(3 \mathrm{H}, \mathrm{s}), 3.93(3 \mathrm{H}, \mathrm{s}), 3.45(2 \mathrm{H}, \mathrm{m})$, 3.37 (2H, m); IR (film) $v_{\max } 3339,2936,1711,1635,1471,1381,1265 \mathrm{~cm}^{-1}$; ESITOF-HRMS $m / z$ 806.1936 $\left(\mathrm{M}+\mathrm{Na}^{+}, \mathrm{C}_{38} \mathrm{H}_{34} \mathrm{ClN}_{7} \mathrm{O}_{10}\right.$ requires 806.1948).

28: $[\alpha]^{23}-26(c 0.1, \mathrm{DMF})$.

ent-28: $[\alpha]_{\mathrm{D}}^{23}+28$ (c 0.1, DMF). 

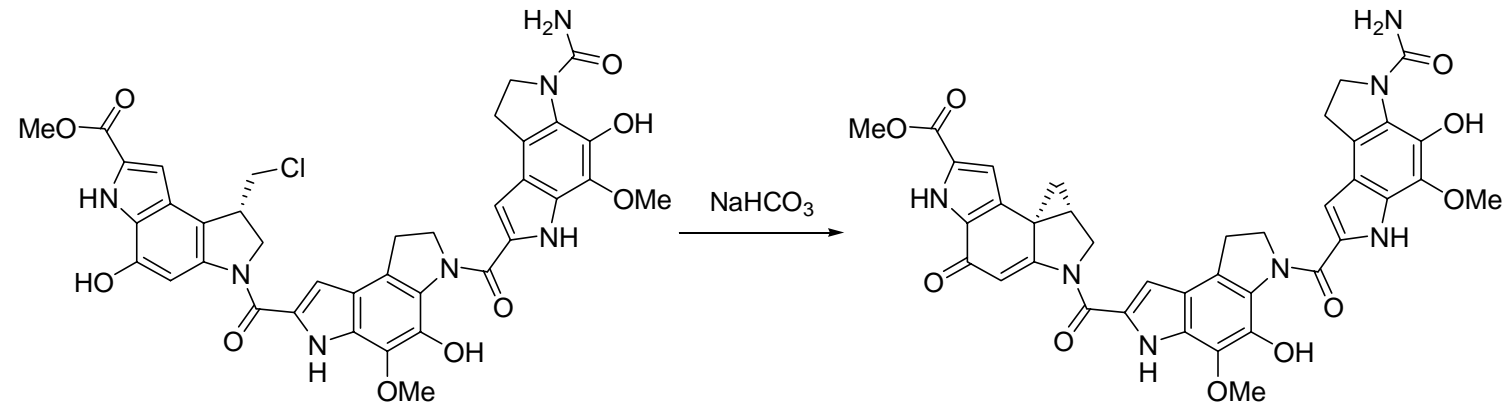

DSA-PDE-PDE (24). Compound $28(1.50 \mathrm{mg}, 0.00191 \mathrm{mmol})$ was dissolved in DMF $(1.0 \mathrm{~mL})$, treated with a solution of $\mathrm{NaHCO}_{3}$ in $\mathrm{H}_{2} \mathrm{O}\left(0.5 \mathrm{~mL}, 15 \mathrm{mg} / \mathrm{mL} \mathrm{NaHCO}_{3}\right)$, and the mixture was stirred vigorously for $0.5 \mathrm{~h}$ at $25{ }^{\circ} \mathrm{C}$. THF $(2 \mathrm{~mL})$ was added, and the precipitated base was removed by filtration through a pad of silica gel. The solvent was removed by a $\mathrm{N}_{2}$ stream, and the residue was purified by flash chromatography $\left(\mathrm{SiO}_{2}\right.$, 17\% DMF-toluene) to afford 24 (1.11 mg, 78\%) as a yellow solid: ${ }^{1} \mathrm{H}$ NMR (pyridine- $d_{5}$, $500 \mathrm{MHz}) \delta 14.84(1 \mathrm{H}, \mathrm{br} \mathrm{s}), 13.97(1 \mathrm{H}, \mathrm{s}), 13.36(1 \mathrm{H}, \mathrm{s}), 13.13(1 \mathrm{H}, \mathrm{s}), 11.83(1 \mathrm{H}, \mathrm{s})$, $7.90(2 \mathrm{H}, \mathrm{s}), 7.25(1 \mathrm{H}, \mathrm{d}, J=2.0 \mathrm{~Hz}), 7.12(1 \mathrm{H}, \mathrm{d}, J=2.1 \mathrm{~Hz}), 6.82(1 \mathrm{H}, \mathrm{s}), 4.56(2 \mathrm{H}$, m), $4.48(1 \mathrm{H}, \mathrm{dd}, J=4.8,10.3 \mathrm{~Hz}), 4.42(1 \mathrm{H}, \mathrm{d}, J=10.3 \mathrm{~Hz}), 4.27(1 \mathrm{H}, \mathrm{t}, J=8.7 \mathrm{~Hz})$, $4.08(3 \mathrm{H}, \mathrm{s}), 4.03(3 \mathrm{H}, \mathrm{s}), 3.87(3 \mathrm{H}, \mathrm{s}), 3.34(2 \mathrm{H}, \mathrm{m}), 3.23(2 \mathrm{H}, \mathrm{m}), 2.80(1 \mathrm{H}, \mathrm{dt}, J=4.8$, $7.6 \mathrm{~Hz}), 1.65(1 \mathrm{H}, \mathrm{dd}, J=4.0,7.6 \mathrm{~Hz}), 1.43(1 \mathrm{H}, \mathrm{t}, J=4.51)$; IR (film) $v_{\max } 3341,1709$, $1633,1468,1376,1266 \mathrm{~cm}^{-1}$; ESITOF-HRMS $\mathrm{m} / z 748.2342\left(\mathrm{M}+\mathrm{H}^{+}, \mathrm{C}_{38} \mathrm{H}_{33} \mathrm{~N}_{7} \mathrm{O}_{10}\right.$ requires 748.2362$)$.

24: $[\alpha]^{23}{ }_{D}+54(c$ 0.1, DMF).

ent-24: $[\alpha]^{23}-60(c 0.1, \mathrm{DMF})$.

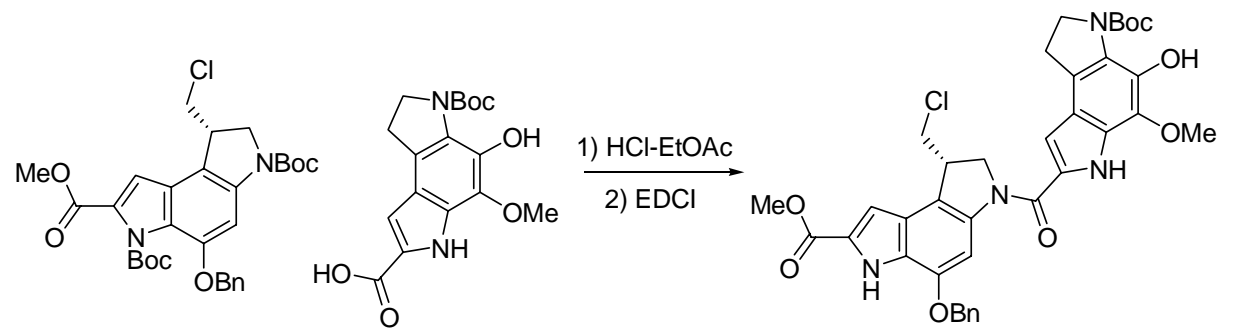

\section{Methyl 3-[3-(tert-Butyloxy)carbonyl-4-hydroxy-5-methoxy-1,2-dihydro-3H- pyrrolo[3,2-e]indole-2-yl)carbonyl]-1-(chloromethyl)-5-benzyloxy-1,2-dihydro-3H- pyrrolo[3,2-e ]indole-7-carboxylate (32). Compound 6 (18.7 mg, $0.0327 \mathrm{mmol})$ was} dissolved in $4 \mathrm{~N} \mathrm{HCl}-\mathrm{EtOAc}(1 \mathrm{~mL})$ and the solution was stirred at $25{ }^{\circ} \mathrm{C}$ for $3 \mathrm{~h}$. The 
solvent was removed by a $\mathrm{N}_{2}$ stream, and the sample was dried in vacuo for $3 \mathrm{~h}$. The crude residue was dissolved in DMF $(0.50 \mathrm{~mL})$, treated with EDCI $(25.1 \mathrm{mg}, 0.131$ $\mathrm{mmol}), \mathbf{3 0}^{10}$ (13.6 mg, $\left.0.0409 \mathrm{mmol}\right), \mathrm{NaHCO}_{3}(5.5 \mathrm{mg}, 0.065 \mathrm{mmol})$, and the mixture was stirred for $14 \mathrm{~h}$ at $25{ }^{\circ} \mathrm{C}$. The reaction mixture was diluted with THF, applied to a silica gel plug, and eluted with THF. The THF was removed by a $\mathrm{N}_{2}$ stream and the residue was purified by flash chromatography $\left(\mathrm{SiO}_{2}, 40 \%\right.$ EtOAc-hexanes) to afford 32 $(18.6 \mathrm{mg}, 81 \%)$ as a white solid: ${ }^{1} \mathrm{H}$ NMR (acetone- $\left.d_{6}, 400 \mathrm{MHz}\right) \delta 11.33(1 \mathrm{H}, \mathrm{s}), 11.14$ (1H, br s), $10.07(1 \mathrm{H}$, br s), $8.18(1 \mathrm{H}$, br s), 7.34-7.64 $(5 \mathrm{H}, \mathrm{m}), 7.31(1 \mathrm{H}, \mathrm{d} J=2.1 \mathrm{~Hz})$, $7.04(1 \mathrm{H}, \mathrm{d}, J=2.2 \mathrm{~Hz}), 5.29(2 \mathrm{H}, \mathrm{s}), 4.81(1 \mathrm{H}, \mathrm{dd}, J=9.6,10.8 \mathrm{~Hz}), 4.62(1 \mathrm{H}, \mathrm{dd}, J=$ 4.1, $10.9 \mathrm{~Hz}), 4.12-4.24(5 \mathrm{H}, \mathrm{m}), 3.97(3 \mathrm{H}, \mathrm{s}), 3.96(1 \mathrm{H}, \mathrm{m}), 3.88(3 \mathrm{H}, \mathrm{s}), 3.26(2 \mathrm{H}, \mathrm{m})$, 1.59 (9H, s); IR (film) $v_{\max }$ 2951, 1710, 1654, 1507, 1425, 1328, $1149 \mathrm{~cm}^{-1}$; ESITOF-HRMS $m / z$ 701.2366 $\left(\mathrm{M}+\mathrm{H}^{+}, \mathrm{C}_{37} \mathrm{H}_{37} \mathrm{ClN}_{4} \mathrm{O}_{8}\right.$ requires 701.2373).

32: $[\alpha]^{23} \mathrm{D}+20(c 0.5, \mathrm{THF})$.

ent-32: $[\alpha]^{23}-20(c 0.5, \mathrm{THF})$.

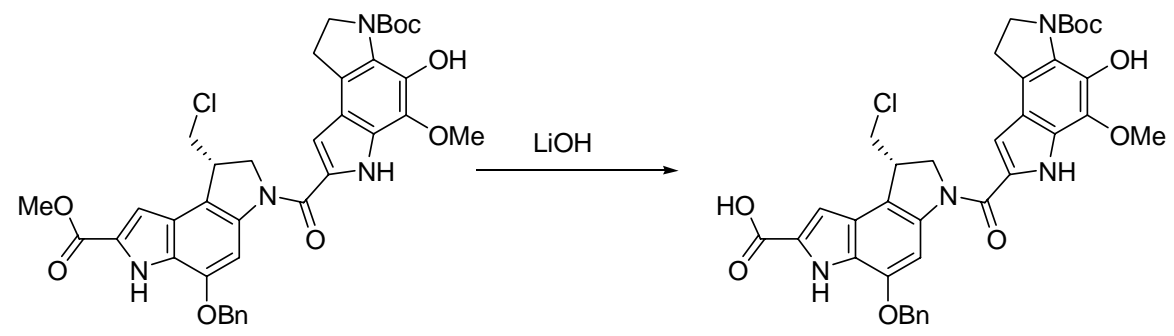

3-[3-(tert-Butyloxy)carbonyl-4-hydroxy-5-methoxy-1,2-dihydro-3H-pyrrolo[3,2-

$e$ ]indole-2-yl)carbonyl]-1-(chloromethyl)-5-benzyloxy-1,2-dihydro-3H-pyrrolo[3,2-

$\boldsymbol{e}$ ]indole-7-carboxylic acid (33). Compound $32(18.6 \mathrm{mg}, 0.0265 \mathrm{mmol})$ was dissolved in 3:2:1 THF-MeOH- $\mathrm{H}_{2} \mathrm{O}(2.5 \mathrm{~mL})$, treated with $4 \mathrm{~N}$ aqueous $\mathrm{LiOH}(50 \mu \mathrm{L}, 200 \mathrm{mmol})$, and the mixture was stirred at $25{ }^{\circ} \mathrm{C}$ for $5 \mathrm{~h}$. The reaction mixture was diluted with $\mathrm{H}_{2} \mathrm{O}$ $(20 \mathrm{~mL})$, treated with $1 \mathrm{~N}$ aqueous $\mathrm{HCl}(20 \mathrm{~mL})$, and extracted with EtOAc $(3 \times 20 \mathrm{~mL})$. The combined organic extracts were washed with saturated aqueous $\mathrm{NaCl}(5 \mathrm{~mL})$, dried $\left(\mathrm{Na}_{2} \mathrm{SO}_{4}\right)$, and concentrated in vacuo to afford $33(15.1 \mathrm{mg}, 96 \%)$ as a white solid: ${ }^{1} \mathrm{H}$ NMR (acetone- $\left.d_{6}, 500 \mathrm{MHz}\right) \delta 11.35(1 \mathrm{H}, \mathrm{s}), 10.95(1 \mathrm{H}, \mathrm{s}), 8.18(1 \mathrm{H}, \mathrm{br}$ s), 7.23-7.64 $(5 \mathrm{H}, \mathrm{m}), 7.31(1 \mathrm{H}, \mathrm{d}, J=2.2 \mathrm{~Hz}), 7.04(1 \mathrm{H}, \mathrm{d}, J=2.2 \mathrm{~Hz}), 5.29(2 \mathrm{H}, \mathrm{s}), 4.80(1 \mathrm{H}, \mathrm{dd}, J=$ 9.7, $10.4 \mathrm{~Hz}), 4.62(1 \mathrm{H}, \mathrm{dd}, J=4.0,10.8 \mathrm{~Hz}), 4.13-4.25(4 \mathrm{H}, \mathrm{m}), 3.97(3 \mathrm{H}, \mathrm{s}), 3.96(1 \mathrm{H}$, 
dd, $J=7.7,11.0 \mathrm{~Hz}$ ), 3.25 (2H, m), 1.59 (9H, s); IR (film) $v_{\max } 2967,1656,1424,1322$, $1148 \mathrm{~cm}^{-1}$; ESITOF-HRMS m/z $687.2212\left(\mathrm{M}+\mathrm{H}^{+}, \mathrm{C}_{36} \mathrm{H}_{35} \mathrm{ClN}_{4} \mathrm{O}_{8}\right.$ requires 687.2216). 33: $[\alpha]^{23}+15(c 0.5, \mathrm{THF})$.

ent-33: $[\alpha]^{23}-14(c 0.5, \mathrm{THF})$.

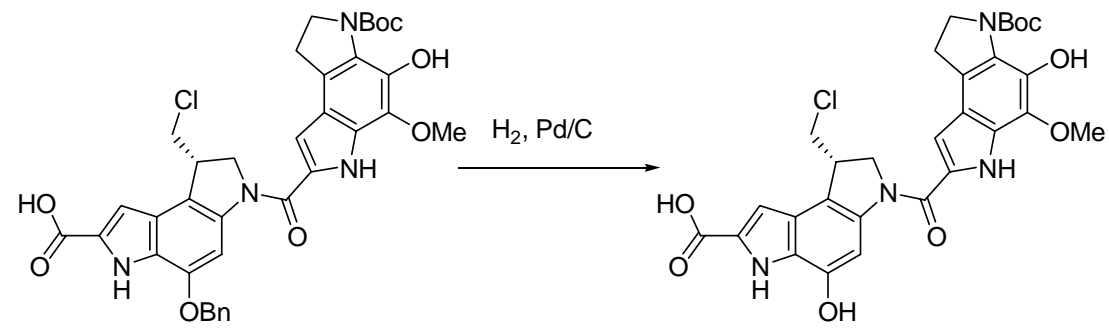

\section{3-[3-(tert-Butyloxy)carbonyl-4-hydroxy-5-methoxy-1,2-dihydro-3H-pyrrolo[3,2- e]indole-2-yl)carbonyl]-1-(chloromethyl)-5-hydroxy-1,2-dihydro-3H-pyrrolo[3,2-} e]indole-7-carboxylic acid (34). A solution of 33 (10.1 $\mathrm{mg}, 0.0147 \mathrm{mmol})$ in 9:1 THF-MeOH $(2.0 \mathrm{~mL})$ was treated with $10 \% \mathrm{Pd} / \mathrm{C}(13 \mathrm{mg})$ and placed under $\mathrm{H}_{2}(1 \mathrm{~atm})$ at $25{ }^{\circ} \mathrm{C}$ for $1 \mathrm{~h}$. The mixture was filtered through Celite and concentrated in vacuo to afford $34(8.2 \mathrm{mg}, 93 \%)$ as a white solid: ${ }^{1} \mathrm{H}$ NMR (acetone- $\left.d_{6}, 500 \mathrm{MHz}\right) \delta 11.33(1 \mathrm{H}$, s), $10.59(1 \mathrm{H}, \mathrm{s}), 10.06(1 \mathrm{H}, \mathrm{s}), 8.85(1 \mathrm{H}, \mathrm{br} \mathrm{s}), 7.96(1 \mathrm{H}, \mathrm{s}), 7.28(1 \mathrm{H}, \mathrm{d}, J=2.1 \mathrm{~Hz})$, $7.03(1 \mathrm{H}, \mathrm{dd} J=2.0 \mathrm{~Hz}), 4.79(1 \mathrm{H}, \mathrm{dd}, J=9.4,10.5 \mathrm{~Hz}), 4.60(1 \mathrm{H}, \mathrm{dd}, J=4.0,10.8 \mathrm{~Hz})$, 4.12-4.22 (4H, m), $3.96(3 \mathrm{H}, \mathrm{s}), 3.92(1 \mathrm{H}, \mathrm{dd}, J=7.8,10.9 \mathrm{~Hz}), 3.25(2 \mathrm{H}, \mathrm{m}), 1.59(9 \mathrm{H}$, s); IR (film) $v_{\max } 2942,1655,1428,1331,1149 \mathrm{~cm}^{-1}$; ESITOF-HRMS m/z 597.1756 (M $+\mathrm{H}^{+}, \mathrm{C}_{29} \mathrm{H}_{29} \mathrm{ClN}_{4} \mathrm{O}_{8}$ requires 597.1747).

34: $[\alpha]^{23}{ }_{\mathrm{D}}+44$ (c 0.3, THF).

ent-34: $[\alpha]^{23}{ }_{\mathrm{D}}-49$ ( $c$ 0.3, THF).

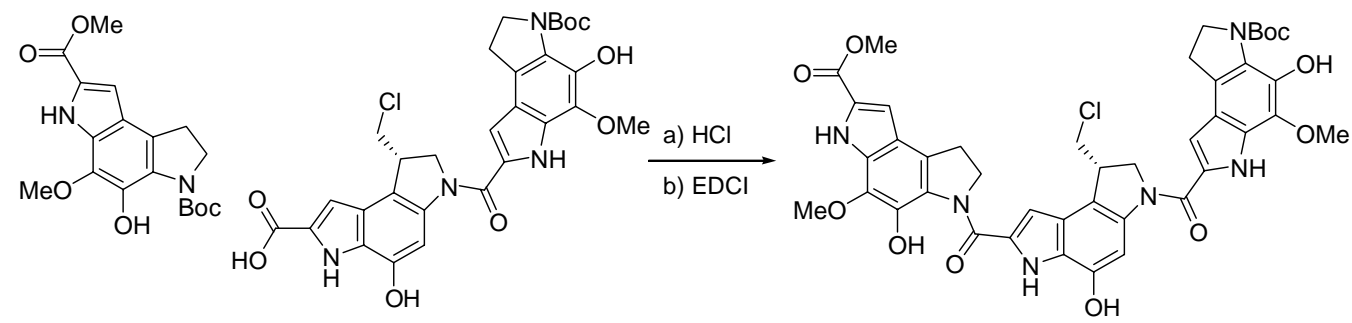


seco-PDE-DSA-PDE (35). Compound $3^{18 \mathrm{a}}(9.0 \mathrm{mg}, 0.025 \mathrm{mmol})$ was dissolved in $4 \mathrm{~N}$ $\mathrm{HCl}-\mathrm{EtOAc}(2 \mathrm{~mL})$ and the solution was stirred for $0.5 \mathrm{~h}$ at $25^{\circ} \mathrm{C}$. The solvent was removed by a $\mathrm{N}_{2}$ stream and the residue was dried for $3 \mathrm{~h}$ under high vacuum. The crude residue was dissolved in DMF (500 mL), treated with EDCI (13.7 mg, $0.0715 \mathrm{mmol})$, carboxylic acid $34(10.7 \mathrm{mg}, 0.0179 \mathrm{mmol})$ and the mixture was stirred for $16 \mathrm{~h}$ at $25^{\circ} \mathrm{C}$. The solvent was removed by a $\mathrm{N}_{2}$ stream, and the residue was purified by flash chromatography ( $\mathrm{SiO}_{2}, 8 \%$ DMF-toluene) to afford 35 (10.4 $\left.\mathrm{mg}, 69 \%\right)$ as a yellow solid: ${ }^{1} \mathrm{H}$ NMR (DMF- $\left.d_{7}, 400 \mathrm{MHz}\right) \delta 11.88(1 \mathrm{H}, \mathrm{s}), 11.49(1 \mathrm{H}, \mathrm{s}), 11.37(1 \mathrm{H}, \mathrm{s}), 11.17(1 \mathrm{H}, \mathrm{s})$, $11.15(1 \mathrm{H}, \mathrm{s}), 10.11(1 \mathrm{H}, \mathrm{s}), 7.92(1 \mathrm{H}, \mathrm{br} \mathrm{s}), 7.57(1 \mathrm{H}, \mathrm{d}, J=2.0 \mathrm{~Hz}), 7.17(1 \mathrm{H}, \mathrm{d}, J=2.0$ $\mathrm{Hz}), 7.08(1 \mathrm{H}, J=2.0 \mathrm{~Hz}), 4.77-4.95(3 \mathrm{H}, \mathrm{m}), 4.59(1 \mathrm{H}, \mathrm{dd}, J=3.9,11.1 \mathrm{~Hz}), 4.29(1 \mathrm{H}$, dd, $J=3.4,10.7 \mathrm{~Hz}), 4.22(1 \mathrm{H}, \mathrm{m}), 4.20(2 \mathrm{H}, \mathrm{t}, J=8.6 \mathrm{~Hz}), 4.05(1 \mathrm{H}, \mathrm{dd}, J=7.9,10.6$ $\mathrm{Hz}), 3.98(3 \mathrm{H}, \mathrm{s}), 3.96(3 \mathrm{H}, \mathrm{s}), 3.90(3 \mathrm{H}, \mathrm{s}), 3.46(2 \mathrm{H}, \mathrm{t}, J=7.8 \mathrm{~Hz}), 3.29(2 \mathrm{H}, \mathrm{dd}, J=$ 8.0, 10.2 Hz), 1.59 (9H, s); IR (film) $v_{\max } 3307,2971,1713,1652,1615,1538,1417$, $1324,1260,1145 \mathrm{~cm}^{-1}$; ESITOF-HRMS $m / z 841.2582\left(\mathrm{M}+\mathrm{H}^{+}, \mathrm{C}_{42} \mathrm{H}_{41} \mathrm{ClN}_{6} \mathrm{O}_{11}\right.$ requires 841.2594).

35: $[\alpha]^{23}{ }_{D}-1(c 0.4, \mathrm{THF})$.

ent-35: $[\alpha]^{23}{ }_{\mathrm{D}}+1(c 0.4, \mathrm{THF})$.

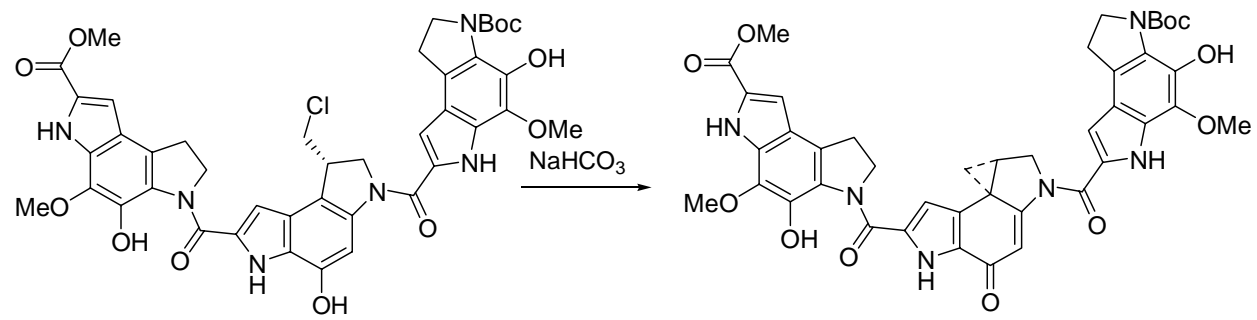

PDE-DSA-PDE (25). Compound $35(5.5 \mathrm{mg}, 6.5 \mu \mathrm{mol})$ was dissolved in DMF (1.0 $\mathrm{mL})$, treated with a solution of $\mathrm{NaHCO}_{3}$ in $\mathrm{H}_{2} \mathrm{O}\left(0.5 \mathrm{~mL}, 15 \mathrm{mg} / \mathrm{mL} \mathrm{NaHCO}_{3}\right)$, and the mixture was stirred vigorously for $1 \mathrm{~h}$ at $25{ }^{\circ} \mathrm{C}$. THF $(2 \mathrm{~mL})$ was added, and the precipitated base was removed by filtration through a pad of silica gel. The solvent was removed by a $\mathrm{N}_{2}$ stream, and the residue was purified by flash chromatography $\left(\mathrm{SiO}_{2}, 9 \%\right.$ DMF-toluene) to afford 25 (4.7 mg, 89\%) as a yellow solid: ${ }^{1} \mathrm{H}$ NMR (pyridine- $d_{5}, 600$ MHz) $\delta 7.60(1 \mathrm{H}, \mathrm{s}), 7.34(1 \mathrm{H}, \mathrm{s}), 7.21(1 \mathrm{H}, \mathrm{s}), 6.72(1 \mathrm{H}, \mathrm{s}), 4.56(1 \mathrm{H}, \mathrm{dd}, J=4.9,10.3$ $\mathrm{Hz}), 4.44-4.49(3 \mathrm{H}, \mathrm{m}), 4.06(3 \mathrm{H}, \mathrm{s}), 4.03(3 \mathrm{H}, \mathrm{s}), 3.92(2 \mathrm{H}, \mathrm{t}, J=9.2 \mathrm{~Hz}), 3.86(3 \mathrm{H}, \mathrm{s})$, 
$3.22(2 \mathrm{H}, \mathrm{t}, J=8.0 \mathrm{~Hz}), 3.12(2 \mathrm{H}, \mathrm{dd}, J=7.8,10.2 \mathrm{~Hz}), 2.95(1 \mathrm{H}, \mathrm{dt}, J=5.0,7.7 \mathrm{~Hz})$, $1.78(1 \mathrm{H}, \mathrm{dd}, J=4.1,7.6 \mathrm{~Hz}), 1.51(9 \mathrm{H}, \mathrm{s}), 1.50\left(1 \mathrm{H}\right.$, partially obscured); IR (film) $v_{\max }$ 2932, 1699, 1652, 1393, $1301 \mathrm{~cm}^{-1}$; ESITOF-HRMS $\mathrm{m} / \mathrm{z} 805.2821\left(\mathrm{M}+\mathrm{H}^{+}\right.$, $\mathrm{C}_{42} \mathrm{H}_{40} \mathrm{~N}_{6} \mathrm{O}_{11}$ requires 805.2828).

25: $[\alpha]^{23}+125(c 0.4, \mathrm{DMF})$.

ent-25: $[\alpha]^{23}{ }_{\mathrm{D}}-113(c$ 0.2, DMF).
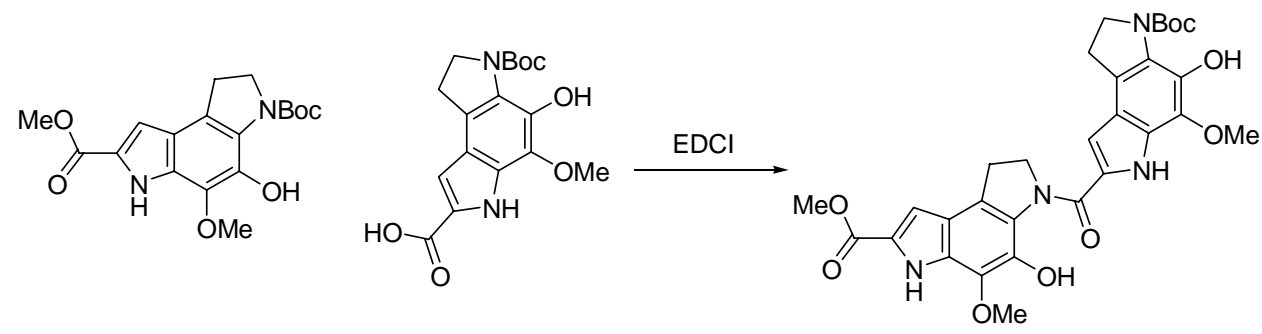

PDE dimer (36). Compound $30(28.2 \mathrm{mg}, 0.0778 \mathrm{mmol})$ was dissolved in $4 \mathrm{~N}$ $\mathrm{HCl}-\mathrm{EtOAc}(2 \mathrm{~mL})$ and the solution was stirred for $0.5 \mathrm{~h}$ at $25^{\circ} \mathrm{C}$. The solvent was removed by a $\mathrm{N}_{2}$ stream and the residue was dried for $3 \mathrm{~h}$ under high vacuum. The crude residue was dissolved in DMF $(2.0 \mathrm{~mL})$, treated with EDCI $(58.0 \mathrm{mg}, 0.300 \mathrm{mmol})$, carboxylic acid $31^{6 \mathrm{~d}}(26.2 \mathrm{mg}, 0.0752 \mathrm{mmol})$ and the mixture was stirred for $14 \mathrm{~h}$ at 25 ${ }^{\circ} \mathrm{C}$. The reaction mixture was diluted with EtOAc $(100 \mathrm{~mL})$ and extracted with $1 \mathrm{~N}$ aq. $\mathrm{HCl}(100 \mathrm{~m})$, saturated aq. $\mathrm{NaHCO}_{3}(100 \mathrm{~mL})$ and saturated aq. $\mathrm{NaCl}(50 \mathrm{~mL})$ and concentrated to afford $36(29.2 \mathrm{mg}, 66 \%)$ as a tan solid: ${ }^{1} \mathrm{H}$ NMR (acetone- $d_{6}, 500 \mathrm{MHz}$ ) $\delta 11.44(1 \mathrm{H}, \mathrm{s}), 11.09(1 \mathrm{H}, \mathrm{s}), 10.63(1 \mathrm{H}, \mathrm{s}), 10.36(1 \mathrm{H}, \mathrm{s}), 7.17(1 \mathrm{H}, \mathrm{d}, J=2.1 \mathrm{~Hz}), 7.10$ $(1 \mathrm{H}, \mathrm{d}, J=2.3 \mathrm{~Hz}), 4.80(2 \mathrm{H}, \mathrm{t}, J=8.0 \mathrm{~Hz}), 4.19(2 \mathrm{H}, \mathrm{t}, J=8.4 \mathrm{~Hz}), 3.96(3 \mathrm{H}, \mathrm{s}), 3.95$ $(3 \mathrm{H}, \mathrm{s}), 3.42(2 \mathrm{H}, \mathrm{t}, J=8.0 \mathrm{~Hz}), 3.27(2 \mathrm{H}, \mathrm{t}, J=8.4 \mathrm{~Hz}), 1.59(9 \mathrm{H}, \mathrm{s})$; IR (film) $v_{\max }$ 3320, 2934, 1713, 1645, 1506, 1417, 1329, 1250, $1147 \mathrm{~cm}^{-1}$; ESITOF-HRMS $\mathrm{m} / \mathrm{z}$ $593.2232\left(\mathrm{M}+\mathrm{H}^{+}, \mathrm{C}_{30} \mathrm{H}_{32} \mathrm{~N}_{4} \mathrm{O}_{9}\right.$ requires 593.2242).

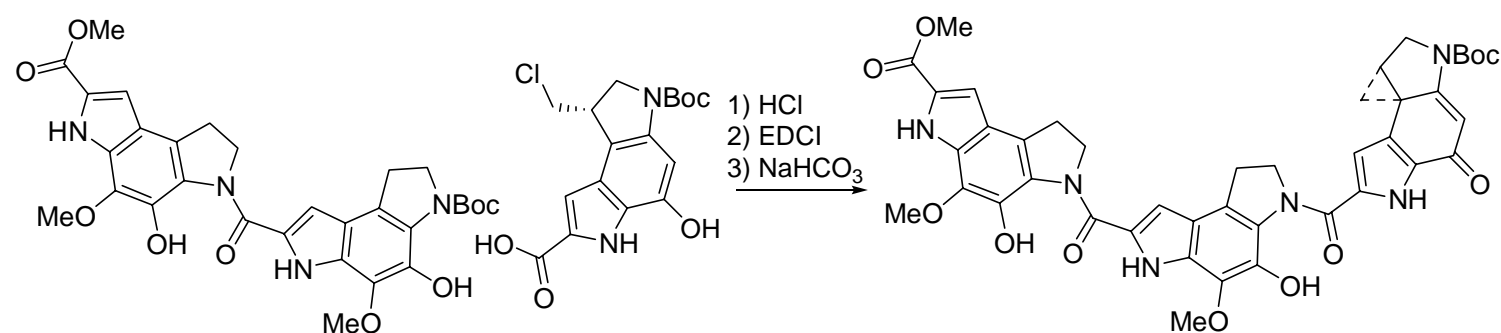

PDE-PDE-DSA (26). Compound $36(8.7 \mathrm{mg}, 0.0147 \mathrm{mmol})$ was dissolved in $4 \mathrm{~N}$ 
$\mathrm{HCl}-\mathrm{EtOAc}(2 \mathrm{~mL})$ and the solution was stirred for $0.5 \mathrm{~h}$ at $25^{\circ} \mathrm{C}$. The solvent was removed by a $\mathrm{N}_{2}$ stream and the residue was dried for $3 \mathrm{~h}$ under high vacuum. The crude residue was dissolved in DMF $(0.5 \mathrm{~mL})$, treated with EDCI (11.3 mg, $0.0588 \mathrm{mmol})$, carboxylic acid $37(5.4 \mathrm{mg}, 0.015 \mathrm{mmol})$ and the mixture was stirred for $16 \mathrm{~h}$ at $25^{\circ} \mathrm{C}$. The solvent was removed by a $\mathrm{N}_{2}$ stream, and the residue was purified by flash chromatography $\left(\mathrm{SiO}_{2}, 7 \% \mathrm{DMF}-\right.$ toluene $)$ to afford $38(8.3 \mathrm{mg}, 67 \%)$ as a yellow solid, contaminated with 26 . The product mixture $(4.3 \mathrm{mg}, 0.0051 \mathrm{mmol})$ was dissolved in DMF (1.0 mL), treated with a solution of $\mathrm{NaHCO}_{3}$ in $\mathrm{H}_{2} \mathrm{O}\left(0.5 \mathrm{~mL}, 15 \mathrm{mg} / \mathrm{mL} \mathrm{NaHCO}_{3}\right)$, and the mixture was stirred vigorously for $40 \mathrm{~min}$ at $25^{\circ} \mathrm{C}$. THF $(2 \mathrm{~mL})$ was added, and the precipitated base was removed by filtration through a pad of silica gel. The solvent was removed by a $\mathrm{N}_{2}$ stream, and the residue was purified by flash chromatography $\left(\mathrm{SiO}_{2}, 8 \% \mathrm{DMF}-\right.$ toluene) to afford $26(2.8 \mathrm{mg}, 68 \%)$ as a yellow solid: ${ }^{1} \mathrm{H} \mathrm{NMR}$ (acetone- $\left.d_{6}, 500 \mathrm{MHz}\right) \delta 11.15(1 \mathrm{H}, \mathrm{s}), 11.09(1 \mathrm{H}, \mathrm{s}), 10.97(1 \mathrm{H}, \mathrm{s}), 10.58(1 \mathrm{H}, \mathrm{s}), 10.41$ $(1 \mathrm{H}, \mathrm{s}), 7.13(1 \mathrm{H}, \mathrm{s}), 7.07(1 \mathrm{H}, \mathrm{d}, J=1.7 \mathrm{~Hz}), 6.79(1 \mathrm{H}, \mathrm{s}), 6.69(1 \mathrm{H}, \mathrm{br}$ s), 4.52-4.80 (4H, m), $4.06(1 \mathrm{H}, \mathrm{dd}, J=4.7,11.1 \mathrm{~Hz}), 4.02(1 \mathrm{H}, \mathrm{d}, J=10.9 \mathrm{~Hz}), 3.35-3.43(4 \mathrm{H}, \mathrm{m})$, $2.93(1 \mathrm{H}, \mathrm{dt}, J=5.0,8.3 \mathrm{~Hz}), 1.76-1.80(1 \mathrm{H}, \mathrm{m}), 1.43(1 \mathrm{H}, \mathrm{t}, J=4.5 \mathrm{~Hz})$; IR (film) $v_{\max }$ 2935, 1716, 1607, 1521, 1386, 1307, 1259, $1143 \mathrm{~cm}^{-1}$; ESITOF-HRMS m/z 805.2817 $\left(\mathrm{M}+\mathrm{H}^{+}, \mathrm{C}_{42} \mathrm{H}_{40} \mathrm{~N}_{6} \mathrm{O}_{11}\right.$ requires 805.2828).

26: $[\alpha]^{23} \mathrm{D}+84(c 0.2, \mathrm{THF})$.

ent-26: $[\alpha]^{23}-81(c 0.2, \mathrm{THF})$.

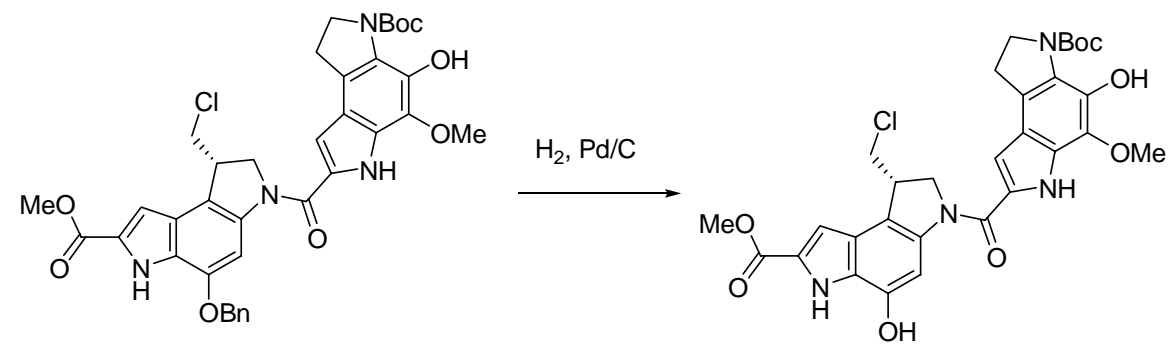

Methyl 3-[3-(tert-Butyloxy)carbonyl-4-hydroxy-5-methoxy-1,2-dihydro-3Hpyrrolo[3,2-e ]indole-2-yl)carbonyl]-1-(chloromethyl)-5-hydroxy-1,2-dihydro-3Hpyrrolo[3,2-e ]indole-7-carboxylate (39). A solution of $32(11.8 \mathrm{mg}, 0.0168 \mathrm{mmol})$ in 9:1 THF-MeOH $(3.0 \mathrm{~mL})$ was treated with $10 \% \mathrm{Pd} / \mathrm{C}(8 \mathrm{mg})$ and placed under $\mathrm{H}_{2}(1$ 
atm) at $25^{\circ} \mathrm{C}$ for $2 \mathrm{~h}$. The mixture was filtered through Celite and concentrated in vacuo. The residue was purified by flash chromatography $\left(\mathrm{SiO}_{2}, 2.5 \% \mathrm{MeOH}-\mathrm{CH}_{2} \mathrm{Cl}_{2}\right)$ to afford 39 (9.5 mg, 93\%): ${ }^{1} \mathrm{H}$ NMR (acetone- $\left.d_{6}, 600 \mathrm{MHz}\right) \delta 10.08(1 \mathrm{H}, \mathrm{s}), 7.96(1 \mathrm{H}, \mathrm{s}), 7.26$ $(1 \mathrm{H}, \mathrm{s}), 7.03(1 \mathrm{H}, \mathrm{d}, J=2.2 \mathrm{~Hz}), 4.78(1 \mathrm{H}, \mathrm{t}, J=10.1 \mathrm{~Hz}), 4.59(1 \mathrm{H}, \mathrm{dd}, J=4.5,7.0 \mathrm{~Hz})$, $4.18(2 \mathrm{H}, \mathrm{t}, J=8.3 \mathrm{~Hz}), 4.14-4.16(1 \mathrm{H}, \mathrm{m}), 4.13(1 \mathrm{H}, \mathrm{dd}, J=7.5,3.5 \mathrm{~Hz}), 3.96(3 \mathrm{H}, \mathrm{s})$, $3.90(3 \mathrm{H}, \mathrm{s}), 3.87-3.92(1 \mathrm{H}, \mathrm{m}), 3.25(2 \mathrm{H}, \mathrm{m}), 1.59(9 \mathrm{H}, \mathrm{s})$; IR (film) $v_{\max }$ 1701, 1647, $1505 \mathrm{~cm}^{-1}$; ESITOF-HRMS m/z $611.1904\left(\mathrm{M}+\mathrm{H}^{+}, \mathrm{C}_{30} \mathrm{H}_{31} \mathrm{ClN}_{4} \mathrm{O}_{8}\right.$ requires 611.1903).

39: $[\alpha]^{23}{ }_{D}+20(c 0.2, \mathrm{DMF})$

ent-39: $[\alpha]^{23}-18$ (c 0.2, DMF)

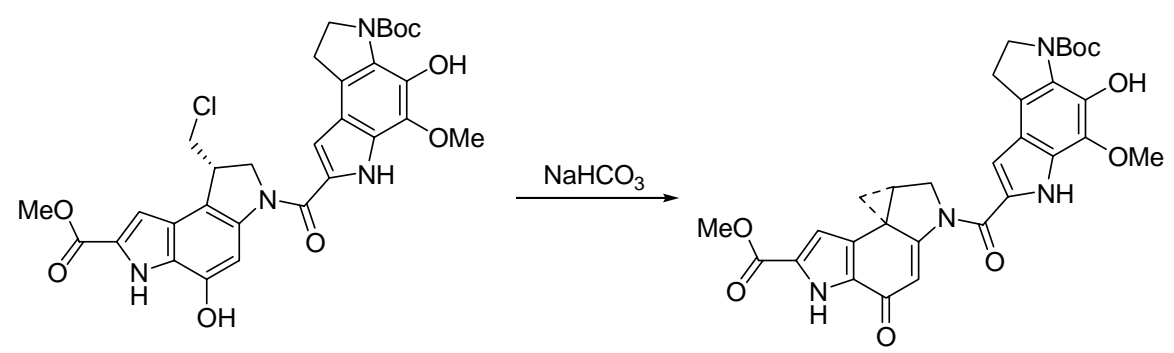

Methyl 2-[3-(tert-Butyloxy)carbonyl-4-hydroxy-5-methoxy-1,2-dihydro-3Hpyrrolo[3,2-e ]indole-2-yl)carbonyl]-1,2,8,8a-tetrahydrocyclopropa[c]pyrrolo[3,2-

e]indole-4-one-6-carboxylate (40). Compound 39 ( $4.2 \mathrm{mg}, 0.0069 \mathrm{mmol})$ was dissolved in DMF $(0.66 \mathrm{~mL})$, treated with a solution of $\mathrm{NaHCO}_{3}$ in $\mathrm{H}_{2} \mathrm{O}(0.33 \mathrm{~mL}, 15 \mathrm{mg} / \mathrm{mL}$ $\left.\mathrm{NaHCO}_{3}\right)$, and the mixture was stirred vigorously for $1 \mathrm{~h}$ at $25^{\circ} \mathrm{C}$. THF $(2 \mathrm{~mL})$ was added, and the precipitated base was removed by filtration through a pad of silica gel. The solvent was removed by a $\mathrm{N}_{2}$ stream, and the residue was purified by flash chromatography $\left(\mathrm{SiO}_{2}, 2.5 \% \mathrm{MeOH}-\mathrm{CH}_{2} \mathrm{Cl}_{2}\right)$ to afford $\mathbf{4 0}(3.8 \mathrm{mg}, 96 \%)$ as a yellow solid: ${ }^{1} \mathrm{H}$ NMR (acetone- $\left.d_{6}, 500 \mathrm{MHz}\right) \delta 10.35(1 \mathrm{H}, \mathrm{s}), 7.08(1 \mathrm{H}, \mathrm{d}, J=2.2 \mathrm{~Hz}), 6.85$ $(1 \mathrm{H}, \mathrm{s}), 6.75(1 \mathrm{H}, \mathrm{s}), 4.58(1 \mathrm{H}, \mathrm{dd}, J=6.1,5.1 \mathrm{~Hz}), 4.49(1 \mathrm{H}, \mathrm{d}, J=10.3 \mathrm{~Hz}), 4.17(2 \mathrm{H}$, $\mathrm{t}, J=8.8 \mathrm{~Hz}), 3.92(3 \mathrm{H}, \mathrm{s}), 3.84(3 \mathrm{H}, \mathrm{s}), 3.22(2 \mathrm{H}, \mathrm{td}, J=8.4,2.9 \mathrm{~Hz}), 3.04(1 \mathrm{H}, \mathrm{dt}, J=$ $4.8,1.8 \mathrm{~Hz}), 1.81(1 \mathrm{H}, \mathrm{dd}, J=4.0,3.3 \mathrm{~Hz}), 1.63(1 \mathrm{H}, \mathrm{t}, J=4.4 \mathrm{~Hz}), 1.58(9 \mathrm{H}, \mathrm{s}) ; \mathrm{IR}$ (film) $v_{\max } 2924,1632,1267 \mathrm{~cm}^{-1}$; ESITOF-HRMS m/z $575.2138\left(\mathrm{M}+\mathrm{H}^{+}, \mathrm{C}_{30} \mathrm{H}_{30} \mathrm{~N}_{4} \mathrm{O}_{8}\right.$ requires 575.2136$)$.

40: $[\alpha]^{23}+158(c 0.2, \mathrm{DMF})$. 
ent-40: $[\alpha]^{23}{ }_{D}-156$ (c 0.2, DMF).

DNA Alkylation Selectivity. General procedures, the preparation of singly 5' endlabeled double-stranded DNA, gel electrophoresis, and autoradiography were conducted according to procedures described in full detail elsewhere. ${ }^{24}$ Eppendorf tubes containing the 5' end-labeled DNA ( $4.5 \mu \mathrm{L})$ in TE buffer (10mM Tris, $1 \mathrm{mM}$ EDTA, pH 7.6) were treated with the agent in DMSO $(0.5 \mu \mathrm{L}$ at the specified concentration). The solution was vortexed and centrifuged prior to incubation at $25{ }^{\circ} \mathrm{C}$ or $37{ }^{\circ} \mathrm{C}$ for the specified period of time. Unbound agent was removed by EtOH precipitation. The covalently modified DNA was resuspended in TE buffer $(5 \mu \mathrm{L})$ and heated at $100{ }^{\circ} \mathrm{C}(3 \times 10 \mathrm{~min})$ to effect thermal depurination at the alkylation sites. Samples were allowed to cool to $25{ }^{\circ} \mathrm{C}$, centrifuged, and $2.5 \mu \mathrm{L}$ of formamide dye $(0.03 \%$ xylene cyanol FF, $0.03 \%$ bromophenol blue, $8.7 \% \mathrm{Na}_{2} \mathrm{EDTA} 250 \mathrm{mM}$ ) was added to each sample. Prior to electrophoresis, each sample was denatured by heating at $100{ }^{\circ} \mathrm{C}$ for $5 \mathrm{~min}$, centrifuged and placed in an ice block. The sample was loaded directly onto the gel $(4.5 \mu \mathrm{L})$ alongside Sanger dideoxynucleotide sequencing reactions run as standards and analyzed by polyacrylamide gel electrophoresis (PAGE, $8 \%$ sequencing gel) under denaturing conditions (8M urea) in TBE buffer (100 mM Tris, $100 \mathrm{mM}$ boric acid, $0.2 \mathrm{mM} \mathrm{Na} 2 \mathrm{EDTA}$ ) followed by autoradiography.

DNA Alkylation Relative Rate. Following the procedure detailed above, an Eppendorf tube containing 5' end-labeled w836 DNA ( $4.5 \mu \mathrm{L}$ per time point taken) in TE buffer ( $\mathrm{pH}$ 7.6) was treated with agent ( $0.5 \mathrm{~mL}$ in DMSO per time point taken, $5 \times 10^{-6} \mathrm{M}$ in DMSO). The solution was mixed, incubated at $25^{\circ} \mathrm{C}$, and a $5 \mu \mathrm{L}$ aliquot was quenched by EtOH precipitation at the prescribed time point. Following EtOH precipitation, samples were resuspended in TE buffer $(5 \mu \mathrm{L}, \mathrm{pH} 7.6)$, thermally depurinated $\left(100{ }^{\circ} \mathrm{C}, 3 \times 10 \mathrm{~min}\right)$, formamide dye was added $(2.5 \mu \mathrm{L})$, and samples were analyzed by PAGE and autoradiography as described above. Relative rates of alkylation for each agent were derived from the slopes of the plots of the percent integrated optical density of the fulllength DNA bands versus time. 
a (+)-DSA-PDE-PDE

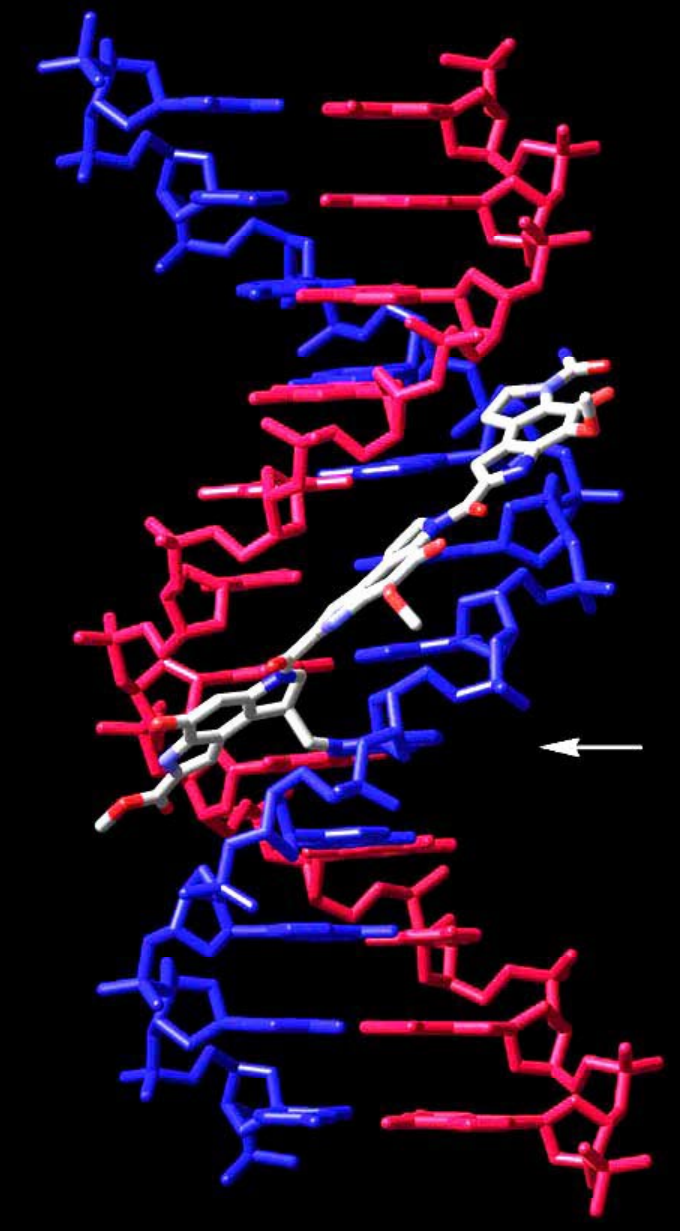

$3^{\prime} 5^{\prime}$ (-)-DSA-PDE-PDE

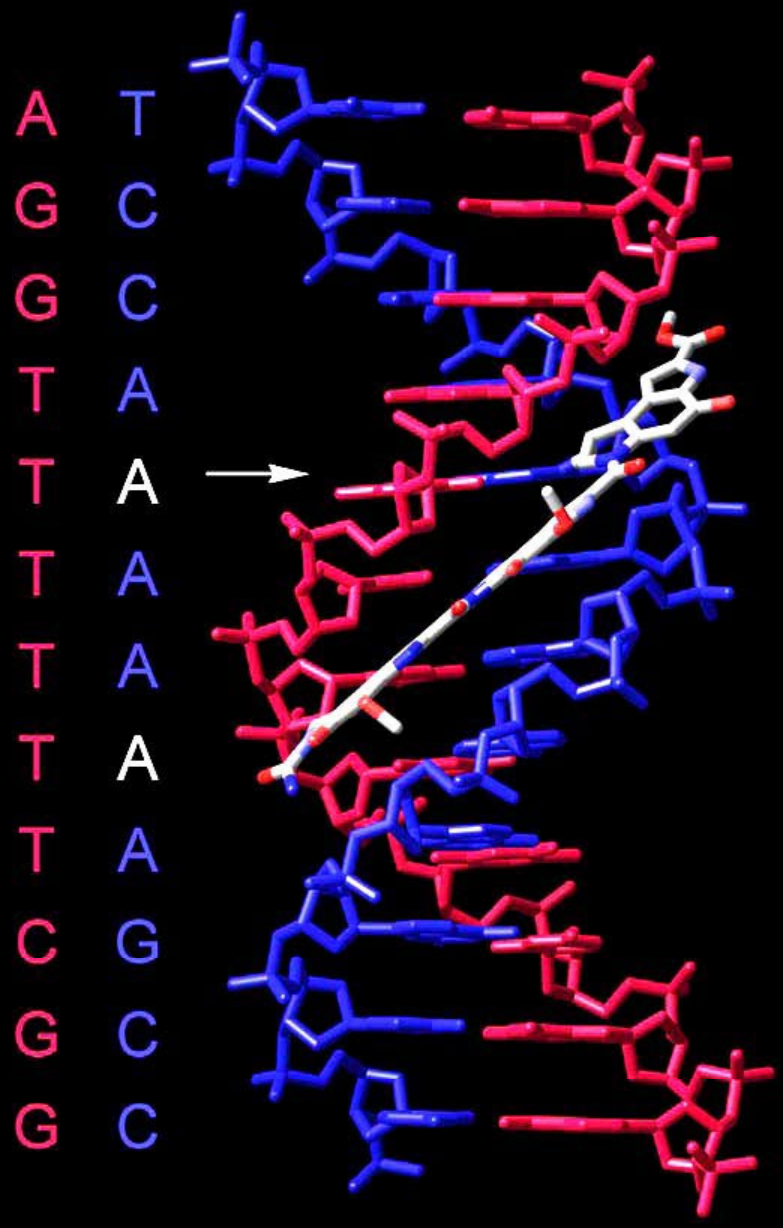




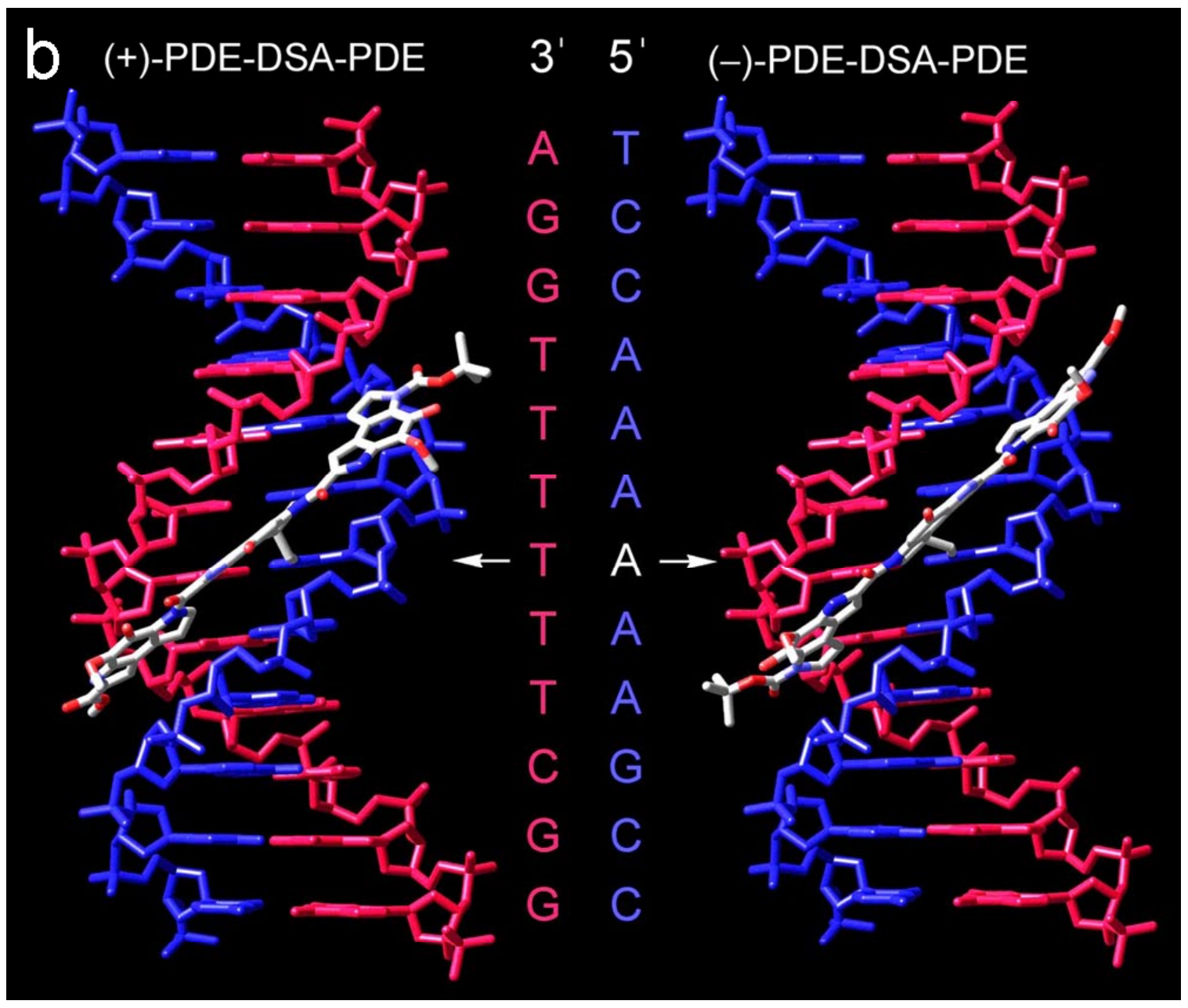




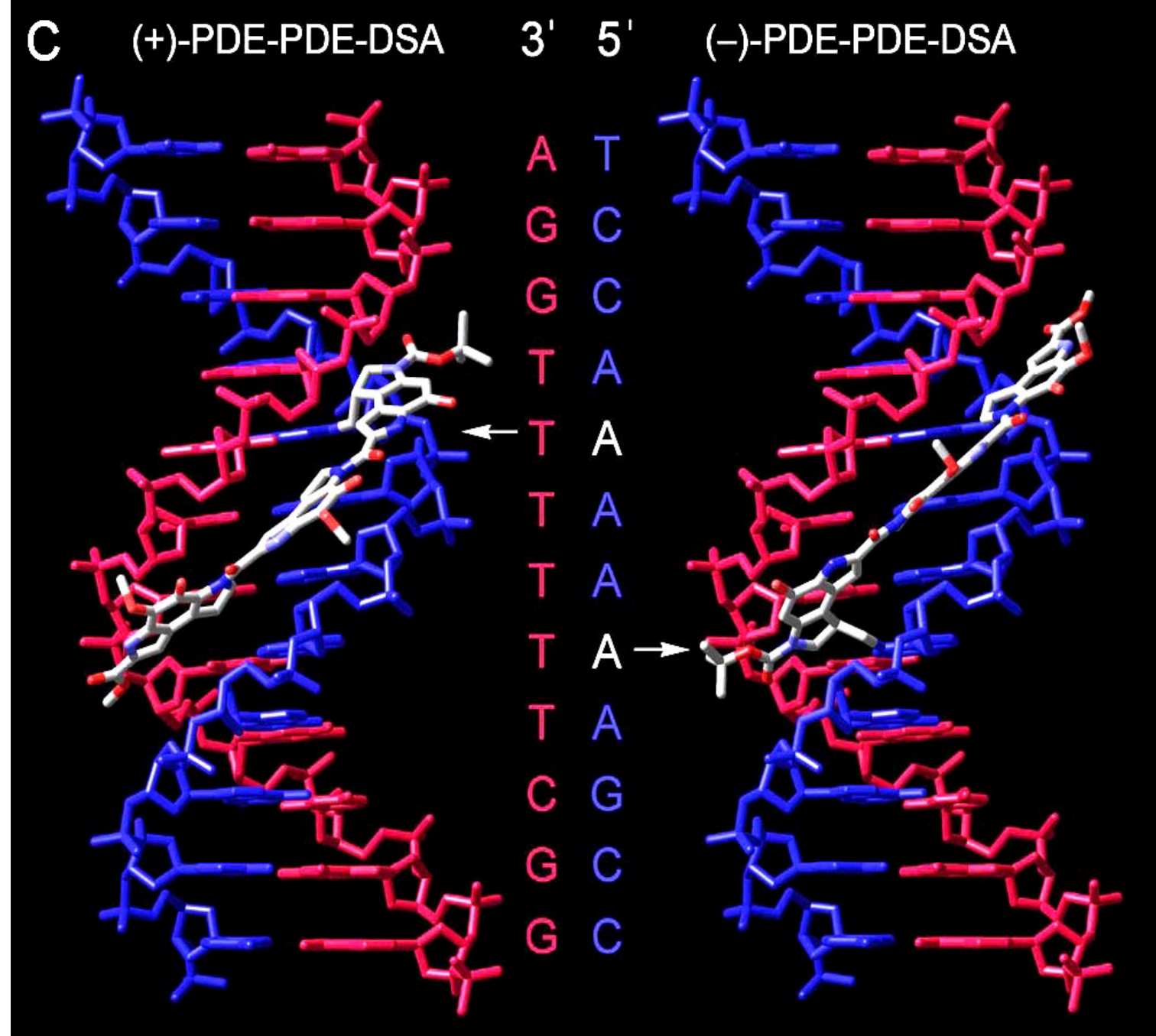

Figure S1. a) Models of (+)-DSA-PDE 2 (left) and ent-(-)-DSA-PDE 2 (right). b) Models of (+)-PDE-DSA-PDE (left) and ent-(-)-PDE-DSA-PDE (right). c) Models of (+)-PDE $2^{-}$ DSA (left) and ent-(-)-PDE2-DSA (right). 